\title{
MAKING SENSE OF THE EVERYDAY WOMEN RUGBY PLAYER
}

BY

KATERINA TOVIA

\author{
A thesis \\ submitted to the Victoria University of Wellington \\ in fulfilment of the requirements for the degree of \\ Master of Arts
}

Victoria University of Wellington

(2014) 


\begin{abstract}
This thesis examines the cultural and social significance of women's rugby. It attempts to make sense of the experience of the everyday women rugby player at a grass roots level and is an area that has received limited attention in sociology. The purpose of this thesis was to document, explore and reflect upon personal stories and experiences of women rugby players by using qualitative research methods. The participants in the research were 12 women rugby players from different rugby clubs. They were arranged in small focus groups that ran over a period of four weeks where personal stories and experiences were shared and critical reflection of the narratives took place. Common themes identified throughout the research process included the current structure and organisation of women's rugby that still results in women's rugby being less valued on and off the field. The stories and experiences revealed the fine line that woman rugby players tread as they try to manage the tension of playing to the ideal image of a rugby player on the field and maintaining their femininity after the game. The findings suggest that the pleasures of rugby found in physicality, roughness, drinking, and associated with masculine culture, are equally pleasurable for these women rugby players. These findings provided insights into the lived experiences of the everyday women's rugby player at a grass root level. They also suggest that the various experiences of women rugby players, both positive and negative, need to be recognised so that women can be better valued as rugby players rather than as women who just play rugby.
\end{abstract}




\section{ACKNOWLEDGEMENTS}

I would like to express my thanks and gratitude to the participants of this research for the thrilling, interesting and entertaining stories and experiences you have shared. Furthermore, for the continued interest and introducing me to different aspects to women's rugby as well as the support through this research project. Your commitment to women's rugby is what drives me to finally finish what I started.

Also, I thank my supervisor Allison Kirkman for the useful comments and getting me to think about those that do not follow rugby. Thank you for keeping me grounded and engaging in my learning process for this masters thesis.

I would like to thank my loved ones, who have put up with my postie notes all around the house and heated discussions about women's rugby every weekend and keeping me engaged in my research.

I am very grateful for the overall support from my workplace that have been flexible and allowed me to take the necessary time out to complete my research.

Without this support, it would not have been possible to write this thesis.

Thank you 
Table of Contents

\section{PREFACE}

Abstract

Acknowledgements

Contents

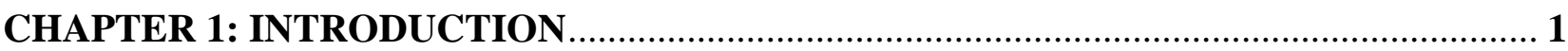

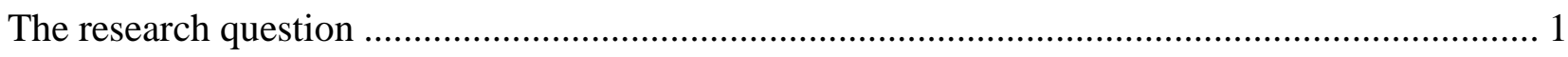

The significance of women's rugby in New Zealand …........................................................... 2

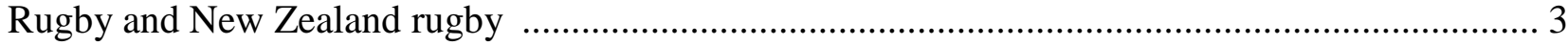

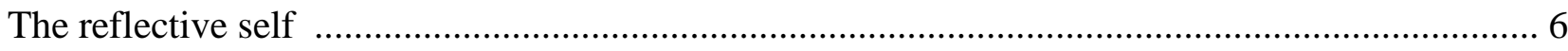

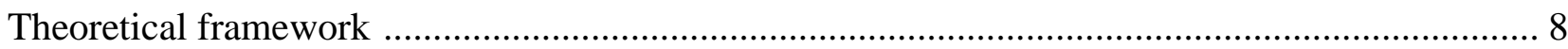

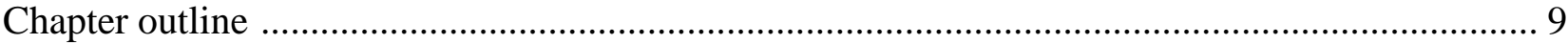

The images and experiences of rugby

Rituals: part and parcel of rugby

Sexuality and perception of women rugby players

Impact on the everyday women rugby player

Conclusion

CHAPTER 2: LITERATURE REVIEW

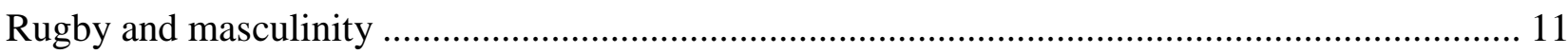

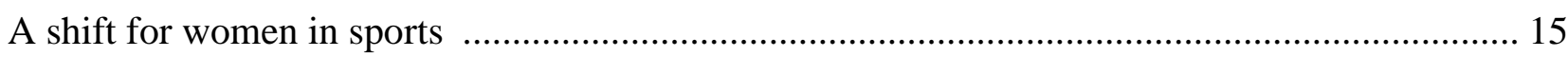

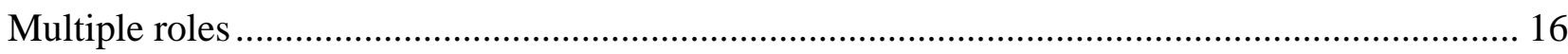

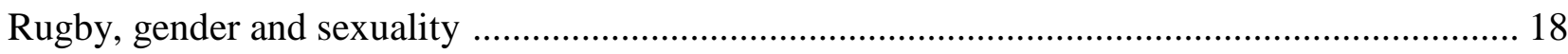

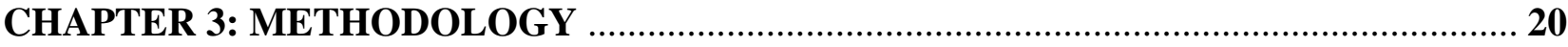

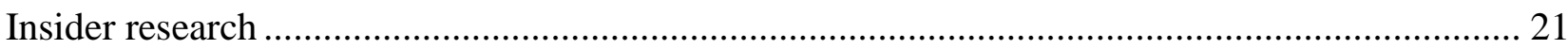

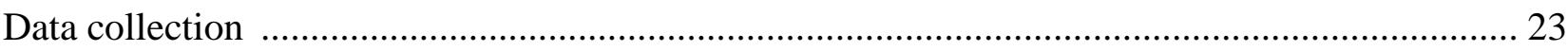

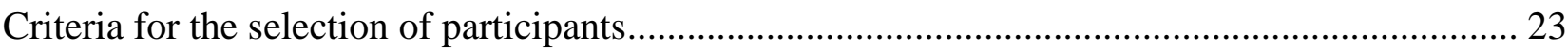

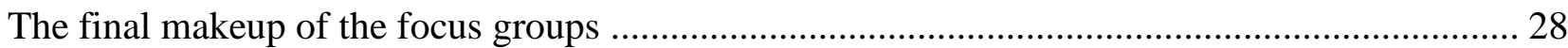




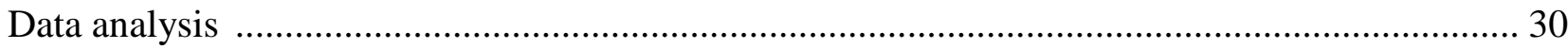

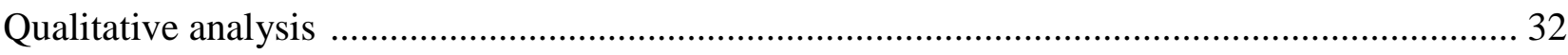

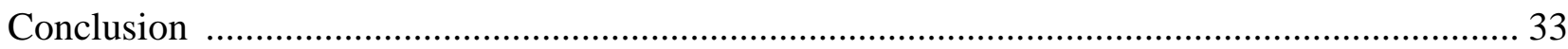

CHAPTER 4: THE IMAGES AND EXPERIENCES ...................................................... 35

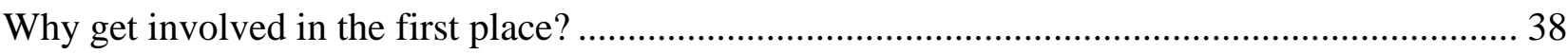

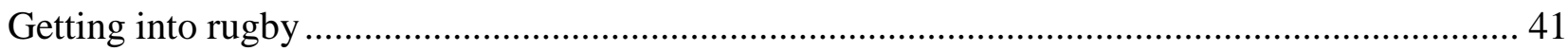

"Making no apology for loving the game of rugby".................................................................... 48

\section{CHAPTER 5: FINDING OUT ABOUT THE EVERYDAY WOMEN RUGBY PLAYER .. 55}

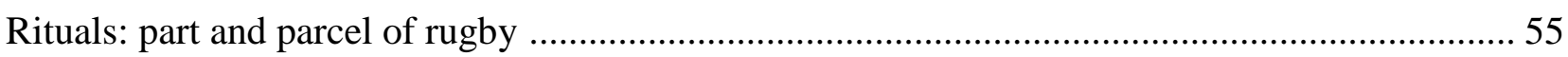

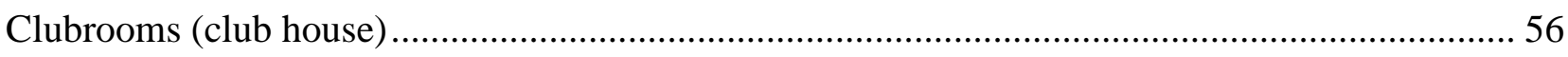

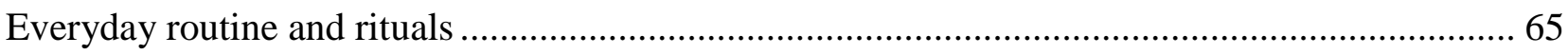

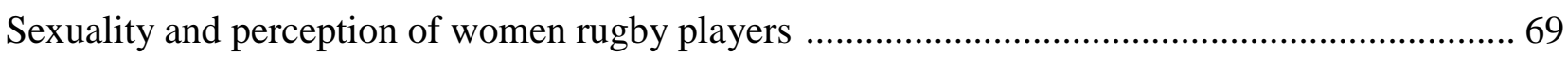

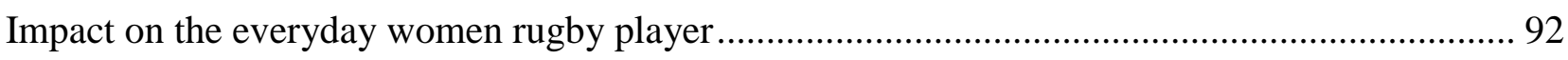

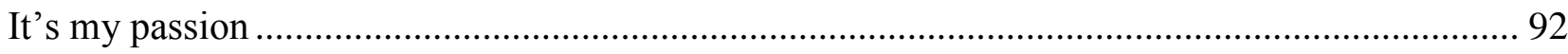

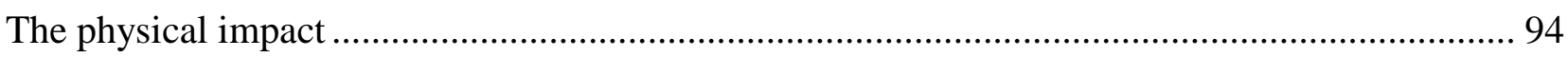

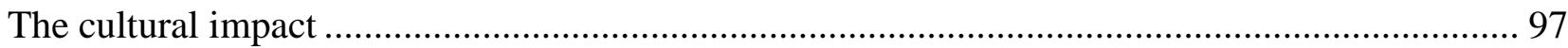

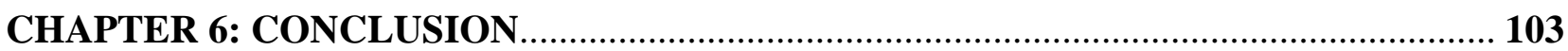

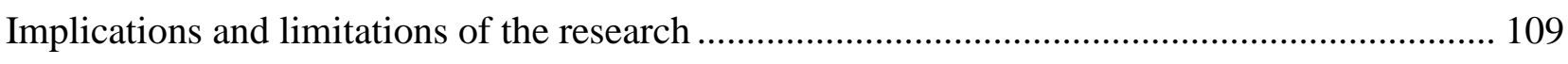

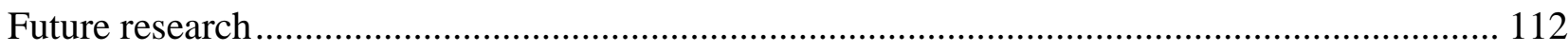

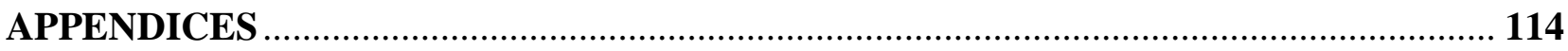

Appendix A - Information sheet \& consent form …........................................................ 115

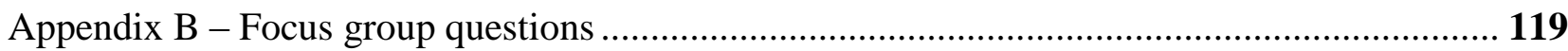

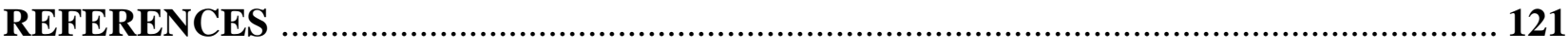




\section{CHAPTER ONE: INTRODUCTION}

Rugby is fundamentally coded as masculine. It depicts the masculine virtues of physicality, competitiveness and ingenuity that are tied back to frontier values. Femininity conjures up qualities of cooperativeness, emotional responses, gentleness, passivity, all attributes that are not ideal in a game of rugby (Crawley,Foley \& Shehan, 2008). To date, rugby is still a patriarchal domain that represents the values and elements of male culture, those of roughness, physicality and other masculine attributes on and off the field. Because of the gendered nature of rugby women's involvement in the game is worthy of close examination and analysis.

Research on the involvement of women in rugby has largely been undertaken by physical educationalists or health specialists who have focussed on the physical aspects rather than the social aspects of this involvement, or those who theorise in sports who have failed to recognise that not all women share the same voice or stories when challenging the mainstream (Currie, 2004; Janes, 2002; Palmer \& Leberman, 2009; Shaw \& Frisby, 2006; Shaw, 2006; Thompson, 1999). Therefore, care needs to be taken that one does not attribute absolute victim status to all rugby women players, or universally generalise the attitudes of women athletes towards hegemonic masculinity in sports. The reality yet to be realised, is that the various experiences of women rugby players, whether pleasurable or not, need to be given space.

Research into women's rugby has largely concentrated on elite players or players at the highest levels of amateur rugby. It therefore excludes the analysis of difference within the various cohorts in women's rugby, and the everyday women rugby player becomes invisible, unexamined and her experience inadequately theorised. 
In this thesis the cultural and social reflections and experiences of women rugby players at grass roots level will be explored, including a focus on gender, sexuality, and age. The thesis provides an analysis of women's rugby from a sociological stance rather than a physical education or health perspective, although aspects of all of these are not mutually exclusive. Hopefully this study will also provoke future research into women's rugby by first providing an understanding of the key cultural and social conditions of those playing the game.

The following sections will provide an overview of women's rugby, rugby in New Zealand, the theoretical framework that will guide this thesis, followed by a summary of the chapters.

\section{The significance of women's rugby in New Zealand}

The history of women's rugby is limited because it has operated behind closed doors away from public scrutiny for such a long time. There are limited records dedicated to the beginnings of women's rugby and, although several people have written about particular aspects of early rugby, it remains a largely untold story.

Rugby histories of countries in the northern hemisphere show women's teams were established as early as 1903 in France, 1913 in England, 1970s in North America. The earliest record of women playing rugby at any level has been credited to Emily Valentine from Ireland around 1887 (Crewdson, 2010). The attempt by Nita Webbe in 1891 to start a women's rugby team in New Zealand failed following public disapproval and public outcry of unwomanly behaviour (Curtin, 2011) and this is on the public record.

Women rugby players are socially and culturally less valued on the field, and are criticised for exhibiting masculine characteristics and social practices of rugby that are viewed as 
unfeminine. Masculine attributes associated with rugby such as the display of aggression, an analytical approach, assertiveness, toughness and competitiveness are not viewed as appropriate for women (Anderson \& McGuire, 2010; Bryson, 1990; Carl \& Nauright, 1999; Ferguson, 2004).

The disapproval of their active participation as players of the game came from those inside and outside of rugby circles. This disapproval was largely based on the ideal that women need to maintain their femininity and poise by playing sports that express the feminine and heterosexual image of the wholesome women (Hall, 2002). These are attributes, that critics argued, women rugby players could not fulfil should they play rugby. As Cameron \& Kerr (1999) argued, organised sports were developed by men for men and unfortunately for women, and women rugby players, 'there is no bloody room for Sheila's in the game' (Cameron \& Kerr, 1999: 337). Today, women rugby players continue to struggle with how their bodies and their choice to play a traditionally male dominated team sport is portrayed and how it comes into contradiction with the traditional forms of femininity and gender (Hall, 2002).

\section{Rugby and New Zealand rugby}

William Webb Ellis of Rugby School, England, is credited with developing the distinctive feature of the rugby game - playing with ball in hand and running towards the opposition. The development of the game grew when players left school and moved onto universities later forming rugby clubs (Huw, 2006).

As the British Empire expanded, migrants and traders took with them a modified version of the game. They used it to exercise values that supported life in the frontier (Collins \& 
Jackson, 2007). The masculine values of physical strength, courage, ingenuity, competitiveness and mateship that Jock Philips asserts grew naturally out of a game of rugby, where settlers could interpret their rural and provincial character not as a mark of inferiority but as an attribute (Philips, 1996). As Collins and Jackson (2007) point out rugby generally embodied familiar elements of home, so where necessary the game was used to ease the transition into the new colonial life by playing a game that was legitimately English (Collins \& Jackson, 2007). As a borrowed sport from England, New Zealand as well as other colonial outposts used rugby as a vehicle for nation building (Laidlaw, 1999; Nauright \& Black, 1999). Keith Sinclair summaries the role and power of nationalism in sports, in which war and sport are the only contexts in which people from one nation can measure themselves against each other (Sinclair, 1986).

The tour of the British Isles and France by the All Blacks in 1905 was a defining point in New Zealand society, largely because it displayed that colonials from a distant outpost of the empire could play an intellectual game with a degree of speciality and physicality far in advance of that in the country where the game originated.

The success of the 1905 tour not only allowed for the emergence of colonial 'cockiness' and male chauvinism, it also put New Zealand on the map two years before it become a dominion. The pre match haka gave the team a special quality unique only to New Zealand, and the superior physical and mental characteristics of the New Zealanders were attributes that were widely cited by the press, politicians and the public (Howitt, 2005). The success of the tour also confirmed that New Zealand's administration style of an open entry policy to playing rugby and its maintenance of frontier values that mirrored key New Zealand 
attributes were key factors to its success. New Zealand culture and identity has been locked into sports ever since (Laidlaw, 1999; Nauright, 1999).

As the game evolved, so too did the country. Rugby has become an entrenched aspect of New Zealand society. We are now in a position with half of the country regarding themselves as experts, active spectators and players (Laidlaw, 1999; Richards, 1996). Evidently, the success of the 1905 tour to Great Britain, and Rugby World Cup wins in 1987 and 2011 bound the nation, over and above social and political differences. As Gregory Paul asserts, “it's almost a patriotic duty to watch or go to a game or expect the family to huddle around the radio ...the idea is that all New Zealanders will build a good sense of being able to read the game" (Paul, 2009:14).

As the New Zealand frontier become more urbanised and settlers moved into structured roles controlled by a waged system there were growing concerns over the diminishing pioneer virility and masculine qualities of the frontier male, largely because skilled jobs required little physical or practical labour. The urbanisation drift resulted in the decline of rugby, however it would be the schools that led to the revival of the sport. Rugby legitimately became a ritualised activity in schools, and dominated the physical education curriculum (Ferguson, 2004, Fougere, 1989). The rationale behind its inclusion in the curriculum was that it displayed a sense of manliness and built character. As Philips notes "the perception of rugby as the guarantor of a clean life" (Philips cited in Chandler \& Nauright, 1996). The game took on a moral importance of character building for young boys it also allowed "engagement of legitimate form of combat violence and was deemed good clean fun controlled by the whistle" (King, 1906: 278). 
Sport is one of most visible and important components in a developing society. Rugby in New Zealand has become a national sport and is a reflection of the frontier traits of roughness, aggression, domination and denial of pain (Jackson \& Mackenzie, 2000). Rugby in its current form provides a platform where hegemonic masculinity is displayed proudly in the public sphere and goes unchallenged. The 1981 Springbok tour was seen as a political and social movement that lead to conflict within and across most groups and families (Nauright \& Black, 1999: 80). The political and social movement paid little attention to the frustrations of feminists who argued that male sports, in particular rugby, contributed the maintenance of patriarchal power that developed a particular form of hegemonic masculinity that was ambivalent to women (Thompson, 1997). Establishments such as Women against Rugby (WAR) called for women to stop doing the labour which had traditionally serviced rugby for men and boys, until the presence of women in rugby was examined (Thompson, 1999). To date, rugby is still a patriarchal domain and the presence of women in rugby is relatively left unexamined.

\section{The reflective self}

As an insider to the world of women's rugby as a player, I have a personal interest and involvement in this study. It is my own experience that drives me to write about women's rugby from within. I am not simply studying women who play rugby, but also listening to and confronting myself. This research was out of my own self-conscious struggle to deconstruct the concept of what it meant to be an everyday women rugby player slogging it out on a Saturday in the mud with 14 other women, playing the same rules as the men's game and playing just as hard. Women players also challenge the stereotype that women cannot play the game and at grassroots level they receive less recognition for their contribution to the survival of our national sport. 
My images of rugby growing up were of Buck Shelford, Sean Fitzpatrick, Michael Jones, Phil Kearns, David Campezie, Terry Wright and John Kirwan. My memories of watching live rugby was largely at my father's premier club games, the 'take no prisoner's' mentality and pure power displayed by forward play. The backs play did not interest me as much as I had no desire to be a fast and elusive runner, but rather the player that would just 'hit it up'. The smell of 'deep heat' from the changing rooms and after-match functions with visiting teams and the club itself was part and parcel of rugby as I knew it. It was a taken-for-granted experience with a major part of the off-the-field activities directly related to the hospitality and getting the regulars to buy you a punnet of hot chips.

Although I entered the women's game rather late compared to the women I interviewed, I share similar experiences of when I first played street rugby which consisted of playing on the concrete surface with a lot of creativity and fluid play. It was a no-holds-barred attitude, epitomising for me that the ideal rugby player is a 'tough nut'. This to me constituted the ideal rugby player and whether women rugby players fitted this image proved to be one of the key themes for the focus groups involved in the research.

As an insider to the world of women's rugby, I have gained access to spaces that would otherwise by inaccessible to others, in particular, non-rugby players or male sociologists. I have been able to capture the meanings of individual experiences and being able to articulate these experiences and reflections in a more detailed manner. The study will highlight that cultural and social reflections and experiences of women rugby players are worth examining by first understanding key cultural and social experiences of those playing the game. 


\section{Theoretical framework}

This study explores the lived experiences of women rugby players. It involves trying to uncover their experiences and understand the meanings associated with playing a physical sport and its associated activities. The best way to capture these stories was to have women recall their experiences of playing women's rugby on and off the field. The primary method used was small focus groups (Polkinghorne, 1995).

Gender theories are important to this research, especially when looking at women's involvement in sports. Rugby is coded as a masculine sport, and much of its history has been characterised by its patriarchal relations. The engagement of women, either playing or actively engaged as spectators, has disrupted this patriarchal flow. It has resulted in an encroachment of a sacred space that is now contested and up for negotiation (Carle \& Nauright, 1999).

Liberal feminists in sports argue for structural and institutional changes that will facilitate gender-equality in sports through the resourcing of better facilities, funding, management and decision making (Scarton \& Flintoff, 2002; Shaw \& Frisby, 2006). In comparison, radical feminists in sport's argument developed out of the work of radical feminism in the 1960s, with the goal being to establish independent institutions designed and developed by women for women (Birrell, 1988; Lenskji, 1991). However liberal feminist approaches sometimes fail to account for different women in sports but instead treat all women in sports the same and radical feminist approaches in sport take a separatist position which focus on moving so far away from the mainstream sports that they become stand-alone institutions. 
This research critiques the gender separatism that has been at the foundation of sports and still continues its influence in sports through means of sport philosophies based upon the assumed biological and psychological predisposition of men and women in sports (Hargreaves, 1994). This thesis contends that this position does not belong in modern sports, especially women's rugby, because it does not challenge inequalities for women who play traditionally male sports.

Separatist policies are prevalent in sports (Shaw \& Hober, 2003). Policies that provide separate facilities, access to equipment and resources such as coaching, recruitment and marketing strategies disadvantage minority groups, which in this context, are women (Hargreaves, 1994). Advocates for women only sporting policies argue that they appear empowering and provide women with the experience of female solidarity in a sporting environment in a manner that men have historically experienced, however conversely it is argued to have the disadvantage of creating a space separate from the mainstream. It becomes framed as an equal opportunity mechanism with limited substance, labelled as 'other' and becomes isolated. In this thesis, different spectrums of separatism are identified, experienced and discussed in detail.

\section{Summary of chapters}

The first and second chapter of this work will establish the basis for this research and provide the historical and sociological significance of why a closer look into women's rugby is warranted. In this chapter, I outline the theoretical perspective that will frame this research. 
The third chapter will provide a detailed account of the methods I used in this research. I used triangulation with methods that included interviews, discussions, observations and conducting the literature review.

The fourth chapter focuses on the early images and experiences of these women rugby players, and by doing so, outlines the journey of the women rugby player. It involves discovering and analysing and, in this case, articulating the experiences and stories of the everyday women rugby player.

The fifth chapter has been separated into three separate sections each relating to different themes such as the perception and sexuality of the women rugby player, routines and rituals on and off the field, and the impact of women's rugby from the participants' own perspectives.

The final chapter of this work recognises the limitations of this research and calls for further analysis and sociological research not able to be included in this project. This chapter calls for the recognition of women's rugby and its cultural significance and contributions to the game in Aotearoa New Zealand. 


\section{CHAPTER TWO: LITERATURE REVIEW}

This chapter provides an overview of the existing literature on women in sport as well as exploring the literature on women's rugby. In surveying past literature, there is limited research by sociologists, rugby historians or physical education specialists that discusses the significance of the everyday women rugby player, something which this research hopes to correct.

\section{Rugby and masculinity}

Rugby has been framed within a hegemonically masculine discourse, according to Pringle \& Markula, (2005) who point out that sport has long been valued as a masculine practice owing much to character building of the ideal man. For Connell (1987) hegemonic masculinity operates as the dominant form of masculinity, placing itself over other forms of masculinity and other genders. It represents the socially acceptable norms and behaviour that are embedded in our culture and institutions of society. The concept itself does provide a platform for the deconstruction of masculine identities and the constant struggle on the part of men to sustain their particular dominance. Carle and Nauright (1999) suggest that dominant forms of masculinity are at the centre of sports, and the power relations between other forms of masculinity and gender that is prevalent in rugby. Rugby masculinity, as Carle and Nauright point out, was characterised by the ability to sustain pain, display toughness and aggressiveness in game play. It was, as Carle and Nauright show, an example of gender hierarchy in action in which masculinities that do not conform to the hegemonic masculinity of men's rugby are relegated to a lower position on the gender hierarchy ladder.

Richard Pringle's (2009) work looked at the discourse of pleasure in sports. He documented the experiences of 14 rugby players and tried to articulate their understanding of the pleasure 
of playing rugby but this work fell short of providing an overview of the everyday rugby player. Although his concentration was on the everyday male rugby player, he paid tribute to others that play rugby, in particular women, by mentioning them in one sentence and implying that women rugby players have limited pleasure in playing rugby. This is in contrast to what Carle \& Nauright (1999) reveal in their case study of Australian women rugby players where the pleasure of playing rugby relates to the physicality of the game. Chu, Leberman, Howe and Bachelor (2003) also noted that their participants had a particularly appreciation of the physicality of the game. Howe (2001) reported his informants played the sport due to its reputation and masculine tradition.

Ferguson (2004) used focus groups to collect individual and collective stories. He argued the language of sport is similar to the language of warfare of "organising troops, lines of battles, setting up counter attack...which has the potency of a physical battle...” (Ferguson, 2004: 76). He further argues that rugby players are trained to use their bodies, and while women rugby players are required to do the same, they receive less value for it, because rugby is unambiguously male and male driven. Ferguson uses Foucault's concept of the panopticon when exploring the perception that non-playing rugby males are effeminate and sporting females are butch. His idea is that these individuals are under surveillance and they assume that they are being watched all the time and therefore act accordingly. The dominant public perception of women rugby players leads to self-surveillance. This is what Ferguson finds useful to shedding light on the ways of hegemonic discourses operations. He points out that external surveillance becomes internalised and an act of self-monitoring takes places for these sporting or non-sporting individuals. 
Jennifer Hargreaves (Hargreaves, 1984, 1986, 1994, 1997) has undertaken a comprehensive feminist analysis of women's sport and points out that male hegemony within sports is hard to change compared to other areas in society. Sport is largely male orientated and still operates along masculine values and virtues. This is likely to be similar to Simpson (1984) and Cameron \& Kerr's (1999) argument that sport is still a patriarchal and masculine domain. A position that Anderson (2009) takes up in his argument is that contemporary sporting institutions are institutionally codified as masculine and will continue to reproduce masculine standards that are gender-segregated until more meaningful structures and narratives are presented that will support moves towards gender-desegregation in sport.

Literature on women's rugby has predominantly taken a structural position by looking at the representation of women in the media and their relationship to sport (Cahn, 1993; Hargreaves, 1982, 1990, 1994; Simpson, 1993; Thompson, 1997, 2003,). Charman \& Exelby (2010) article scrapes the surface on the structural injustices experienced by local women rugby teams within their provinces. Curragh claims that 'Women's rugby was a thriving code right up until the mid-1990s when it came under the NZRU umbrella. Since then it's been run down some would say systematically' (Curragh in Charman \& Exelby, 2010).

While these authors should be applauded for providing a framework for placing women within the sporting context, the examination of women's rugby needs to move beyond the social injustices that are well rehearsed in research, and start to include the lived experiences of different women rugby players, not only elite, but also everyday players in some form of analysis (Carle \& Nauright, 1999). 
An area that both Rita Felski (1999) and Henri Lefebvre (1984) and others (Silverstone 1994) have taken up and scrutinised is the taken-for-granted concept of the everyday life. Lefebvre argued that women were caught up in the habitual, repetitive aspects of everyday life and questioned whether these routines constituted a form of constraint for women or whether they can, in fact, be empowering and life-affirming. For Lefebvre women were less likely to develop the broader intellectual foresight that might place everyday life in a critical perspective. In simpler terms, women are unable to critically analyse the everyday life inside and outside the home. When applied to women in sports their habitual routines and practises are not given the adequate value of critique that other males in sports would receive. Felski (1999) suggests that everyday life is characterised by a sense of time of repetitive tasks that form routine. The everyday life is also characterised by habit and is rarely reflected on.

The everyday life is mainly centred on the home because of the role it plays in anchoring routines, rhythms and a taken-for-granted base. Therefore, she has defined the everyday as consisting of three related forms, routine, habits and home. It can be argued that all three can shift depending on a shift in situation. For Felski, routines of everyday life emerge in a more positive light than they did for Lefebvre, In this, she views the habitual aspects of everyday life as being essential to the formation of a stable, coherent and productive sense of self.

What is more interesting is how Felski argues that the politics of the everyday life of routines and habits can be transferred from the boundaries of the home to better understand how other social institutions such as sports are also bound by a similar structures of the everyday life. What Felski gets her readers to think about is how time, routine and habits are valued differently between genders. That is, why is the time expended routines and habits of women in sports not more highly valued? Felski argues that a similar critique of women and their 
everyday routines whether inside or outside the home or those women involved in sports deserve the same amount of critique as men do.

While Jennifer Curtin (2011) provides an historical perspective of women's presence in rugby as mainly spectators, she only briefly mentions women rugby players being involved in National Provincial Competitions (NPC) and International competitions. I had hoped that the current state of women rugby players, as well as the position of the presence of women as spectators, administrators and managers, would have been highlighted more substantially. The crux of her article is really a contribution to the on-going debate of (re)defining the sport fan identity, as well as trying to make sense of female sports fan against male standards of authentic sport fans. Hoeher \& Kerwin (2012) discuss in their review how women perform gender within the context of being a sport fan and in effect confirm what Palmer and Thompson (2007) suggest as hegemonic masculinity existing within the sport fan domain. It needs to be noted that discussion of the sport's fan's identity has been focussed on the traditional behaviours of sports and team knowledge and patterns, which Crawford (2003) suggests acts as a marker of what an authentic sport fan is. It paints a clear picture based on the previous literature that men are viewed as predominately authentic fans in comparison to women who are still viewed as spectators on the side lines.

\section{A shift for women in sport}

Braid (2010) looked at the attempts of identity construction of women rugby players on and off the field. His findings are similar to the works of Cahn (1994) and Wright and Clarke (1999) who found that participants were aware of the social perceptions associated with playing a masculine sport but played anyway. In this space, women rugby players were re- 
assessing, re-aligning and re-applying some the masculine characteristics that are attributed to rugby and formulating their own ideal women rugby player.

There is a shift in the way women participate in sports, most notably women participating in traditionally male dominated sports. As Dunning (1986) suggests the shifts in the balance of power between the sexes, with the growing symbolic expression of masculinity by women, presents a threat to the traditional image of men dominating over women. An argument that Coakley (1990), Hargreaves (1994) and Cahn (1993) believe relates to physical pleasurable experiences and a sense of emotional, social and cultural empowerment

\section{Multiple roles}

Other literature looked at the multiple identities of females in sports including the demands of motherhood. As Thompson (1990) argues the sporting code had historically exploited women's domestic labour and that had facilitated and contributed to the sport while excluding them from public life. She suggests that women have been "co-opted and exploited by a cultural ideology in the name of national interests" (Thompson, 1990: 80). She also demonstrates in her research that the participation of mothers in sports tends to be uneven as managing households, childcare, family life often comes at the expense of their own sporting experience. In her work she looks for indications of how the institution of sport accounts for women's contributions though their labour and association with sports.

Clare Simpson (1984) looked at the misrepresentation of women in the media and the focus on the trivial issues relating their personal appearance and domestic arrangements rather than their athleticism. She argues that while women's sporting performance may not be considered newsworthy, their conduct and physical appearance are. Sports media research 
has shown that all media routinely comment on the feminine images of sportswomen and agree that the portrayal of sportswomen is consistent with stereotypical images of femininity rather their athleticism. Simpson argues that the way media report on sportswomen also suggests that sport is of secondary importance in their lives and not taken too seriously by them. The fundamental explanation for the inadequate coverage of women in sport could be subconsciously that most people believe that sport is essentially a masculine concern. That is by depicting masculinity as active, aggressive and competitive, and femininity as gentle and passive means that the latter attributes have no place in sporting discourse, in particular rugby. Finally, she argues that elite women athletes still require an air of femininity in order to capture and hold media attention. Despite the increased participation of women in sports, the media coverage has persistently failed to reflect the changes or to show sport as a primary consideration in the lives of sportswomen.

Leberman \& Palmer (2009) contribute to this growing literature on women in sports. Their work adds value to the investigation of the structural constraints of women reaching higher appointments in sports by way of coaching and sporting management. It also supports, what other writers (Shaw in Hassan \& Lusted, 2013; Shaw \& Frisby, 2006; Thompson 1990, Wearing 1998) have already argued, that the constraints experienced by women in sports are negotiable. That is, that women adjust and move with the changes relating to their commitments. Although the common assumption is that women's own personal leisure time takes a back seat, the research indicates that women with multiple identities work around these changes by negotiating with their families and support networks. While this literature proved beneficial in addressing the perspectives of mothers in sport leadership roles, it focussed on a particular group of women who were elite athletes and predominately white 
and middle-class. This indicates that different type of constraints will be felt by different groups of women in relation to access to resources.

Collins \& Jackson (2006) provide a comprehension analysis of the different aspects of sport in New Zealand. They further explore how sports impacts on family life and whether women were more committed to servicing the needs of family sports then engaging in sports themselves (Thompson, 1999). Their work shows the relationship of sports to other aspects of life that they draw on by looking at how our way of life through culture has led to values that have become the norm. As Thompson indicates in her writings women still service the sporting needs of this country, through organising social events such as club and team fundraisers, running food stalls and providing social occasions at rugby clubs, taxiing children to and from games, doing the laundry and preparing the children's sports bags.

\section{Rugby, gender and sexuality}

As Cameron and Kerr (2007) attempt to untangle the ideology of masculinity, they present the common perception by sportsmen that "there is no bloody room for Sheila's" (Cameron \& Kerr, 1999: 337) in sport in New Zealand. New Zealand sportsmen lay claim to the game of rugby as a sport for men and only men, and where women must abide by their biological destiny to not play masculine sports. Women instead are assigned to socially acceptable sports that are feminine specific, such as netball. This argument supports what Hall (1996) and Hargreaves (1994) view as the ideology of masculinity and how it influences what a suitable real women is, and anything out of the socially prescribed framework is marked as deviant (Menneson \& Clement, 2003). Cox and Thompson (2000) link men's sports, gender and sexuality as products formed through discourse. They developed four different body perspectives that they applied to the type of participants they were researching. The sport 
body, the private body, the feminine body and the heterosexual body. A multi-dimensional body matrix which these authors argued explained the conflict faced by women in sports, and most importantly how bodies are always interwoven into discourses relating to heteronormativity.

Furthermore, for women participating in masculined sports a number of authors (Hargreaves, 1984, 1994; Ross and Shinew, 2008) recognise the perceived need by women in team sports to display heteronormativity to avoid being labelled as lesbian, butch or overly manly (Lenskyj, 1999, 2003; Scarton 1999; Theberge, 1997; Wright and Clarke, 1999). The framework of heteronormativity also influences male rugby players. Anderson and McGuire (2010) look at the changing forms of masculinity and maleness and they argue that masculinity is reflective of the changing times in society and that the homophobic hysteria has somewhat declined within masculine sports. This is a change that has seen team environments becoming more gay-friendly compared to environments that might have been exclusionary. A space that Howe (2001) refers to could already exist within women rugby teams. Overall both writers lead to a similar conclusion that traditional masculinity within masculined sports is being challenged and contested by both men and women within that same space.

Overall, this section has provided an overview of where I have situated my research within the context of the current understandings and debates in the field related to women in sports. It has provided a frame where findings from key literature can be made visible by the stories and examples of these participants, which will help inform my research. The next chapter will review the methodological approach taken in this research project. 


\section{CHAPTER THREE: METHODOLOGY}

"..how you see the world is largely a picture of where you view it from, what you look at, what tools you use to help you see, what you reflect on and report to others"(Anderson, 1990, 11).

The aim of this chapter is to present the research strategy and methods used in this research project. The chapter defines the scope and limitations of the research design, as well as situating the research amongst existing research traditions.

To get an insider perspective on the lived experiences of the everyday women rugby player, I recruited as participants twelve women rugby players who came from rugby clubs in the Wellington region. These women rugby players were selected on the basis of their age, ethnicity and playing experience. This particular number was thought to establish a sample that would provide adequate data to enable an analysis of different themes. In order to triangulate the qualitative data, I used a range of methods, including interviews, discussions, observations and conducting the literature review.

I have favoured an approach that makes the experiences and values of the participant's central to the research. As Denzin and Lincoln point out, the goal of qualitative research is to understand the complex world of lived experience from the point of view of those who live it (Denzin and Lincoln, 1994). In the present study the focus shifted from observing reality from the outside to an emphasis on understanding the social worlds from the inside, and this underpinned how the data was gathered.

This data was also used as a comparative tool and the data collection method needed to be able to provide qualitative descriptions of key themes that emerged throughout the research. 
According to Kidder (1981), face-to-face interviews hold several strengths in qualitative reporting. There is a greater capacity to correct misunderstanding by respondents, and interviews are better positioned to reveal information that is complex and emotional. They are also used to probe the sentiments that may underlie an expressed opinion. Interviews therefore provided the opportunity to both clarify and further define the themes that arose through the research process.

\section{Insider Research}

As an insider to those being observed the group showed a willingness to share their experiences with me. I posed less of a threat by being an overt researcher as opposed to operating undercover. As already noted rugby networks are well protected and operate through gatekeepers who mainly are sport administrators or team managers. As an already established player within the local network, I found it easier to navigate between different teams and found the boundaries were less difficult to cross. I had access to spaces that are otherwise inaccessible to others, such as males or non-rugby playing women. Within this space I was able to critically examine the situations and experiences that a rugby player might take for granted.

According to Kvale (1996) it is well known that the social sciences prides itself on its interpretive approach by arguing that life is more complicated and that meaning and understanding must be taken into account rather than looking for clear causal connections between facts. Therefore on the basis of the statement that social scientists should never expect to comprehensively know the social reality held by any individual or group, the optimal best one could achieve would be to bring the social reality to life within the context of a specific study (Silverman, 1993). I am inside the domain of women's rugby and 
participate within their social world, and therefore have not kept my values and subjectivity out of the research process, and I have accounted for my values as part of the research. In conducting this research, I also reflected on my often taken-for-granted experience. I drew on my own knowledge and experiences to interpret or reinterpret what participants were saying. The challenges of being an insider was the degree of familiarity and the risk of being unable to gain distance from my insider's knowledge (Labaree, 2002; Taylor, 2011).. However I was mindful of these risks and recognised that participant's responses may or may not be fully understood, so I had to look to the meanings beneath their statements to uncover the cultural forms from which those responses originated by probing for more understanding (Krueger, 1998).

As an active participant within the domain of women's rugby, there existed no tension between the relationship between myself and the participants during or post data collecting, however I recognise with the on-going relationship with my participants and the familiarity with club environments this could have been an issue. I have reassured the participants that the data gathered and analysed will not identify any of them and they will be given pseudonyms. My point here is to emphasise that the conversational dialogue already implies close and valued interaction between myself and the participants. Although the ownership of the data gathered during the research would be held for seven years, and a selection of their stories and experiences would form the evidence of the research project, participants were continually reminded of their right to review and correct data prior to final analysis of the data. This practice of sharing research data and milestones with the participants within their focus groups also allowed me as the researcher within to reflexively observe my own assumptions during the process of data collection (Guba and Lincoln, 1989; Krueger, 1998). 


\section{Data collection}

There were several steps involved in the data collection process. The steps included gaining ethics approval, recruiting the participants and conducting and recording the interviews.

Prior to commencing data collection the research was approved by the School of Social and Cultural Studies Human Ethics Committee. The ethics application dealt with how focus groups and interviews would be undertaken in an ethical manner. The participants were provided with an information sheet and signed a consent form (see Appendix A)

The primary data was collected through semi-structured focus group discussions, with no more than five participants in each group. Limiting the number of participants in each group allowed for the range of experiences to be told in depth. As expected, the range of stories and experiences told were extensive and allowed each participant time and space to make their contribution. Observation of key clubrooms and players in their environment also contributed to building a picture of a player and club environment. It allowed me as a researcher to confirm my personal recollection and knowledge of a particular club or team environment. I focused on three clubrooms within the Wellington area. My initial approach was made through Wellington Women's Rugby Management to gain support and establish the goodwill necessary for obtaining access. The sample of participants was obtained by sending an email via established rugby women's network describing the research and requesting people to participate. A final sample of 12 participants represented different rugby clubs.

\section{Criteria for the selection of participants}

The criteria for selection of players included a minimum of three years or more playing experience for any rugby club at a developmental or senior level. This allowed for the 
capturing of experiences of participants who had transitioned from college rugby to club level rugby. It is well known in women rugby circles that there is a drop in participation rates from college to club rugby level. There is an awareness that young players move onto different sports as they depart college, however it is not yet known why this happens. For those young rugby players who do continue with their rugby to club level it is anticipated that there could be a mix of positive or negative experiences with the transition. Therefore being able to include this group, who are often not captured in research, provided an opportunity to explore age and generational differences and provide a clearer picture of what is happening within this age group.

As a range of players were incorporated into this study, terminology and language was adjusted depending on the literacy of participants, often there were periods in the study where examples had to be used or the question adjusted and put in plain English for participants to understand.

From my working knowledge as a player, the range of rugby clubs represented in this study had members who play at various level of rugby offering a range of experience and knowledge. Each focus group featured at least a member of each club, a different range in ages, playing experience and ethnicity.

My rationale for pre-arranging the focus group membership was because the represented rugby clubs each had a point of difference that provided an opportunity for other participants to provide a critique. For example, while one club is known to attract a specific ethnic group, the other two clubs have seasonal players (often students) who often come from abroad to complete a trimester at a university or use a club to club twinning programme to broaden 
their rugby experience. It was also noted that the generational gap was uneven between the clubs, as one club made yearly attempts to bridge the gap between secondary colleges to club rugby, the other two clubs attracted more mature players in their recruitment drive.

The focus groups were tape recorded and varied from 45 minutes to an hour, and were held weekly with each focus group over a four week period. These were later transcribed verbatim and the transcript sent to relevant focus groups for their review and comments.

Accompanying the tape recordings and transcripts were my own field notes. These contained notes and observations of responses and interesting themes raised by participants during the focus group discussions. The field notes also provided key summaries of each session and any follow up action plans I needed to undertake, although my field notes were used predominately to capture quotes and observations of participants through participants' body language. Often group agreement or consensus was met with silent agreement signalled by head nodding. Disagreements on certain themes such as sexuality and perception was also noted in the field notes, this was often marked by remaining silent or being disengaged from the group discussion. From the beginning, participants were advised that one to one interviews would be easy to arrange should they feel the need to talk about a theme in private. The offer was taken up by two participants from different focus groups concentrating on the topic of sexuality.

King (1994) writes that interviews are the most suitable data collection instrument for capturing different interpretations and experiences (King, 1994). Although a list of questions in a set order was used in the research, they were open-ended questions with a conversational style (Patton, 1990). As participants talked about their various experiences often they would 
move onto other topics that were to be discussed downstream. As I did not want to disrupt the flow of discussion between the participants, their points was noted down and revisited later on. I found the strength of the semi-structured interview allowed flexibility to focus on emergent areas of interest raised by participants, for example, once participants started probing each other for understanding they were themselves discovering unknown dimensions of each other or themselves in general.

Each session concentrated on one specific theme for the week to allow participants to focus on one area (see Appendix B). As difficult as it was to keep participants on track, questions were designed to pull them back in and re-focus on the question.

The series of questions progressed from easy to difficult or sensitive themes. In the first week only, participants within their focus group were invited to provide an introduction of themselves and why they decided to participate in the research study. I provided this space for each focus group as I believe this introduction would help me to paint a picture of participants and for other members to understand each other's background and intentions if they chose to share it. Prior to starting on a new theme for the week, a recap of the previous week's discussion was undertaken. This allowed for participants to raise any questions or issues and a chance to clarify any misunderstandings between myself and the participant or the focus group as a whole. Towards the end of the current session, focus groups were told of the upcoming theme. This was to allow participants time to think of what they wanted to share in terms of their experience, and provided a self-management tool in that participants could then decide what to disclose in the group setting. 
The overall progression of the themes allowed for the natural flow of how a life-story would ideally be set out. For example, I started with a background theme about the sort of images and experiences participants grew up with and asked them to describe their first experiences playing rugby. As the questioning progressed through young adulthood, the theme turned to the concept of sexuality and their perception of women rugby players. As participants told their stories, questions were asked surrounding their individual, team and club rituals on and off field, and finally the wrap-up theme on their thoughts on women's rugby rated in terms of its cultural and social significance and why they continued to play the game. As mentioned earlier, the series of questions and related topics were designed to set up a story telling response from these women rugby players from beginning to end. There were many times that I used probing questions to ensure participant's elaborated on often taken-for-granted experience and knowledge of rugby. They were also used to gain more understanding of the responses, as typically there were shifts in opinions and positions after interacting with others within their group.

However there were spontaneous statements that featured within and across the focus groups, where probing was not needed. It signalled that the participants were interested and thinking about associated ideas during the interviews. As anticipated, their experiences and meanings sometimes needed to be explicitly spelled out so that they were understandable to others. It was evident across all the groups that meanings and language was familiar to some participants, but not others. To facilitate discussion required listening for inconsistent, vague and cryptic comments, and when these comments were apparent I asked participants to elaborate on their meaning (Krueger, 1998). To reduce the silent spaces in between responses, I found that contributing my own experience and stories to the group help generate more discussion. What was observed in the different groups, was the majority of discussion 
showed shared meanings and understandings as well as disagreement amongst participants about certain themes, such as sexuality and masculinity.

The following section is a summary of the makeup of each focus group. Across the groups, they each exhibited a mix of age and ethnicity, playing experience and knowledge.

\section{The final makeup of the focus groups}

\section{Focus group one}

This group had a mixed make up of generational age, rugby experience and ethnicity. The age ranged from early twenties to mid-thirties, with a range between seven years to eighteen years of playing experience. Two members categorised themselves as European and the remaining two were of mixed Pacific Island/Maori descent. In regards to background, one identified a rural/country family upbringing and others had placed their upbringing as Wellington city based. The exposure to rugby also showed that most members had at one stage played representative rugby at either college or club level, as well as playing overseas as part of their cultural exchange programme in college. A couple of participants talked about their six month exchange with another school that predominantly took students who were learning another language and could play rugby as part of their exchange programme. At club level, this exchange is often referred to as a twin programme where the intention is to link clubs around the world to strengthen rugby networks and provide potential players with a broader rugby experience. There are rugby clubs that have established twinning clubs that they currently work with to help place or assist players as they progress their playing careers. 


\section{Focus group two}

This group featured two Pacific Islanders and one who identified herself as European. Their ages ranged from mid-twenties to mid-thirties, with their rugby experience and exposure to rugby ranged widely between the members. The background of each of the members also highlighted the different pathways to women's rugby. One identified her experience of exposure mainly from being away at boarding school in the central North Island, while one placed her experience largely overseas at university and the other placing her exposure at college within the Wellington region.

\section{Focus group three and four}

Due to the changing number of members in group four, it was agreed to merge group three and four together. Based on the feedback of certain participants to combine the two groups, it was discussed with focus group three prior to any commencement. To bring everyone on board, the first combined focus group was spent going over the ground rules and revisiting the first topic of images and experiences. As the largest of all the focus groups, it exhibited a range of age, ethnicity, rugby experience and background. Three members identified themselves as European and one Maori and one Pacific Islander. The age ranged from late twenties to late thirties. The majority of the participants indicated they started playing women's rugby due to the encouragement of the friends at college or university and most notably from their sisters. In regards to their background, three identified their upbringing largely from a rural/country base compared to the remaining two who identified their upbringing largely based in main city centres. All these participants had played at a representative level at one stage with one playing internationally therefore providing a range of playing experience. 
Overall the focus groups were made up of participants who predominantly indicated they were from an all-girl family. There were eight participants who had come from all-girl families, while four participants had brothers that were either old or younger. There were four participants that indicated that they started playing rugby at university, five started playing at college, two at primary school and one late introduction to rugby at club level.

While it is known that community rugby is strong in the 'heartland', be it central North Island (Waikato, Bay of Plenty) or down in the South Island (Canterbury, Otago) it was interesting to note the geographical range and ethnicity of these participants. For example, three came from the South Island, five from the North Island with three from central north and one from overseas. There were five Pacific Islanders, five New Zealand Pakeha and two Maori who participated in this study.

\section{Data analysis}

As a Pasifika qualitative researcher I have decided not to follow the numerical reliance of surveys, questionnaires, numbers or measurements that research into sports often carries. I have instead decided on the use of conversational discussions in a semi-structured manner to provide a platform for these women rugby players to articulate their stories. I wanted to take into account their history, their philosophies and their struggle for empowerment and selfidentity of who they are as rugby players.

As Thompson (2002) writes

'While it could be said that the use of narratives in social science research could be fraught, we should learn to de-teach ourselves from our western training and develop original frameworks and models that could be properly used and not let academicia suffocate our thoughts'(Thompson, 2002:278) 
I agree with this statement about the need to take a step back from quantitative social science research methodologies. The argument that Pacific researcher Vaioleti (2006) makes clear in his work is that western research methodologies are used to research things...that doesn't take into account the stories behind their responses" (Vaioleti, 2006:22). Although Vaioleti is not a sports sociologist or sport feminist writer, his overall argument of developing a methodology and theoretical framework that is different and possibly pulls researchers away from their mainstream hierarchy could be the ideal pathway to provide authentic research framework and outcomes for those being researched. This research methodology has been developed into the Talanoa method by Pasifika researchers (Clifford, 2001; Diaz \& Kehaulani, 2001; Thaman, 2003; Wesley-Smith, 1995).

I have taken on board the fundamentals and principles of Talanoa in my research project. A methodology that is grounded in phenomenological approach of understanding meanings and events from participants. It removes the distance between the researcher and participants and provides the space for participants to challenge, clarify, and probe for more information and understanding between each other. It furthermore encourages the researcher to engage in conversation rather than take an objective stance. It is also provides a platform for experiences to be validated (Vaioleti,2006). Tala refers to talking, to tell, to re-tell, to converse, to command, whereas Noa refers to talking about anything. There are various meanings between different Pacific nations, for example, in Samoa, Talanoa is a practice of multilayer critical discussion in which the style of talking is formal. Talanoa in Tongan is referred to as an informal conversation about anything (Vaioleti, 2006).

Talanoa is a Pacific research methodology that is applicable in this research. It allows people to engage in a social conversation that may lead to critical discussion through story telling of 
personal narratives. Women, along with ethnic groups, have endured years of disempowering research driven by standard methodologies that have failed to shift with change, and therefore the ideas underpinning a Talanoa method seemed relevant to this research. I will now explain how each of the methods has contributed to gathering the narratives of these everyday women rugby players (Anderson \& Jack, 1991; Mauthner \& Doucet, 2003).

\section{Qualitative analysis}

The use of the semi-structured interviews in small focus groups opened up dialogue in a form that allowed open discussion on topics controlled by the participants after I had set the tone with the key question. Such dialogues allowed people to engage in critical discussions that lead to other insights (Reinharz, 1979, 1992).

I also took into account the social dynamics that pervade the physical settings of where the research took place. It is a basic human condition for individuals to behave differently in different social settings, and this could result in participants being more or less forthcoming about their opinions and experiences depending on the location of the research (Steward, Shamdasani \& Rook, 2007). The environment was set in a neutral space away from the public and was as natural as possible to build positive relationships amongst participants (Krueger, 1998).

As mentioned at the beginning of this chapter, my aim was to get the insider perspective from women rugby players other than myself about their lived experiences. The aim was to focus on the everyday experiences of ordinary people told through the authentic voices and words 
of the creative and thinking self-narrators. The method meant taking the time to reflect on taken-for-granted knowledge and experience. As one participant mentioned

It's been really good and getting us to think about the different aspects of it, you know stuff that you don't consider cause you just play and don't think about the stuff behind it (Jasmine).

It was clear that the limited literature being produced on women's rugby in general was an issue, and the participants wanted to give something back to the sport by having their experiences documented for the purposes of research on women's rugby. The other reason recorded was the excitement of literature being developed by a women rugby player about women rugby players such as themselves and their eagerness to read the final analysis of the research project.

It should be noted that while there is literature on women's rugby that concentrates on the higher levels of women's rugby or higher levels of amateur rugby players, and either written by retired women rugby players or those who are outside the domain of women's rugby, there is minimal research on the everyday women rugby player written by an insider. What drives this research project is the question that I have been asking from the beginning- where are the stories of the everyday women rugby player?

\section{Conclusion}

The use of triangulation provided coverage of major areas for this research. The review of the transcripts of these interviews provided different or new meaning towards understanding their experience in women's rugby. It has provided me with an improved understanding of negotiating space and exploring methods to unpack different responses by probing for 
understanding. I have engaged with the intimate realities and perceptions of the sport from the perspective of women rugby players while also incorporating my own viewpoints. 


\section{CHAPTER FOUR: IMAGES AND EXPERIENCES}

The aim of this chapter is to capture and analyse the images and experiences of these women rugby players. The chapter introduces and expands on the gender theory that will flow through this chapter supported with examples from the experiences and stories of these everyday women rugby players. The chapter is split into two sections. The first section labelled 'why get involved in the first place' looks at specific examples that influenced the women's decisions to play the rugby in the first place. The last section of this chapter labelled 'Making no apology for loving the game of rugby' aims to capture what exactly keeps these women rugby players engaged in a sport that is predominantly perceived as unfeminine. These findings provided valuable insights into the cultural and social significance of women's rugby.

It is important to identify what sort of gender theorising will be used in the analysis of these experiences. I support the argument that the concept of separatism championed by radical sport feminists and features as a foundation of sport feminism literature does not belong in modern sports (Vetere, 1977 cited in Gill, 1986; Weinberg \& Jackson, 1979, Weinberg \& Ragen, 1979). The intention of women's rugby is not to play a rugby game apart from mainstream rugby nor to distance ourselves by creating a 'for women only' rugby zone, but rather to be integrated into the rugby culture in its entirety, rather than standing on the fringes of it (Daly, 1978; Hargreaves 1984).

The concept of separatism, is not new to women's sports and is inadequately theorised (Theberge, 1980). This means that it has not been analysed critically enough so that it captures the traditional and new images of femininity in sports, especially women playing traditionally male team sports (Hargreaves, 1994; Harris, 1981; Jarratt, 1990). It was 
developed and maintained as an ideal foundation for organised women's sports and it made its debut on the premise of biological and psychological predispositions of men and women. The predisposition that men are naturally suited to sports and women less suited underpinned the development. Characteristics normally ascribed to men and associated with sports, proof of toughness, display of aggression, inadequate communication were characteristics of sportsmanship that women should not emulate, and hence lead to gender-specific models of feminine-appropriate and masculine-appropriate sports (Broverman, Carlson, Rosencrantz \& Vogel, 1970; Eitzen, 2009). As Twin (1979) mentions in Out of the Bleachers "sports should not become for women what they have been for men: a display of aggression, a proof of toughness, and a kind of primitive communication that replaces emotional intimacy" (Twin, 1979:164).

These notions have featured in the early physical education curriculum in Europe and North America aimed at building alternative models for women in sports that were more liberating (Theberge, 1985; Hargreaves, 1984). The ideology dominating the New Zealand Physical Education curriculum has largely focussed on notions of individualism, competition, rationality and self-interest. Recently physical education has moved towards a strong focus on the science of physical education, with a minor focus on the examination of the social, cultural, economic and ethnical understanding and meanings of movement. Ian Culpan argues that the scientisation of physical education serves to reproduce existing social hierarchies by privileging the already successful (Culpan \& Bruce, 2007).

The point being addressed here is the link physical education programmes have in school cirrculums and the importance and focus on rugby as the ideal winter code to play. This is more so in boys schools than in girl schools. Furthermore, the study into physical education 
draws its focus on areas that privilege males as they are more in-tune with their own physicality. It is a relatable form of study for males compared to home economics which could be classed as being more feminine.

I recognise that the goal of creating separate organisations give women access to masculinised sports, which creates wider definitions of sporting femininity and provides women with opportunities to administer and control 'their' activities (Hargreaves, 1984:31). However, this approach fails to counter inequalities of game scheduling, adequate field allocation, uniform allocation and funding that are still prevalent in modern sports. In other words, if one emulates separatism and separate institutions for organised women's sports, then how does one gain the same cultural value that male rugby players enjoy.

Separatism focuses on the difference in biological and sexual differences between men and women and looks to create separate models of separate sports that are feminine-appropriate and masculine appropriate .

I always say that I play women's rugby, I don't say I play rugby and I only started recently thinking about it..."why do I say I play women's rugby?...what do I...as if I will be playing with men! (Arataki)

Jay Coakley (1990) writes that gender-role socialisation results in inequalities (Coakley 1990; Dyer 1982; McPherson, Curtis and Loy 1989). Separatism does not challenge the cultural inequality of women in sport, but instead adds unnecessary division and stacks another difference between men and women in sport. 


\section{Why get involved in the first place?}

Each focus group was asked a series of questions related to certain themes. The first theme concentrated on the images and experiences that rugby participants had growing up. Participants in each focus group identified strong images relating to sports such as the All Blacks. Working through this section showed that while the younger participants related well with recent images of rugby such as Christian Cullen, Jerry Collins, Jonah Lomu, Tana Umaga the older participants identified the likes of John Kirwan, Ian Jones, Sean Fitzpatrick and the 1987 rugby world cup finals, which showed a generational gap between groups:

...for me it was like I remember the 1987 world cup, which is showing my age, but I can still remember that day...I don't really think I probably understood what it meant or what it was or whatever but that was like my first rugby memory and how it was just such a major deal for all the adults...I wanted to be John Kirwan when I grew up, and I got a short spiky haircut or like navy and white were the only colours I would wear...that was like so cool to me and I honestly never dawned on me that he was a man and I couldn't even be that...(Phyllis)

It also represented their exposure to rugby. One participant clearly articulated that these popular images were largely All Blacks orientated because

they were the most prominent for us when we were getting into rugby... and you wanna motivate yourself $f$ to that level and so you look to those players in that era (Ollie)

While it could be easy to class these experiences as your typical women's rugby story, I should point out that the majority of the participants themselves self-identified that rugby was not a major feature in their household, and many grew up in female dominated households, where rugby was not considered an ideal sport to play. It was interesting to observe that the majority of these participants were women rugby players largely from the South Island or Central North of New Zealand. 
I actually come from a female dominated family with 7 girls and 1 boy... and he's the oldest... and I'm in the middle. (Arataki)

Um, rugby didn't really feature in our household at all...my dad was Dutch and so he's an immigrant so he knew only football...(Ollie)

I never grew up in a rugby orientated family... anything associated with rugby apart from watching NPC or watching from the embankment... (Staci)

It is also interesting to note that out of their siblings whether sisters or brothers older or young, they tended to be considered the sporty ones who played a mixture of sport before settling on rugby.

Some participants drew on other family members, in particular their father or brother or male cousins, for their memories of rugby.

For me, I had my cousin, my boy cousin, we were around the same age and we would go to each other places and play basketball and then it turned into rugby, so it would be my cousin and me against my brother and other cousins, and it all started from there, I use to watch heaps of rugby on telly... I played hockey since I was standard 2 and played it right through college and there was school notice that they were gonna start up a rugby team, and thought I'd give it a go, cause I love my sports and try and get involved everywhere. So I signed up for rugby even though my mum said no, I still played, and so my last two years of college my mum came down to support me, and yeah it started from playing rugby with my cousins in the backyard. (Karoline)

Their views largely consisted of urban based upbringing and some attributed the sport as ethnically fitting for particular ethnic groups 
It's mainly fobs ${ }^{1} \ldots$ I guess, um it's in the genes. The game is natural for islanders, but you have that island flavour and strength. (Nelly)

It would be fair to conclude that while images are easily remembered, that as the participants suggested it's the experience of watching live rugby that seemed the most-memorable experience. Those who came from a non-rugby family environment were able, through their involvement and taking the sport seriously enough, to increase family support and awareness of playing a national sport.

Um, back in the days, the only experience.... grew up in Samoa, like I was born in New Zealand, but then my parents went back after about 2 years when I was 2, so I grew up in Samoa my whole life and I only came to New Zealand when I got married 12 years ago...But when I was growing up, there was no TV, the only thing you would be able to watch rugby, and if you could afford it was to go to Apia park, the main stadium of Samoa, like my parents were, like, they wouldn't waste their time taking us to the park to watch the rugby world cup games... and they would have this huge screen in Apia park. And, well I never went to one of those, yeah, my parents, were those typical Samoan parents. So I only heard about, but, I've never watched rugby. So from memory, um... the only time I've heard about Manu Samoa and the Hong Kong sevens or when Samoa won the Hong Kong sevens everyone when to Apia park, but, at that time, my parents wouldn't allow us to go there, and then, um, I went to NUS and that is where I really got into rugby... cos I remember, we came back from Nauru from the weight lifting... and a year later, they started women's rugby. (Nelly)

Based on these preliminary images and early experiences of rugby in general and the start of their involvement in women's rugby, it is clear that their early memories are tied to some of their father's playing the game or popular figures such as the All Blacks. Their socialisation into the sport was largely through their friends and being in new environments rather than

\footnotetext{
${ }^{1}$ Fobs: the term makes historic reference to Pacific Islanders migrating to New Zealand who came by boat, and who have been characterised as individuals with limited English. They are therefore known as Freshies or Fresh of the boat. The use of the label in current times, is now more generalised to encompass all those who self-identify as a Pacific Islander
} 
their family environments, possibly as a consequence to not naturally having the same access to the sport as men and boys through school or sport programmes. They possibly experience what liberal sport feminist would argue is a good platform of access to the sport through a change in social programmes to encourage active participation such as Push Play campaigns or sports days (Daly, 1978, Hargreaves, 1994).

\section{Getting into rugby}

The following section focusses on participant's journey into women's rugby and what keeps them engaged in the game. It was evident that while there were varying rugby experiences of how the women got involved in the sport, they shared a similar answer as to why they continue to play the game.

An analysis of the focus groups indicated certain entry points of engagement, at 5 years of age, secondary school or at university clubs. The young participants under 24 years of age placed their first experience at a young age playing ripper rugby in a mixed grade at 5 years old. Up to between 10 to 14 years old their years were spent playing other sports, predominantly netball, soccer, volleyball or hockey, and returned to the game at either mid or senior years of their secondary schooling. The most memorable were two participants who talked about their first experience of playing from a young age

um...yeah I've been playing since I was 10. I'm 23 now. Um, started playing because I got bored with netball. Um my dad actually suggested it, because I use to play ...well I use to tackle my brother. So he thought "oh rugby should be good for you" So I started playing with the boys.... I didn't get much game time... I was like the only girl. So they put me on the wing. And then I got to college and they formed the all-girls sport and I've been playing since. (Lucy) 
I started playing when I was 5 for Y, um my dad actually coached me for like the first 6 years I think, and then the first season...we were all little kids running around and had no idea what we were doing. But then the second season I was sort, of really got into it and then developed a real love for the game, and I think having dad there as well sort of, it was sort of our thing we did together...and its became a family thing (Jasmine) and um as I got older I became the only girl in the team and as the boys ...it got to a point that the boys were getting bigger and I was sort of (laughs) staying the same...I then switched to netball till about year 7 and played netball for two years and then as soon as I got to college, well I've been playing rugby ever since... (Jasmine)

It is clear that these experiences highlight the social acceptance of the female participation in the sport up to a certain point. Greendorfer and Yiannatis $(1974,1976)$ argue that the role of the family as a primary agent for sports participation changes over time where childhood support in sports involvement is significantly higher compared to later stages in the life cycle. It would seem that early involvement in sports is acceptable as a hobby and non-threatening because of the age of the participants.

It can be argued, and this is not exclusive to rugby, the gate to sports was wider in childhood, but as we will see later in this study, that gate closes as participants age with, the bid to regain the sporting space as a male only space (Haig-Muri, 2002). It becomes evident through these stories that structures, such as scheduling women's game at times not favoured by women rugby players, act to privilege male sport

I also think the time women's game are on is stupid, like 11.30, I think if they moved our game later to 1 o'clock then I think more women will play the game, cos they can take their kids to their games and take a bit of time to get an actual game, but I reckon it's part of WRU ${ }^{2}$ not recognizing women's rugby as an important need (Ollie)

\footnotetext{
${ }^{2}$ Wellington Rugby Football Union, now known as Wellington Rugby Union to distinguish between soccer and rugby.
} 
I'm not asking for equality, I'm asking for some value. I'm asking for you to get us a field that we can play on, that it's not just gonna be mud. I'm asking you to get us some coaches that can teach us, not just anybody that applies for the job (Holly)

The majority of participants began their first playing experience in college from 14 years of age, driven to play a game other than the typical female sport such as netball.

so I when went to high school, sort of third/fourth form I did everything else except for netball and hockey cause you had to wear a skirt, yeah I played everything else, volleyball, athletics but anything that involved a skirt, nah I wasn't gonna play it (Ollie)

While it was often through their friends or sisters that they got involved in rugby, what these participants soon realised was the different environment rugby cultivated compared to other team sports such as netball.

I started playing 5 years ago so when I was $23 \ldots$ well my sister convinced me to play because they were short of players so kind of a common women's rugby story... she would say yep you should come and play, and I'd be like nah, I mean I was a netball girl, it was non-contact netball, volleyball that was me...I just gave in...like I was up for a challenge, and went to training and then 3 days after my first training I played 80 minutes and got thrown up in line outs...so I didn't have a clue what was going on...so I don't know what it really was in that game but it was fun (Marama).

Another participant from a different focus group mentioned that while rugby was not on much at home, a change of environment such as being at boarding school was where she acquired a specialist skill learnt in the lounge of her school hostel

I can remember it very very clearly I was 14 years old it was at night time and I was in the common room of my boarding hostel and there were boys there who thought shock horror. Cause every year we did a fashion show with the boy boarders. So the boy's home would come over and we would make up this hilarious fashion show and we would model clothes from all different places around town and stuff and A played for the first fifteen and I was little and they had hilarious names for me. Tank and 
Keg that was it... So I was like their little kid and A was a hooker and he taught me how to throw the ball in the lounge and we practiced that night and every night he came over to practice for the show we would do like hooker throws together like hundreds of them and then I decided that the next year I was going to play rugby and I was going to be a hooker. So that was one of my first experiences hanging out with one of the boys from the first fifteen. Then the next year I started playing and I was quite good and my main experiences I had was at college and it was awesome and we played heaps of sevens...(Holly)

The last group placed their early experience largely in the last year of college to the beginning of university.

I started playing when I was 20 at the University of Waikato and that was through my mates...you know... as you do, you just wanna hung out with your mates, and then I realised that I was quite good at it, I started as a loose head...I've always played in the front row...(Arataki)

The starting point of these women's playing careers is consistent with the gradual rise of women's rugby in certain areas of the country. For example, the mid 1980s and early 2000 s saw cities fielding more than 20 women rugby teams in the Bay of Plenty alone (SPARC 1997-2001). As Curtin (2011) notes in her research, out of 27 unions, 22 included women's rugby. The majority of this age group identified that being away from home attending a university outside of their community meant joining a women's rugby team was a good way to meet people and hang out with their friends. It also meant trying to make sense of the experience while also adjusting to their changing environment

when I was young and coming into university teams and stuff, you know, I come from a small town, so I didn't know any lesbians, and I definitely was quite scared of showering, I was like...fuck the lesbian is showering and checking me out? But I don't know if that was a rugby thing or actually going from school age to being an adult, and understanding that, that happens in the world...well I just love playing rugby, so I didn't really give a shit. I just didn't shower... (Phyllis) 
I moved to Otago to study... it was my first exposure to women's club rugby level...it was pretty scary...there was a one lady in the team, she was a bit of a legend in women's rugby down in Dunedin, all I know is that she scared me because she bit someone's ear in the first game...(Staci).

An important observation is while it is easy to group participants into certain boxes, what is not picked up is the difference between these women rugby players, especially with reference to access, resources and expectation (Banks, 1981; Barrett, 1982; Hargreaves 1994). One participant from a different focus group pointed out although they had limited resources to buy the equipment such as rugby boots or protective gear, they learnt the hard way participating in a physical sport at university

...I remember, I remember not having any rugby boots, when somebody subbed off, and I'm like...can I wear your boots...yeah looking back, it was very hard, we didn't have any boots and no such things as those protective gears like shoulder pads...I had to borrow huge (Nelly)

It is not only gender that cuts its way in sports, but also ethnicity. Participants who identified themselves as Pacific Islander made reference to their experience as "not being my choice" This is similar to an earlier statement where some participants identified how the sport is over represented by certain ethnicities such as Pacific Islanders, and therefore is ethnic specific.

But then you look at people, like B who are machines. You look at B she won't get noticed in the $\operatorname{PRIDE}^{3}$ but she is an awesome player...she's just goes unnoticed and for people like her, it's just hard...so I don't know if it's a race thing, but you look at most of the PRIDE team and they are mostly fobs aye. I think there are only 4 white ones, the rest are beige... (Selina)

\footnotetext{
${ }^{3}$ PRIDE: Wellington Pride NPC women's team who compete in the National Provincial Competition.
} 
This also indicates a social acceptance of Pacific Islanders as women rugby players. When I asked if women rugby privileges some and disadvantages other ethnicities, the consensus was that some ethnic groups are more suited to the sport

I think it's pretty inclusive of all races; there is a large amount of respect around the Polynesian cultures which is a reflection of their dominance in this sport. (Phyllis)

The following is a conversation between two younger participants on the question

You definitely see the dominant races in there, like you see the Polynesians, the Maoris and the white people, like you don't really see Indians or Asians playing rugby in New Zealand. Like I don't know what it is, maybe it's the genetic build (Jasmine)

I would say that it seems quite poly to be honest, I don't know if that's got to do with the size of PI, like I think you can get some skinny PI's in there, so I don't think it's got to do with build, I think it's more...I don't know what it is (Sue)

Yeah that is strange cause there's no Assyrians, Indians...none...like is it a cultural thing (Jasmine)

What I found interesting was the way culture has not been defined by the participants. Questions of what is culture and what does culture look like to different people may or may not have the same meaning. It therefore implies that possibly our rugby culture might not be significant in places like India, however what we have here is a notion that culture in Oceania or New Zealand is marked by our rugby culture.

Maybe it's what's acceptable and what's not...so I don't think it's a cultural thing. (Sue)

Yeah I don't know...maybe it cause...it's a kiwi culture and not looking at it like the kiwi culture of PI, Maori and white people within New Zealand...we grow up with it, but then you look at like in India where there's no rugby. (Jasmine) 
However this sits in contrast to some of the experiences of those identified as Pacific Islanders. One participant talked about her college rugby team as being referred to as the "Barbie's on the field" by the rugby boys of her school. When discussed further, it was revealed that herself and her friends were largely seen as the dolled up girls in their school who transformed into rugby players.

like believe it or not we were called Barbie's at college. We would like dress up and the main reason why there was like five of us in the group got into rugby because the guys came and watched the game. ..yeah so that was one of the reasons we got into rugby...yeah and we got a lot of attention at college to. It was then like the tough Barbie's (Selina).

While another Pacific Islander participant decided on rugby over hockey.

I was a hockey player before rugby. I played centre forward which was the person in the middle that did a lot of running and ups and downs (Karoline)

While the average playing experience was between 14 to 20 years, the least was placed at 5 years of playing experience. This participant provided an insight of a new person playing and entering the game late when compared to other members of her group and also across all the focus groups in general. However, this participant had a lot to say in relation to technical and positional knowledge of the game. It was only when she moved from her home base in the South to a new city that she joined a rugby club and became a senior player in her current team and playing at higher club levels.

I'm probably still in my baby years of rugby cause this is only year five so I'm still at the point of pushing myself probably harder and harder at every season, I'm probably nearing the point where I'll be like 'yeah nah'...I've got nothing compared that experience, so yeah I try to push myself as hard as I can at each point of the game 
that sometimes looks really energetic and fit and sometimes that is me dragging my arse off the ground, and you know jogging or stumbling a few meters, and I think I'm getting more confident from year to year in my rugby cause I've still been learning heaps and heaps. (Marama)

Within the groups and amongst the focus groups it appeared that their interpretation of women's rugby at that level was illuminating for most. It exposed them to different aspects of social team activities on and off the field such as court sessions and club/team nights which will be discussed in chapter five. Individuals in each of the focus groups provided an in-depth description of their early experiences to women's rugby, while the majority of them were positive there were distinctive and important parental relationships between parents and their rugby playing daughters that were identified in their stories which will be discussed more thoroughly in later sections.

Due the age range of the participants in each focus group, the participants shared similar images of the All Blacks or a rugby world cup games or their family as their early memories. The early experiences of these participants highlight different starting points of their playing journey, and reasons why they decided to play was varied.

\section{'Making no apology for loving the game of rugby"}

Participants made no apology for playing the game of rugby whether their first experience was pleasurable or not. The intensity and physicality that rugby carries goes against the public perception of feminine behaviour towards sports. Their knowledge base of the game which has predominately come from their playing experience allows them to carry a rugby conversation should they wish to engage and an aspect they are proud of. These women rugby players continue to play because they love the game despite the perception and attitudes of some. 
its not what people expect and that's what makes us really proud to still play and to say “yeah we still play, and yeah its tackle, and no it doesn't hurt or yeah it hurts but I still keep playing... you know (Phyllis)

Their passion could be summed up by a quote from Spiro Zavos in his book 'After the final whistle' refers to the love of rugby is the way a goldsmith loves gold, not for the value of gold alone, but for what can be crafted from it (Zavos, 1979).

about rugby...I have lots of other sports like snowboarding that is up there with rugby in terms of intensity, but rugby itself to me is on a different and separate level... and I can't describe it...it's the ideal package. (Staci)

As a collective group, it was signalled clearly that these everyday women rugby players play for their mates who are standing on either side of them whether it is in a positive or negative light. As Holly puts it

I guess there's another side of it to for me I have like a love/hate relationship with the social aspect of rugby like I play for my mates definitely but then that doesn't also mean that I don't get frustrated with people because that's the nature of being in a team. Like would you agree with that? You love playing in a team because you have people around you but at the same time some of those people in that team you just want to smash in the face sometimes. (Holly)

There is something about rugby that keeps drawing them in to play another season or to hang up the boots only to get itchy feet.

You know as much as I say it takes a lot of my life that I don't get back...sometimes it's the only thing that gives you happiest like you say so I could've had the worst day at work and just be angry at the world and I'll go to training and have a good hit out and you know...just running free and laughing with your mates just makes life so much better, so those are things...that's the passion....and those are things that make you never wanna give it up because that feeling doesn't become less over time and there's not many things in your life that can still give you that same amount of happiness I guess... (Phyllis) 
I did my knee last year just in the off season playing flag out at P-Town where I went to step and twisted my knee but my leg stayed put, and ended up with a torn ACL and well they said about 6-8weeks after op and it only took me about 3-4 weeks to walk/limp and then the season started, but it's still sore but I keep it strapped up tight, and the thing is I couldn't stay away and just got itchy feet and ended up playing again. (Karoline)

It is clear that the early experiences and their journeys to where they are now have displayed a structured pathway of 'coming through the ranks'. The dominant public perception outside and inside rugby circles is the view that rugby and other sports such as the shot-put is a nonfeminine appropriate sport because of the characteristics of masculine attributes (Brundage in Simri, 1979; Hargreaves, 1994; Kay \& Jeanes, 2008), however, what is often not acknowledged is the emotional aspect that women bring to the game compared to men's rugby. This is on a different scale compared to what some feminist sports groups argue as inhibiting women's development (Butt, 1987, Dyer, 1976, Ferris, 1981b, Wilmore, 1979). Bringing emotion to the sport is not considered a sign of weakness to some of these participants.

I think you can be compassionate, like you see like the real savage players... who swear at the ref....like there is definitely like an etiquette that you can bring, like you can bring the politeness and positiveness rather than "oh fuck that rah rah" the masculine sort of...(Jasmine)

I agree and after the whistle has gone I don't think you'd have to be mogul (laughs) but that's the thing, you can, you might be that person on and off the field or you might be a totally different person on and off field. (Holly)

Nelly talks about her children and her husband, she describes her family as being sporty. Her children are involved $\mathrm{n}$ many extra-circular activities and her husband who also plays rugby. 
While the majority of her time is spent taking the children to their sports leaving little time left to prepare for her own rugby game (Thompson, 2000).

Her story is not unique in the sense that there are other women in sports holding multiple roles, but it is unique in that she self-identified herself as being a mother trying to balance her passion for the sport and manage the rugby identity that comes with it and work and family life.

Well I think, um they would be mainly (aggressive) on the field, but the person outside would be a totally different person...like I'm a mother as well... (Nelly)

Nelly positions herself as a rugby player and a mother. She recognises the dominate trait of a rugby player as being aggressive, as well as recognising that it's a role you play in rugby compared to the person you are or want to be after the whistle has gone and you are off the field.

Palmer \& Leberman (2009) has examined the situation of women in sports in general and how they manage their different responsibilities. Nelly through her experiences of managing family commitments and her rugby playing journey also demonstrate this balancing act.

Within the context of the game, rugby can be viewed as a good way to relieve stress and regain some control. It could almost be seen as a way to offer a work-life balance pathway to some people.

I don't know if it's helping me mentally but differently physically it helps me. I feel more controlled and in more control of my life. If I didn't play rugby I probably would be not in a very good place. (Selina)

For me, it's always been an outlet for my anger and aggression in other areas of my life and that's for my personally...it manages my overall well-being. (Arataki) 
However, contrary to this, is the disappointment of some players to see players use the sport as an outlet of bringing the sport into disrepute

The ugly - for all the wonderful people I have met, I've also been exposed to some really ugly people. Nut cases, manipulators, weirdo's, drama queens, people from really messed up backgrounds that use a team sport as their last ditch effort to socialise. Girls who think rugby is a legal outlet for their aggression. (Phyllis)

The following conversations highlight that while it could be easy to note that friends and family provided the influence to play rugby; it is largely through the changing environment of one's situation that has been the main drive and why they continue to play the game. Some of these participants mentioned that the sport is outside the typical women's sport, however being able to play something different provided the means to 'prove society wrong'

I think it's to prove society wrong, even if it's like, you hear like the old fashioned people, oh you don't play rugby, that's a man sport, and it's like, you should come down and watch one of our games to see how good some of the girls are out there, and I think (in) New Zealand we are real lucky, cause we sort of got, the women's sort of have a natural talent for it, compared to like, I don't know... I remember like, when I played in France a little bit, and the girls there are so, like it's not like their natural, but here like we are, it's like it's sort of like in our blood to be rugby players, and I think if people saw how good we were then they'll get on board as well, so yeah, so to play, to get to the high levels so people can start seeing you... and see how good we are. (Jasmine)

The majority of the participants described in lots of words their passion of playing the game.

Like I like the idea that I play rugby and that I'm from New Zealand. Like I actually like that. I like that when I go overseas and go travelling. I'm a kiwi girl that plays rugby. Like as much as that sounds terrible I quite like that. I like that I'm playing our national sport and yeah that sort of makes who our nation is and also who I am too. But I guess All Blacks also have something to do with that to I'm very proud of them. But yeah it's turned into more than that for me now. In terms of why I keep fit and healthy, the people I play with. So you know I don't play rugby because the all 
blacks are great I play rugby because I love the social side of it. I love that we tackle people, it's physical. I have great mates. I run around the field and have a laugh and cry sometimes as well. (Holly)

Playing a team sport with such high level of body contact carries many benefits. Keeping fit together was the common response from all participants, as well as socialising off the field and building networks within their team environment and across other clubs.

I wonder if rugby is important to me or just team sport is important to me, and rugby is the one that I'm really into like previously I was really into netball and that was everything and then rugby took over...nothing on the atmosphere of rugby, and maybe it's a lot bit social that the same commitment to the trainings and teams.... and that sort of thing but it is...there is something different about rugby that I can't put my finger on, but maybe it's the way you interact...it's the frequency and working together. (Marama)

The sport has provided many with a platform to play at higher levels than their male counterparts and building transferrable skills as Phyllis had summarised beforehand and supported by Arataki statement when she talks about why she still plays

Because I can...that's why I still play... and like this year and it comes from my family and friends...jokingly most of the time, in regards to how old I am and that I'm still playing rugby...I'm like...I still love it and I'm still good at it, I'm fit. When I stop enjoying it or if physically can't play it then I'd stop, but I'd always be involved in rugby...um...and whatever that might look like whether that might be coaching or whether I have babies...but I will always love it (Arataki)

These women rugby players through their early experiences of playing rugby and continued presence on the field are proactively challenging the position of women rugby players by remaining in the game. As reflective as I am in my practice, I myself ask that question all the time. For me it's the physical nature of the game and contesting barriers and perception of 
women rugby players. So for me, its physical and social empowerment that drives me to play.

This section looked at the participant's images and experiences and why they continue to play a sport that carries a predominately masculine image of rugby players. As identified by the participants, they largely come from female family households, where rugby as a sport to play did not feature as an option. Instead they were introduced to what could be called social events of 'active participation campaigns' and encouragement of friends or being new environments.

Some participants described their passion for the game as something that over time increases through their involvement in the sport. The ideal package identified here is the camaraderie of the sport that binds them together on and off the field. 


\section{CHAPTER FIVE: FINDING OUT ABOUT THE EVERDAY WOMEN RUGBY PLAYER}

\section{Rituals: 'parcel and parcel of rugby'}

This section will look at the social activities on and off the field in women's rugby. This section will cover the significance of rugby clubrooms (clubhouse). By using Lefebvre's (1991) concept of representation space, I will be looking at the changes within the rugby clubrooms that the presence of women and women rugby players has made. I will also be utilising George Lukacs (1971) concept of the everyday to take a closer look at the everyday routine and rituals of individual and teams, as well as drawing attention to social activities off the field - namely court sessions.

In men's rugby, hosting a visiting team and sharing a beer after the game is considered good hospitality within the sporting circles. The majority of the social activities involve heavy consumption of alcohol at the clubrooms or in changing rooms where 'court sessions" ${ }^{4}$ are typically held. A court session is set up similar to a court of law layout with judges at the front table and where players stand before the judges to hear their misdemeanours and receive their ruling. The placement of the social activities off the field in a men's game that have been put down as traditional practises distinctively male have been mirrored in the women's game. Carle and Nauright (1999) contend in their article "A man's game? Women Flaying Rugby Union in Australia" that the emerging female rugby culture reinforces and echoes historical, masculine-orientated behaviours and stereotypes. The research suggested that the group of women rugby players they focussed on stretched the boundaries of feminine appropriate behaviour and conformed to the male expectations of social activities on and off the field (1999: 71).

\footnotetext{
${ }^{4}$ Court session are drinking sessions where typically large amounts of alcohol are consumed as punishment for real or made up misdemeanours as part of a team social event.
} 
In this section I have adopted Lefebvre's (1991) concept of representational space where the cultural practices, imbued with shared social meanings, are understood and experienced and where symbols and images emerge through practice with that space.

Space is neither a neutral backdrop to social life nor a series of fixed or essential attributes that shape the social life. As Lebrbvre emphasises such space allocates two sets of relationships, that of reproduction and production, where labour is typically organised. When I apply these two relationships in a sporting context, the values, passion and culture of the sport are reproduced along the lines of gender or generational lines, and what is produced is how these everyday women rugby player's habitual routines are produced and organised in a public and private space. This in itself generates social significance that is worth analysing.

\section{Clubrooms (Clubhouse)}

The clubroom or club house functions as a central point for teams to socialise before and after the home game. It is typically set up with a main function area, kitchen facilities, a bar and possible children's play room that typically overlooks the main playing field. The establishment of the club room would normally occur when a registered club team comes into existence, for example, the Wellington Rugby Football club is the oldest football club in Wellington playing its first match in 1870 and further matches prior to the foundation of the Wellington Rugby Union in 1879. Another example of a long established rugby club is Poneke. Established in 1883 Poneke is one of the oldest and more traditional clubs within the Wellington Rugby Football Union. In more recent times senior netball and soft ball teams womens teams have become afflicated to rugby clubs, for example, Wellington East Old Girls associated to Poneke Rugby club, St Mary's Old Girls assocated to Marist St Patricks Rugby club. Club mergers show that despite the merging and the pulling together of 
resources, it still does not open the door for wider participation of women in rugby club management. We are yet to see a women chairperson or a coach coordinator office at rugby clubs in the Wellington region.

Upon reading different rugby club histories and current management structures, it is obvious that the structure of clubrooms is maintained along patriarchal lines, where administration and culture is male dominated (Carle and Nauright 1999).

Other examples of rugby clubs are those that have merged with other clubs for various reasons with Marist St Pats (MSP) who officially merged with St Pats Old Boys in 1974.

Oriental - Rongotai Football club, also known as (ORIES) became the $5^{\text {th }}$ club established in Wellington in 1888 and also shares a similar story with several amalgamations with other rugby clubs over time. Their website presents a colourful club history to the public.

Ories is not noted for winning Jubilee Cups outright. It was noted for its irritating ability to spring an upset at any time over more favoured opposition. (www.ories.org.nz)

The role of the clubroom is to make connections between the social relationship with the club and the wider community of which it is part of. Even today some women rugby players still experience isolation and disapproval of their presence (Dempsey, 1991; Thompson, 1992). While the clubrooms are slowly moving away from being private and exclusive to men, women in sports, in particular women rugby players could do more to assimilate into the environment. While there is no intention of portraying the clubrooms as an everyday social site of a pub, it does share similar characteristics with the difference being reduced to trading days and hours. 
Some club rooms are or have adapted in response to changing social and cultural conditions however this does not necessarily mean the social processes taking place in the clubrooms are appropriate for a modern day clubroom (Curtin, 2011). Despite changes in norms and expectations, the presence of women in clubrooms, particularly women rugby players is often still seen as problematic (Hey, 1986). There has been a change in the space that the clubroom provides for its members, who have been predominantly male. This change of this space represents a cultural shift and a change of meaning to what the clubroom now represents.

It is typical for a rugby club to field at least eight men's teams in all divisions from Premier club rugby through Colts (under 21) to the restricted grades and a couple of men's social teams. However the majority of the rugby clubs are only able to field one women's team due to low participation rates from school girl college rugby to women's club rugby (SPARC 1997-2001). It is evident that the percentage of men and women rugby players in rugby clubs are uneven with $85.5 \%$ of men participating in rugby compared $14.5 \%$ being women, (SPARC 2007/2008). A further review of the statistics showed 83.2\% who self-identified themselves as Pacific Island males and $69.6 \%$ Maori males who play rugby compared to 45.6\% New Zealand European males who play rugby. These statistics also support how ethnic dominant the sport has become with pacific islanders leading the way. This is of significance because it is an area that the participants talked about as part of their narratives. The statistics do indicate higher participation rate of male rugby players on the field because of its traditional beginnings as a male dominated sport, however my observations have seen women participate at a higher rate in social activities off the field and in spaces that have traditionally been classified as male zones, in particular the club rooms (Birrell and Cole, 1994; Campbell, 1999; Jackson \& McKenzie, 2000). For most of the century, and still for some women, their roles have been restricted to the domestic labour which has traditionally 
serviced rugby for men and boys, from laundry tasks, hosting social events, supplying food or appointments to secretary roles on rugby club management boards (Theberge in Birrell and Cole, 1994; Thompson, 1988). As Jennifer Curtin articulates in her chapter, women's involvement has paralleled their domestic role, where women supported the game as fundraisers for clubs as wives and mothers of players (Curtin, 2011). Rugby contributes to the maintenance of patriarchal power through a particular form of hegemonic masculinity that is still ambivalent to women. Women have facilitated and contributed to the sport, but their work had been co-opted and exploited by cultural ideology in the name of the sporting interests of the nation (Thompson, 1999: 8).

What is evident in the data is that the presence of women rugby players in rugby clubrooms is generally not received well. While the experiences of the participants have been varied, the majority have been negatively received. The women observed a difference in treatment of women rugby players and netball teams associated with the club from male members of the club and the overall club themselves. Some of the participants indicated they experienced a degree of isolation and disconnection between men rugby teams and their women's team within their own club rooms. As the data suggests, they are the invisible insiders who are at the fringes of a space that was typically male (Birrell and Cole, 1994; Carle and Nauright, 1999).

down south in my first year of playing, the males wouldn't speak to female rugby players, um you were invisible, we had our wee table and there wasn't really any interaction, um, from the senior teams down to the age grades, um I didn't even know who coached the prems ${ }^{5}$ team... like there was no interaction and we had a couple of netball teams associated with the club and they got the attention from the rugby boys, so yeah we were pretty much ignored (Marama)

\footnotetext{
${ }^{5}$ Prems is an abbreviation for the premier men's team.
} 
Although some have signalled slight improvements within their respective clubrooms towards the presence of women rugby players or women in general, it has taken some almost nine years for changes to take effect.

Like making sure we have a table, giving us a seat, asking us if we want a drink, like gentlemen, but that hasn't always been my experience....and I think behavioural wise has improved, like when I first started playing there used to be some pretty disgusting behaviour where like the naked pyramid or taking their shirt off which I found really disrespectful, one to their own team and two to anyone and to use it as some sort of play pen. (Arataki)

Arataki's statement reveals the tension experienced by most of the participants of being the ideal rugby player on the field and looking at maintaining their feminity after the game. This is similar to a statement made by a different participant in a different focus group. What it suggests is that courtesy off the field is shown to all women who are present in the rugby club rooms regardless of whether they are a women rugby player or not.

One participant highlighted the presence of women at the clubrooms had rejuvenated the clubrooms.

...there was so much opposition to women rugby players coming out of a Catholic club so the perception of the old men in the club was that women didn't play rugby....and because it is a hard out Catholic club, had never had a women's team like forever... most of the boys weren't going to the clubrooms before the women's team and all of a sudden there's women up there and um, they became interested again...like there was no one but just that we were up there and having a good time...it impacted on the rest of the club, I mean the team itself wasn't hugely successful in terms of on-field results but socially we lifted the club again (Ollie)

This observation was supported by a similar experience from another participant moving to a different rugby club 
Um, I wouldn't say the environment overall, but probably a slightly more welcoming environment when we're there, like we feel more part of the club rather than hanging out in the corner kind of thing... becoming more considerate of the women's team, like you have noticed that the guys are more comfortable bringing partners or it's kind of...it's not so insular perhaps, like it's not just rugby players that will be there, there will be friends, partners (Marama)

Although we recognise the increase of women's participation in rugby and other hypermasculine sport, we are yet to understand what social activities on and off the field women rugby players participate in. This section aims to present examples of the culture prevalent within women rugby teams as one participant puts it "it's part and parcel of rugby" (Phyllis). It also highlights other activities that some participants have identified as club specific as they present their views as to what is socially acceptable for women's rugby off the field.

Based on the data and literature conducted on women's rugby, there is a consensus that the social environment surrounding the team is a major contributing factor to their enjoyment of playing the sport (Carle \& Nauright, 1999; Masters, 1996).

The physicality of the sport requires putting one's body on the line which leads to forming close knit friendships on and off the field. Rugby players are trained to use their bodies forcefully and encouraged to use their bodies as weapons (Ferguson, 2004; Messner 1992; Pringle 2009).

The game is described by the use of military metaphors. Graeme Ferguson makes the point that the language of sport, in particular rugby is the language of warfare, the organising of troops, setting up battle lines and preparing for counter-attacks (Ferguson, 2004; Laidlaw, 1999). As Chris Laidlaw says "rugby is war, minus the shooting”(Laidlaw, 1999:16). Rugby 
is known for its militarised formation of organising the line of defence, counter attacks, running offensive lines, scrum format and flankers (Ferguson, 2004). As participation in women's rugby increases, the aspect of choosing to use one's body in a physical manner in a sport has come under scrutiny, and it is this attribute that society finds hard to reconcile with women who play rugby and choosing to use their body in an aggressive manner to play rugby versus being women off the field.

I do feel like I would go into battle for anyone in my team but you do feel a bit different when it's someone you have played with for a long time. I feel like my best friends are the people that I play rugby with. Not because I play rugby with them but because they have my back. It's sort of like you're going to a battle, like on Saturdays you're going to war, you're going to smash people, you are going to get rucked and injured and then all these people around me it's like they are with me on this. So my best friends are the people that I think have had my back in war. (Holly)

Upsetting the opposition or simply winning a ball in a line out or doing well in a scrum are aspects they celebrate often. The potency of the physical battle, the attributes of preparing for a battle or war and having a sense of camaraderie of trust and experience is an aspect that features strongly amongst all the participants.

someone who did her job on the field and did it $120 \%$, you've got girls who did their job and you give them a pat on the back but then you've got girls that make the tackle and go hunting for the ball and are straight back on their feet and back into it, you know it's not just make the tackle and that's it, it carries on from there (Sue)

Linked to the themes in these quotes is the recognition of their team members' effort on the field that are followed by unofficial celebrations that can take place on the field, but most notably off the field after the game either over a shared meal or beer. Having a player voted the most valuable player of the day award to having a wooden spoon for the funniest play of 
the day seems to be a regular feature in the majority of these teams where they commended the effort and celebrate the commitment on the field.

Official recognition of the most valuable player of the day would be typically recognised during regular club speeches at the clubroom, and depending on the clubroom, would be awarded a prize such as a Player of Day T-shirt or a jug of beer; however what is interesting about the player of day awards for one particular team, was the feminised version of a typically male system of reward

we've had a player of the day dress and you would wear the dress that's horrifically ugly, um you wear it at the club rooms and your team mates must buy you drinks or whatever you want for the whole time you've got the dress on...cause man it was ugly but man we got really competitive, like people would accessories the ugly dress the best you can, and because we've all real competitive, it got really hard out like, I'm going to wear mine like tucked up at the bottom with this belt and with this side stash and then it was like a bloody fashion competition, which was funny cause you wanted to get down to the clubrooms to see what the dress looked like. (Phyllis)

Another regular feature that forms part of the team's social calendar are the court sessions also known as courties. In a court session the player stand before the judges to hear their wrong doing. The accused then pleads guilty or not guilty to the accusations, and if found to be guilty the person typically would be fined and the requirement is to either drink from a jug or shots in a jug, with the size of the fine dependent on the accusation being heard.

Rugby is just a huge team bonding with things that you're doing pre and post rugby with little courty sessions in the middle you know (Staci)

you would just shut up and listen and take you punishment and drink, not this "I can't drink that or what, like there is a lot of whining you get now, but you would just shut up and you do it...they were serious (Karoline) 
Court sessions are not exclusive to women's rugby, it is a widespread culture within team sports which could form 'part and parcel' of any team sport (Carl \& Nauright, 1999; Philips, 1987). One participant describes her observation of court sessions in the following way It's a real old tradition. Like even the All Blacks have massive court sessions. Like I don't know about here but we had coaches that used to coach down in Otago and man those ones were hard out. Like if you talk you take off an item of clothing and one of the ones was put your tits on the wall...so court session and boozing goes with rugby in New Zealand I don't know if it's all around the world but in New Zealand it certainly does but I suppose having male coaches that culture continues but I think it's getting less and less especially now we have people that don't drink and that's fine. (Holly)

More extreme examples of the culture of excessive drinking in court sessions were also discussed:

I think when I was at Uni as well that was the best courties, we had guys from the prems who were our judges and people actually shut up and listened to them and did what they told us to do... we actually got banned from a pub that we had our court session at cause of the damage that we caused... and I don't even remember how I got home that night, there was at least a couple of kegs (Ollie)

...I like getting drunk. I like the court sessions... (Selina)

The off field activities, in particular the court sessions, and drinking culture within rugby illustrate the rugby culture, and provided that women rugby players conform to the dominant behaviours of drinking and team bonding activities within the rugby culture, their presence at the clubrooms would be deemed acceptable (Palmer, 1994). 
Experiences vary between teams with most adopting dress themes for the occasion and punishing those by having them drink to resolve their fine at one end to deciding to be more socially responsible

we've got a young team and some of these girls are still in school and everyone is sensible when they drink around them, and the other ones watch the younger ones and those trying to do the sneaky ones, yeah the girls look after each other (Sue)

It is clear that when I asked what type of activities their team or club put on for them, the majority signaled that the club environment mainly functioned to get all the teams interacting with each other via inter-team competitions. Participants talked extensively about club specific activities from Idol nights, where each team had to compete in singing or dancing acts, others included annual fundraising nights, quiz nights and old timers and supporter's day. Team specific activities included holding bake offs which showed different cooking styles and a chance for foreign players to have a cultural experience with the different ethnic groups. What is evident is the degree of management that is maintained over social activities and the continued relationships off the field.

\section{Everyday routines and rituals}

Right through my analysis I have referred to the social space for the everyday women rugby player to tell of her experiences. While women's rugby is often marginalised within the rugby clubs and trivialised by the public, what also goes unnoticed and often not captured is the routine and familiar aspects these women rugby players go through in preparation of their game.

Sports feminists fall short in the area of analysing the everyday life of women in sports, often concentrating on activities through a broader analysis of domestic routines of women's 
servicing of men outside and inside the home, so much so, that they neglect the actual sportswomen and their routine within a sporting context (Costa, \& Guthrie,1994;.Thompson, 1997). It could be argued that the current literature produces a one-dimensional portrayal rather than exploring the possibility of alternative ways of analysing the everyday women rugby player.

It's generally agreed that the concept of the everyday life made its appearance in social thought through the work of Georg Lukacs (1971) whose initial use was derived from the accounts of the everyday social routines and rituals that had been developed by George Simmel. For Lukacs the mode of relating to the social world in which existing social relationships were spontaneously reproduced in and through daily routines were often taken for granted. His work directly attempts to give an account of why and how individuals experience influence patterns of thought and behaviour that actively maintain and reproduce the status quo. The forms of social behaviour and social settings where social relationships meet and intermesh can often form distinctive dynamics. What these women rugby players see as part and parcel of rugby are taken for granted assumptions about the social life of a women rugby player or rugby player in general. They are normal occurrences, however they seem like strange events outside of those social sites.

From looking at the role of routine and repetition of these women rugby players, what is clear is that the mundane, repetitive and taken for granted aspects of the everyday, are of considerable significance in the life experiences of individuals and groups.

Taking a micro-sociological approach to these experiences and focussing on the finer details of interaction and ways in which social life is made possible through the creation and 
maintenance of shared meanings, and understanding the unwritten rules of behaviour, has allowed for rich data to be captured in which the small-scale every day practises are lived through and reproduced.

One participant talked about the challenges of balancing motherhood and preparing for her game

Friday nights, picking up the kids and go home and having a snack and drop them off to swimming from 5.30-7.00 at night, and by that time, cooking dinner or take away and by then, its 8 and I'm really tried, and can't be bothered packing the bags or getting my kids rugby things ready. I am a last minute person...It helps me take my mind off the game and because I will be busy with the kids, I will be like really busy preparing the kids for their own games. But it will start hitting me at 10 o'clock (laughs), on my way to the field, and when you get there, you're like “ok, I'm playing rugby today" (Nelly)

A couple participants talked about their mental preparations

I deliberately don't think about rugby.... cause I reckon in the past that I have exhausted myself with rituals, and mentally preparing, over preparing, then by the time kick-off comes, I'm exhausted. but in saying that though I do not shave my legs the night before rugby...I don't know why...I deliberately wear different undies, deliberately don't have a set pair of boots, or anything, cause then you can't blame it, you can't walk out to the field and say "Oh, you know that was that's fault" (Holly)

...actually there are some little things like...its if I don't do this then maybe things will go mental, like I always put strapping tape on the balls of my feet cause particularly at the start of the season I can (get) serious deep blisters on the balls of my feet (Marama)

The majority of the participants highlighted similar rituals such as patterns of packing a bag, having a hearty dinner, watching a game, abstaining from drinking to limiting socialising on a 
Friday. These examples show how routine and time often co-exist within the self and in relationships and in particular in how individuals organise their routines (Felski, 1999).

In their respective teams, the participants prepared in the changing rooms with team goals and drills and team runs. While participant's experiences varied between players from different clubs, some disagreed with the routine of how their team was structured on a Saturday, while others preferred to get on with the game

Um, personally I like to go to the changing rooms, get changed and get out there. I don't piss around...I just found it pointless, I would also turn up late cause I hate hanging around, so I would turn up, get changed and get out there and not mucking around... I'm not a big fan of huge warm ups.... (Staci)

we actually go through our goals for the game individually... which personally isn't something I enjoy...I find it quite painful because I think that you're never held to it, so it's abit of a, um, lip service I believe, um people talk about what they want to do, but I think because they're scared or put on the spot I dunno they say what is the right thing to say like, I wanna make my tackles I wanna do whatever, but they don't do that on the field...I don't believe... and then those goals are never reviewed afterwards or no one is ever accountable for them, so I think it's a load of shit and it fucks me off (Phyllis)

What is evident is that the structure of their preparation is largely routinised in a manner to help them to prepare well for their upcoming game. The players do not portray routines or rituals in a trivial manner but instead are up front that "Saturday is not a learning day, but rather to prepare for being in the zone to play rugby" (Holly). This behaviour is no different to how a male rugby player or other team sports would prepare. There is no degree of separation of any distinctive cultural practise or experience that is exclusively related to women rugby players. Instead it explicitly signals that these women rugby players are preparing for the same type of game being played by their male counterparts. 
This section has looked at the possible self-identified routines both individual and in team environments. It also highlighted some negative aspects of established team routines as a somewhat token gesture. Some shared some unique individual routines from strapping balls of feet to shaving legs on a particular day.

It was interesting to capturing their rationales to sporting rituals off the field, such as court sessions or their regular events at their respective clubrooms. It possibly signalled the reflective nature of the slow acceptance of women's rugby and the practises they engage in as part and parcel of rugby in general.

\section{Sexuality and perception of women rugby players}

One of the perception is women...it's a sport...and it's...one part of an individual whether you are male or female...there's only one dimension to you and it's not your whole being because you play a SUPPOSEDLY masculine sport that you...must be a feminist (Arataki)

Sport has long been regarded as a masculine domain since the Ancient Greek and Roman times. Ancient Egyptians, Greeks and Romans have all used sports to enhance certain attributes that contributed to their social and cultural capital. Attributes that enhanced diplomacy, cooperation, trust and openness as a means of binding communities together, and enhancing interactions and relationship among people and institutions (Mandell, 1984). This section will analyse the participants' perceptions of sexuality and femininity and how this relates to their image of the ideal women rugby player within the context of their sport. For this section, I will be using the concept of binary oppositions (Derrida, 1981) to illustrate the male sports-female sports dichotomy, and also the dichotomy between traditional female team sports players and females who play traditional male team sports such as rugby. I will 
be drawing on this concept to highlight how women rugby players and women's rugby in general are devalued as 'the other' in sports. Further on, this section will also look at how difference in social interactions, language and culture are used as a marker of identity by reference to the work of Ferdinand de Saussure (1974). The last area of analysis uses Norbert Elias' (1986) model of civilising bodies to illustrate how these participants see and use their bodies to achieve physical empowerment and how it is seen by onlookers outside of the context of their sport.

Rugby can be viewed as an entrenched aspect of New Zealand society. As a borrowed sport from England, New Zealand as well as other colonial outposts used rugby as a vehicle for nation building (Fougere, 1989; Howe, 2001; Laidlaw, 1999; Nauright \& Black, 1999; Philips, 1987). The game promoted the ideal masculine values of power and strength needed to sustain the physical and social needs of a frontier society - values and attributes that are still found in a rough physical game of Rugby (Hargreaves, 1982; Philips, 1987).

Rugby is coded as a masculine male dominated sport and women's rugby challenges the notions of femininity and masculinity as well as the hegemonic power of institutions that have worked to exclude women. The literature on women's involvement in sports (Carle \& Nauright, 1999; Curtin 2011; Dempsey, 1991; Hargreaves, 1994; Poynton and Hartley, 1990; Thompson, 1988, 1991 and 1992) indicates that women have had multiple roles as spectators, fans and supporters.

Before illustrating an example of hegemonic masculinity, I need to provide a brief overview of hegemonic masculinity and its relevance to the relational analysing of gender when looking at masculinity and femininity. Hegemonic masculinity is the maintenance of 
dominate socials roles of men over women, in simpler terms men within a given culture engage in a variety of practices which give them masculine currency, cultural power over other men and women (Connell, 2000). The concept of hegemonic masculinity developed by Connell emerged as a critique of sex role theory which he viewed as being inflexible to social change. Connell developed a four-fold model that allowed for hegemonic masculinity to be seen in multiple dimensions such as cultural representation, institutional power structures, economic representation and symbolism (Connell, 2000).

Hegemonic masculinity may not be exercised through physical exclusion, but rather through ideological exclusion such as the belief that it is more natural for boys to play the sport than women or it is more ideal for men to coach rugby then women at any level. (Collins 2008; Kay \& Jeanes, 2008; Houlihan, 2008). What some of the participants expressed was a disappointment about the selection and allocation of coaches in women's rugby, who are predominately male.

There are processes to appointing coaches, management, uniforms .... and what women are getting. What tier are women at is the question I would like to ask them? Because, we don't seem to have...like, we have the same coach for 3 years and it's now the third year with the same coach. The men nearly have a new coach every year...like there are great men women coaches but there's also bad ones as well...there is a certain type of person you need to be coaching women....communication and they sort of do need to be a bit more sensitive... it goes for women's athletes as well as women rugby players and that changes from club level to rep level to national level to. There are all these different intricacies with women (Holly)

What this indicates is overall cultural dimensions of inequality where male rugby coaches are privileged because of particular ideologies, practises of 'men know sports more than women' 
are made to seem natural, and according to Birrell and Richer "men make sports, and sports make men"(1994:226), which refers to the role of sports in affirming hegemonic masculinity.

Maintaining the patriarchal link and gated entry to the sacred site, male dominated sports have and, to some degree, still operate as exclusive male zones separated from women's presence and participation (Marine May-Muir, 2002). Women's rugby has received its fair share of opposition since 1891 when Nita Webbe's attempt to start a women's rugby team was met with public disapproval and a public outcry of unwomanly behaviour (Curtin, 2011). While women's rugby has come a long way since, it has been slowly integrated into mainstream rugby. Women's rugby is part of regional and national rugby programmes, however they still are treated beneath the social grades of men's rugby and even second tier to secondary boy's rugby. These participants are in a premier senior grade and are yet allocated to poor quality fields. A look at rugby club websites and the profile of women's rugby is listed after the under 21 boys teams or in some cases rugby club websites do not have a women's rugby section. This is an example of the hegemonic institutional power of groups that control the management of the game, union and clubroom.

The masculine attributes of physical strength, power, endurance, size, aggressiveness and competitiveness are traits not socially acceptable for women to exhibit both in the past and to a certain degree in today's modern sporting times. Literature on women in sports investigating the perceived masculinity and feminity of sportswomen has largely concentrated on women playing in the elite and higher levels of amateur status. However little is known about the self-identity of the everyday women rugby player in relation to their perceptions about their own femininity (Birrell \& Cole, 1994; Hargreaves, 1994; Howe, 2001; Nauright \& Chandler 1996). 
I think...maybe people will see or hear about women rugby players or see them only in the game situation and assume that's what they're like throughout their whole life...like people assume that because I play rugby that I'm quite aggressive and I'm not...I'm actually the furthest from aggressive you could possibly get...I'm like passive... and I think they maybe carry that over rather seeing women rugby players in different contexts (Marama)

There are various reasons why women choose to play rugby as a sport, whether it is netball because of its socially acceptable non- contact aspect or rugby because of its physicality. What is evident in the data is that these women rugby players exhibit what Saussure refers to as 'difference' exhibited through their social interaction, culture and language (Cilliers \& Preiser, 2010; Oswell, 2006; Saussure, 1974). These women rugby players play the sport not only because they enjoy it but purposely play rugby to be different rather than choosing a typically female sport such as netball. Participants objected to rugby being compared to sports traditionally played by women, such as netball, as measure of their feminity and sexuality.

Yeah and I wonder if in other sports like, cause its male dominated, like if you look at basketball and if that is viewed as a more masculine sport just because it more male dominated and maybe...I don't know ask people who do you think is more feminine a netballer or a basketballer, and they might say netballer but again it's a female dominated sport and I wonder if male netballers get asked if they're more feminine or something (Marama)

The majority of these participants ask that they be compared to other women rugby players, teams and clubs, rather than men's rugby or women playing different sports.

If one keeps comparing us to men's rugby, then we are always gonna be second rate, and if one keeps comparing us to netballers, then we are always gonna be masculine and viewed as unfeminine (Staci) 
While the decision to play a typically male dominated sport can be over-simplified or reduced to just playing rugby as a hobby, what is signalled is that 'difference' matters to these women rugby players and they openly display and celebrate their 'otherness'

... I've been playing for a very long time, rugby is who I am, so I don't ever think that it leaves me, even in my covering letters and CVs, you know, I always refer back to the skills I've learnt in rugby, you know, being positive, being a leader all those things, I think it's a big part of who I am, and me being a school teacher also has a lot to do with who I am. So for me, rugby is integrated into EVERY part of my life. Even for my health, I keep fit, it's all related. (Holly)

It should be noted that difference can be construed negatively as the exclusion and marginalisation of those who are defined as 'other' or alternatively celebrated as a source of diversity, heterogeneity and hybridity, where the recognition of change and difference is seen as enriching. As a conversation between two participants take place

...the crazy people we have, we love them even more, you know what I mean. Like when $[Z]$ this year and she's speaking in this funny language, and we love it, but we are like, come on $[\mathrm{Z}]$ and we make her feel welcome cause the crazier the better, like the more it pulls us together, you know, the bigger laughs we have. But, not at them, but with them...(Holly)

Learning about them, like two Japanese that couldn't speak English, and what is uniting is the love of playing rugby (Arataki)

And, I'm still in touch of those two Japanese girls, and I'm like, I'm going to come and visit you girls soon, and that's what I'm also banking on that, I'll travel the world one day and I will stop and see all these girls from America, Canada from everywhere and it will just be like they were playing [for us] yesterday you know (Holly)

Being a women rugby player versus a women netball player is essential to how they locate themselves in relation to others and providing a sense of who they are, not because there is 
some essence of the game itself, but because they can contrast it with the opposite typical female sport. A contrast which signifies and carries special meaning of representing femininity or their feminine side of masculinity by marking their difference by not playing the traditional female prescribed sport of netball. While the difference between a woman rugby player and netball player can be due to playing different sport codes, it is often a simplified way to establish meaning.

Holly suggests that in her experience and in general that people tend to be surprised that women can be both pretty and also play rugby or the physicality of the game and its associated masculine attributes of toughness, aggressiveness, physically built that women rugby players are able to act and look feminine at the club rooms. This could also suggest that members of the public are playing catching with ther changing nature of women participantion in typically male dominated sports even by those women who will likely look like netballers.

To understand how binary oppositions create dichotomies within sports, Jacques Derrida (1981) argued, there are very few neutral binary oppositions. Binary oppositions usually operate with the dominant opposite holding more cultural capital, currency and power, and as a result, there is always a power play between the binary opposites that produces an imbalance of power. The following quote by one participant highlights binary opposites relating to the choice of sport and suggest that the meaning of the masculine and feminity is redefined on their own terms.

Women netball players could be seen as holding more cultural power over women rugby players, in relation to programmes, quality coaching, resources and profiling (Dyer 1982), 
just as men rugby players can be viewed as more masculine rather than feminine. Therefore, women rugby players in this analysis compared to women netball players are classed as 'others' just as they are against men rugby players.

It has to do with whether the sport is dominated by males and you look at netball players, and they are awesome and they are well known on TV and stuff, and you then look at soccer or rugby and we sort of go unnoticed (Jasmine)

I still see in NZ that women's rugby is a minor sport - that's women's rugby. Rugby is a major sport, it's all about big successes and successful teams. But Black Ferns are AS successful (Holly)

Social groups purposely assign meaning on their world by ordering and organising aspects into certain categories that allows for difference to be used on purpose to distinguish between them. As Saussure (1974) points out the marking of difference through social interaction and language is fundamental to giving meaning to culture. So the norm for women rugby players may or may not be the norm for men rugby players. Similarly, to women rugby players social activities such a heavy drinking sessions or court sessions which was discussed in the previous section may not be the culture of women netball players or women cricket players.

...this is when things were a little bit rougher, in terms of court sessions being quite firm, you know, quite hard out drinking and quite crazy...you always dress up...the theme was two of a kind, I came as a sheep and L came as a shearer. In the middle of the court session, she would make me do noises and she would do the shearer sounds... anyway, we had this call in our team "dozer" and one of the prems had come up and taken a session of counter-rucking, so if you see a moment that you can counter ruck, you call "dozer" and you smash it together with one of your buddies, and you barge over, and we got really good at it, like our season we did dozer a couple times in a game, and we won other people's ball, it was awesome. Anyway...next door, the prems were having a court session and theirs is finished and ours is finishing up, and then one boy, got pushed in ours, and we were like "hoy get out of here...what are you are doing in here", anyway the door opens up and they try and bust in, you know, people are drunk and what was even the point. But then, 
someone calls "dozer" and then, these girls rammed over, and then we smashed them, and on the ground they are crying, you know and they are yelling "what the hell was that... you nutter" and then, one girl gets a slap over the face, and the girl slaps the guy on the face. But, it was the best dozer ever we have done all season. And then, Y who started that, and he was the one that was crying the most, and I said to him "you should be proud of us, you taught us that" (Holly)

What this participant illustrates is a typical court session with a traditionally male activity of binge drinking being taken up by women. This is a shared experience mixed with rugby movements and interaction with other rugby players.

It can be argued that women rugby players, and also women's rugby in general, disrupt the cultural order of the status quo within male dominated sports, especially when applied to the type of sports women participate in. Traditionally male dominated sports such as Australian Football League (AFL), rugby league, National Football League (NFL), basketball, cricket, baseball, rugby and soccer all have some symbolic boundaries that have kept their sport pure from cultural disruptions. Boundaries that give their community or culture unique meaning and identity, and where women rugby players have broken into that space of unwritten rules, codes and practices.

The argument presented by Marine Haig-Muir (1999) highlights the symbolic representation of hegemonic masculinity. Haig Muir argues that since men are attributed with being stronger and more physically powerful than women, one common ploy to keep women athletes in their place has been to declare the sport unfeminine and unnatural for women to play certain sports(Crosset, 1995; Donnelly \& Young 1985; McKay 1992; Nauright \& Chandler, 1996). What is conveniently supported by these symbolic boundaries is the scientific reasoning that women's reproductive capability would be endangered by 
participating in sports that involve physical contact (Atkinson, 1987). Also highlighted by participants were their perceptions of their parents' approval or disapproval.

my mum and still too this day...hates me playing rugby...she HATES me playing rugby, she thinks it's not a female sport...we don't have conversations, like she will never say to me you can't play, but, um she just thinks...that's just my mother though, she just doesn't think it's a female sport and that's cool...I'm really strong so I'm just like whatever...that's cool...you know...you got your opinion and I've got mine (Staci)

I made fun of my sister's sport once she was playing badminton, I was like that's dumb and my mum was like well you play a lesbian sport. I think my mum was just trying to be funny. I just laughed, that was when I was younger. (Selina)

and um, mum, she's a warrior, she's always like "oh my baby girl, don't stand on her", but then she's never missed a game, so it's like, I think she, she knows how much I love it, I think she's come round, so it's, as hard for her to watch the game, but, she's so supportive as well (Jasmine)

These experiences serve as a reminder that the women play a sport that society does not expect them to play to a higher level. The public perception is that women participating in traditionally male team sports should return to more feminine appropriate sports, such as netball.

The data also showed that the participants reported gradual support from the families to play rugby, the majority showed less objections from fathers and more from mothers.

my parents didn't allow me to play, so I just did it on the sly... and my dad who is just a ferocious rugby man, and has only two daughters,...I think once he watched us, as much as he didn't want us to play, shit he was proud and still is... and makes sure he gets at least one game in a season... (Phyllis) 
I signed up for rugby even though my mum said no, I still played...my mum didn't want me to play it at first, but I would tell her I was playing at this time and at this place, she would come down and support me, and she said I couldn't play because it was a boy sport and she's always been my number 1 supporter for all my sports, like even my mates would ask first where my mum is before even saying hello to me, but yeah its great (Karoline)

The importance of the relationship with their father seemed to be one of mutual respect based on sharing a common experience relating to rugby. It could also relate to understanding the physical demands of choosing to play a highly contactable sport and someone who understands the game.

Um...I think when I started, well the first year, it just started off as hobby thing, and then when I got into it, I don't think, I think that's when my dad been like the proudest and coming to watch the games, and then, like he's always been...he's the harshest critic, but he's like the biggest fan at the same time (Jasmine)

Some participants highlighted their relationship between father and daughter about rugby and sport in general.

me and my dad get along because we both love sport so we both know stuff about rugby so we love watching rugby together and stuff and so we've like "oh did you see that...(Staci)

and I'm probably like argued with my dad about rugby like that, cause I think when did you last play, you don't even know the rules... and so sometimes we just have to watch the game in silence... and my mum and sister just go in the other room, because they're like "oh shit, they're at it again"(Phyllis)

Similar to Jasmine's experience of her dad coaching her and developing a love for the game as well as "our sort of our thing we did together, that it became a family thing". 
I did not ask about the number of children in their family or the gender of their siblings or their place in the family. Instead this information was revealed by the participants' background stories. However, when I probed to untangle the reasons for their mothers' objections, it mainly revealed that they were anxious and that centered on possible injuries through the use of their bodies.

My family was obviously supportive, but my mum was a little bit scared and whenever I got injured she would go tiddly winks, and because my mum is a nurse and she's seen a lot of sports injuries in her time (Ollie)

An experience highlighted by Arataki was the disappointment about the use of their bodies, not from her mother but from other women.

Only one lady who has ever said me, and I'd hardly knew her I met her at a Hui that I went to and she said to me...she was a Maori women and said to me that the female form is a taonga (a treasure)...you are bearer of children and how can you do that...she wasn't serious but she was "what does your mother think of this, you are disrespecting your body" was like "yeah"...that's the only negative reaction I got, and I understand that but it's more a disempowering comment for women and also sort of perceiving women to be lesser than they are (Arataki)

It is clear in this instance of Arataki's experience, there is a mixture of the objectifying gaze and alienated embodiment. The empowering body experience described by Arataki experiences might result from a combination of new experiences of physicality and her previous familiarisation with feminist understandings. Feminism might enable women to identify and problematise their body alienation as a gendered experience, and consequently, seek out ways to redefine and reconnect with their bodies. In this particular example, it suggests that a women's body is treated as an object, and her body valued mainly for its use and ability to give pleasure to others. It signals the body as being external and requiring control, monitoring and shaping. What can be seen is the blurring of boundaries between the individual, her body, and her surroundings compared to Arataki's overall experience. As I did not ask for Arataki to explain her relation to feminism, I can only speculate about this connection. 
Whether it is positive or negative experiences, entering the field of sports, exercise and physical activity has enabled some to experience their bodies in new, more empowerment ways by increasing women's mental and physical self-confidence and well-being. It has created a novel awaremeness of a bodily "I can"mentality. Finding connectedness with the body appear to be the central elements of empowering body experiences (McDermott, 2000; Wright \& Dewar, 1997; Haravon Collins, 2002).

Connell (1995) argues that the ideals of the body are no longer fixed, but we can object and refuse various suggestions to participate in gender defined roles such as child bearing. The work of Pringle (2009) shows that men too are subject to the requirement to alter themselves to meet masculine standards, it is no different for women, who also feel pressured to meet particular stands of physical appearance.

Women are taught very early that the way we come into this world is not the way we ought to remain. Unlike men, who are expected to groom and reorder themselves in small ways, women are pressed to conform significantly to whatever the current ideal is of feminine physical embodiment. These are standards not set up by women, but determined by men and where the patriarchal image of women is maintained both by men and women. It is the image of the natural role of women as home maker, child minder, child bearer and helpmate (Ruth, 1995).

Bodies are the material representations of our selves, both to others and to ourselves. On many levels, from the superficial to the deeply profound, the attitudes directed towards our bodies often determine how we see other aspects of ourselves. In this sense there are negotiations of the body by women. Adrienne Rich (1979) argument was that with the failure of other women see other women's experiences as different from their own, and the misunderstanding of the different meanings attached to the body by different people and those differences affect enormously the kinds of lives we lead or experiences we have (Ruth, 
1995), Women's oppression has been linked to the meanings assigned to women's bodies being typified as white and middle class. Rich asks us to reflect on the culturally assigned differences between having different understandings of bodies, as well as on the differences between having the body of a woman or of a man.

The following section focuses on how women rugby players use of their bodies to play a highly combative physical sport such as rugby. Norbert Elias's (1986) analysis on the civilising of bodies emphasised that individuals were required to control their emotional and body behaviour in order to become more rationalised and standardised individuals. Most importantly it targeted individuals into norms of self-discipline. I have taken the framework of civilising bodies to analyse the relationship between changes in individual behaviour and changes social power. In Elias's framework, he saw the social and the self as inseparable, he argued that individual's behaviours, actions, ideals, socialisation and day to day interaction are conformity acts which are the norms of society and become second nature. Individuals are somewhat bound by the culture and tradition which becomes a way of controlling lives. When individuals break away from the norm, it is where one can identify unstable societal norms or relaxed restraints that allow the break away to occur.

Women rugby players engaging in a masculine team sport are examples of this break away. Not only are they breaking away from the ideal feminine women or the patriarchal image of a woman, but they also break away in terms of how they choose to use their bodies in the sport.

Women rugby players are immersed in their rugby culture and identity. They have accepted that the use of the body is a norm in rugby, where physicality is a standard requirement in rugby. The majority of the participants mentioned that they train in their own time to be 
physically rugby fit and make their own decisions on how to control their own bodies. The use of their bodies in a self-disciplined manner is civilized within the context of rugby, however as Arataki experienced, onlookers outside of rugby would see this as being unfeminine. What is notable in the data is that these women rugby players have reflective moments in their playing career, where they look at their own internal rules about appropriate behaviour with the use of their bodies (Liimakka, 2011, Mansfield \& Maguire, 1998; Markula, 2003).

I definitely see that as a battle...cause me and [Holly] always talk about our friendships through rugby because you are putting your body on the line for your mate and that is to me...going into battle...we know we've got each other backs and its not...you only have a handful of friends that you know are like that for you, you know (Phyllis)

When trying to understand the transformations of how women in sports choose to use their bodies within this framework it could be argued that people in sports learn rules and meanings unconsciously and which are then automatically reproduced. Therefore a person playing rugby has no choice but to conform to the requirements of having to use their bodies as weapons to be successful in the sport (Hargreaves, 1994).

I choose rugby cause I enjoyed the physical game of smashing people (Karoline). One comment was made in relation to Karoline playing experience was 'I think some of the men want to play like you aye and want her to go play for the men's grade' (Selina)

...there's so much freedom of being able to pick up a ball and try and score or until you get smashed or you can do pretty much whatever you wanted within the game just as long as you don't lose the ball, or drop the ball or just didn't get smashed by other people. I mean I only grew up with only brothers and I'm the only girl in my family (Ollie) 
It should be remembered that these women rugby players choose to play the sport for numerous reasons with the major reason being its physicality and intensity. What these women rugby players exhibit are examples of what Elias refers to as the body being inscribed with culture.

I don't know, women'...not just saying women's rugby, just plain rugby is just a...I can't find another sport to replace it, in terms of team atmosphere and physical fitness and that's what I enjoy about rugby...I have lots of other sports like snowboarding that is up there with rugby in terms of intensity, but rugby itself to me is on a different and separate level... and I can't describe it...it's the ideal package (Staci)

However, some participants agreed that certain traits that include masculine attributes of aggressiveness and competitiveness, strength and endurance were required for the game and therefore more often automatically reproduced them on the field.

Collectively, the participants disagreed with the common stereotype of all women rugby players being dykes and lesbians but acknowledged it did not matter to them if there were lesbians in the team or if they were playing against lesbians. To these participants it had no relevance to why they play rugby but rather the passion to play the game of rugby that superseded the sexuality of a player

...we accept all, whether you are gay, straight, black, brown, white, or whatever you are, as long as you are female because its women's rugby, then yeah, it is accepting of everyone. (Selina)

...it just doesn't it matter, like what colour you are, what level you're at, what size or whatever, we are just so welcoming and including, um, and I'm really proud of how we welcome people and, it's about, and our senior players model that, and keeping in communication, you know, "you have got a ride" and that happens for every single new player comes, you know, "what do you need, what can we do for you?"... (Arataki) 
Yeah and I don't think about that either like I don't think “oh, I wonder how many are you are gay" you know or "how many of you have got husbands" ...like how would you know and you wouldn't actually know... (Holly)

While some participants challenged the traditionally masculine attributes assigned to rugby players in general, one quote captures perfectly the misalignment that this sections aims to address, and it is also an area that received less exposure in past literature.

I think maybe we have two different personalities, one when we are on the field and off the field, like, we can be completely dominate and aggressive during the game cause that's the nature of the game, but off the field...we are actually kind of soft (Ollie)

This statement presents another dimension to the different levels of meanings attributed to rugby players in general. The participants do not consider themselves deviant or less feminine for choosing to take up a masculine sport

"yes I wear dress and even own high heels and just because I play rugby doesn't mean I'm not a lady" (Holly)

So it is clear that the expression of using one's body as a weapon in a game of rugby is a masculine style that is a central to the commitment of the sport, but also a new image of femininity in sports that is not analysed enough (Coakley, 1990; Dryer 1982).

I have the responsibility to play cleanly...like that to me is being, kind of compassionate, cause I don't wanna stand on the opponent's face or snap their neck or whatever, like you wanna play hard but wanna play well but, you are still within the rules of the game, so that's kind of being respectful and gracious I suppose (Phyllis) 
The overall perception of the participants that women who play in male dominated sports are typically viewed as unfeminine and unnatural turns our attention to the perception of sexuality and masculinity of women rugby players.

In the past women with short hair, who engaged in male sports with boyish masculine shoulders and assertiveness have been stereotyped as 'the mannish lesbians' (Crossett, 1995; Howe, 2001;Sabo and Runfola 1980; Smith 1979). The realisation that such stereotypes exist is something that these participants talked about

It still surprises me when, um, we are a loving rugby nation, and it still surprises me when people.....like I have to say I play women's rugby because if I say I play rugby, they go "touch" no, women's rugby. "Do you wear boots" yeah we do. And those sorts of conversations still surprise me (Arataki)

I think people are more surprised, yeah cause I get lots of people who know me in a professional capacity in the office, you know, they're really like "oh...you play rugby" whereas I think it's so obvious about who I am and what I look like and how I assert myself, but they're really like "is that...is it tackle"....and I'm like its real rugby. So surprised I guess, that someone who doesn't come across as the stereotype can be or can play (Phyllis)

The participants were aware of the dominant public perception of women rugby players as 'dykes, butch, manly, lesbians' and the level of acceptance of the dominant perception

It's like society expects women rugby players to be lesbians whereas if you're gay and playing rugby it's like two things that don't go together, but I think, you hear and everyone knows lesbians pretty much in rugby and they will parade it, sometimes a little bit too much...its expected of women but completely against the norm for men in rugby (Jasmine)

Jasmine's statement leads to the stereotyping of gay men as effeminate and therefore considered as not rugby players. Whether it could be considered as part and parcel of playing 
rugby or learning to be more comfortable with the images associated to a male dominated sport, the data indicates that what is experienced is the power of well-known labels that denigrate sportswomen in general. Susan Cahn (1993) reminds us that the re-imagining of the ideal women athlete takes place verbally and non-verbally, when she says 'the powerful figure of the mannish lesbian athlete has attempted to rehabilitate the image of women athletes of athletic prowess and femininity' (1993: 343). To combat the stereotype and often negative connotations of being homosexual, most female athletes try to emphasize their feminine characteristics, their sexuality, and to highlight their heterosexuality" (Harrison \& Secarea, 2010). An example used by participants was the track and field athletes who receive a lot of media coverage for their athletic prowess

and they are really feminine they have like diamantes on their face or a crown in their hair and they're still like cut up to pieces [muscles] you know... full on makeup and stuff like that (Phyllis)

It leads female athletes to prove their femininity and heterosexuality, and these participants point out is the public lack of movement to see beyond the image

... when I use to work in the kitchen and some of guys were like do you play rugby and don't you think the girls look really butch or are they lesbians, and so I would say they are ladies and some are lesbians....like they're normal (Karoline)

New images of female athleticism seem to contradict the popular idea that women are passive and compliant. Female body builders, for example, represent a form of female power which can be interpreted as taking control of the body and an unashamed display the female physique of femininity and sexuality while putting the natural order of gender under threat by displaying a masculined body (Hargreaves, 1994, McNeill, 1988, McGuire 2010,).

But it's a sort of a catch 22, cause in order to be a really good you have to be manly and aggressive, cause the stronger you are the better you are gonna be, um so the least feminine part is correct cause you're not gonna get really far... whereas you get 
someone that's really feisty and aggressive and not afraid then they're gonna be better to, yeah, I think on the field you to become least feminine but then off the field you can be who you are... of trying to be a women after the game (Jasmine)

Heteronormativity depicts normalcy as traditional heterosexuality (Adelman \& Woods, 2006). In this instance, it is the distinct assignment of gender roles that tends to reflect traditional values of western patriarchy, physical strength, dominance, control, heterosexual virility and power, and most importantly tends to devalue traditionally feminine traits like emotive expression, collaboration, and community. As such, it restricts both men and women into roles that do not allow either to be fully realised as individuals. In this example, the perceived sexuality of the women rugby players and on-going dominant image of the unfeminine butch and lesbian lead to questions about their sexuality, largely because these characteristics are customarily constructed as masculine and threaten the traditional gender order, and also because they do not fit the heterosexual male images of how females should look and behave (Lenskyji, 1995; Rankin, 1995).

Sexuality was a topic where I tread lightly. There were clear signals that the topic itself was hard to engage with participants. The silent spaces that occurred indicated that the longevity of the women's involvement in the sport had led to developing defence mechanisms towards questions on sexuality. Remaining silent could also be related to the fear of being victimised. I acknowledge that sexuality is intensely personal and suggested one to one discussions with participants outside of the focus groups as an option. I had initially planned to ask questions around sexuality, however due to empty spaces of conversation, I started with general questions or statements about sexuality to help generate wider discussion before moving to specific probing questions once participants were comfortable to proceed with the topic. An 
example of an open question was whether they thought women rugby players were more open to players of different sexual orientations than male rugby players?

While the majority of participants highlighted that the environment in women's rugby is open and more accepting of gays compared to the restricted environment of reduced emotion and affection in men's rugby, they dismissed being collectively referred to as butch or lesbians, and spoke openly about their team environment as being inclusive of all people. These participants acknowledged throughout the data collecting process of the typical reference of women rugby players or women in general who participant in masculine sports as butch or lesbians and predominately went about managing this tension by talking opening about their male partners or children. They talked openly of embracing people of different sexualities. As one person indicated some of their good friends are gay.

Another example of an open question was in relation to the percentage of gay women they believe are in rugby teams and whether it was possible to know if they were lesbians? Participants in various groups were adamant that other teams looked more masculine than their own or as one participant said

I wouldn't know and I wouldn't care... it would be similar to the boys' team, they will have some gay players you know, and why would you wanna know...I don't really care about that part I'm just here for the rugby (Nelly)

The issue about sexuality in sports creates divisions between women with different sexual identities. Lesbianism is stigmatised because it is perceived to violate popular ideals of femininity and therefore has a powerful influence on the attitudes and behaviour of women in sports. 
The perception presented by a lesbian towards those who identified themselves as heterosexual painted a different picture of one looking into a dominantly heterosexual team environment.

Everyone is quick to say "no I don't judge and don't care"... and would say "it's the $21^{\text {st }}$ century...things have changed" but I feel they don't know what it's like and that really annoys me when you know for a fact there was a known reaction to some situations that people have been in, like I don't know if it's a natural instinct and when they know they can be more closed... And from my view, I actually feel uncomfortable sometimes... and like you think that they are looking at you as if you are looking at them, and so my view is that I totally feel uncomfortable being in the changing rooms...I personally don't care which way people swing or whatever, it doesn't bother me. But I do get the impression that some people think that we're gonna leap on every single chick or like, you know, so, yeah, I get a more protective about myself when I'm in a team environment, because people naturally think and it's a stereotype and it's kind of true that there are probably more hidden. And that's probably why they want to play the sport, too get all closer and shit (Selina)

In this experience Selina is recognising that sport as an institution mediates hegemonic masculinity and heterosexuality to the point that it wields power over other sexualities (Messner and Sabo, 1990). The basis comes with the assumption that to be a lesbian is deviant and straight as normal. What possibly is being exhibited is the overwhelming dominance of heteronormative sexuality, where lesbian women in sports hide their sexuality or pass as heterosexual because of the fear of victimisation.

While I am also guilty of being less observant of others, in particular those who identify themselves as lesbian, I therefore recognise that I am part of a system of domination that perpetuates patriarchal relations that operate within a social system of unequal power relations between women and men and women. It may not be the case for individual men in 
relation to individual women or individual women in relation to individual women, but society as a whole is characterised by unequal power relations (Derrida, 1981).

Furthermore, I was able to capture the views of a rugby player, who was also a mother, on the topic of sexuality. She had explicitly laid out her background and her position from the first interview. As this participant pointed out she does not care about public perception of her femininity let alone care about the sexuality of others in the team. She stated that she is married and has children, and currently stays away from the off the field activities

all the girls are the same. I wouldn't even know the difference, or even if, you know that they would look at me and thinking, she sucks, but for me, it's my casual attitude of whatever I just want to play (Nelly)

Based on the data, what is presented is a consensus across the majority of the groups that sexuality of women rugby players was a private matter for the player. The information that participants provided indicated that safe surroundings made it acceptable for women who played on the team to be open about their sexual orientation. Sport is a mainstay of what Jim McKay (1992:250) called 'a dense web of power which both enables and constraints all people in gender specific ways'. These everyday women rugby players celebrate their difference in playing a masculine team sport and their 'otherness' of women in sports. It also leads to redefining the symbolic boundary that exists for women playing a masculine team sport, and is an example of shifting the goal post as a way to restore the balance each time a taboo is broken as it threatens the status quo (Douglas, 1996). 


\section{Impact on the everyday women rugby player}

\section{It's my passion}

'If we're not playing it, we're training or watching it or thinking about it pretty much... no matter what I'm doing' (Sue)

This thesis shows how sport has become central to the self-identity of the participants. The woman recognise the importance of their participation in the sport within rugby circles, however outside that circle women's rugby appears to have little significance to the wider culture of New Zealand. In this chapter how women's rugby has come to play such an important or crucial role in the participants' lives is explored. The cultural practices of the individual, team or club, or a desire to build a profile of the ideal women rugby player or possibly a reflection of their contribution to their sport are examples that need analysis. To do this, it is useful to see the impact through Paul du Guy and Stuart Hall's model of the circuit of culture (du Guy et al. 1997).

The circuit of culture, as 'circuit 'implies, is the continuous circular movement of how cultural meaning is produced, consumed, represented, identify and regulated (Hall, 1997). The five major cultural processes of the circuit helps to explore how women's rugby is represented, to what social identities are associated with it, how it is produced and consumed and what mechanisms regulate it (du Guy et al, 1997: 3).

It needs to be acknowledged that the very definition of culture is in itself a difficult concept to define because it is something we take for granted and hard to measure because it has become inscribed in our informal social knowledge - what everybody knows about the world without consciously knowing where or when they first learned it. Although the definition historically has its links to the arts, music and theatre, the definition itself has moved beyond 
this and now is considered part of our normal lives. In this instance, I have taken what Raymond Williams refers to the social culture in which culture is a description of a particular way of life which expresses certain meanings and values provided there are shared understandings which bind us together in society (Williams, 1961 cited in Storey, 2010). It is the circuit that allows for exchanging meanings that helps us to form comparisons and understand meaning in our daily lives (Williams, 1961 cited in Storey, 2010).

Placing the stories and experiences of these women rugby players within the circuit of culture framework allows us to see essential elements of how rugby is embedded into the lives of these women rugby players and the access they have to shared frameworks of meanings that help make sense of their cultural, social and physical world.

As mentioned in this research rugby is a culture of its own with its own distinctive set of meanings and practises. The very word rugby, in particular women's rugby conjures up an image or an idea of the rugby player as being masculine and aggressive. These participants show awareness of the dominant public perception of women who play masculine sports as butch, lesbian, mannish and unfeminine. This is similar to what Pat Griffin (cited in HaigMuir, 2002: 53) referred to when she claimed that women's sport is being held hostage to the L-word and the way to free the hostage is to establish femininity credentials in accordance to the conventional heterosexual male standards. Heterosexual standards of presenting boyfriends, marriage and motherhood that are visible and verifiable as normal credentials (Griffin, 1998). What it represents to the participants and how they have articulated this obligatory presentation of heterosexual standards lies is revealed in their attitude of 'don't care and don't give a shit' attitude (Arataki). Their rugby playing journey has gone from 
playing the sport as a hobby to developing an abrupt attitude towards questions raised about their feminity and sexuality.

it's probably towards myself in regards to and how I think I look, you know, with short hair and play rugby I must look like a lesbian...its more me than others...yeah I think it's me worrying about me and the perception I give. I'm quite proud to be a women rugby player and don't really care what people think, it's just every so often... and its more the culture of women's rugby...its always the topic of "you must be a lesbian" (Arataki)

For the majority of these participants at this point in time, it is the image that is being produced by operating in a space that is seen to be outside mainstream rugby circles, and an image they are trying to change. What is difficult to contest is that the image is regulated through subtle resistance from institutions such as rugby club's accommodation of women's fitting rugby uniforms or adequate access to facilities to changing room and showers. These participants would prefer to be called ladies rather than girls, and their presence in the clubrooms acknowledged more.

I've encountered bigoted men, who refuse to recognise the contribution that females can make to the game of rugby (Phyllis)

\section{The physical impact}

What was evident in the data was the over-riding commitment they showed to playing the sport. While it could be reduced to the physical requirements to play a highly combative sport, what these participants clearly indicated was the drive to more physically fit, rugby strong and rugby smart about their bodies. The consensus from the participants was that it takes a certain type of women to play rugby, one who is aggressive on the field, one who has no fear of stepping up their game, but also exhibiting a supportive attitude towards their team mates and a willingness to 'have a go' mentality in the game. 
Yeah, I sometimes ponder, and I sometimes wonder like, you know as a prop, you run and hit run and hit run and hit, and then you think one week, what happens if I STEP! (Selina)

As one participant mentioned 'there is some novelty surrounding women's rugby' (Marama), and to the majority of the participants, despite the dominant myth that women cannot play rugby because they do not have the physique or their ability to handle contact, the evidence shows that women can play rugby and to some degree play it well, if not better than some men.

For the majority of the participants, they don't just show up on Saturday to play a game for 80 minutes, but also put in the same, if not more, time training as other men's rugby teams. Not only are they training twice week which seems to be similar to the male teams but they also operate a similar training programme with live scrummage, lineouts and tackling each other. They go to the gym in their own time and at their own expense, fund their own training uniforms and most importantly take the time to learn a game that they would not have played at 5 years old.

... yes I'm a girl and yes I play rugby, just like men who play rugby are considered rugby players, they don't say “oh there goes a man who plays rugby" - I just wanna be considered as a rugby player...I bust my arse in the gym too, we all go to trainings like the boys do and just because we are women it doesn't mean we are any less of a rugby player (Holly)

What is indicated is the difference in value and meaning attributed to what women rugby players do on and off the field.

...this one guy that I work with, who is like, "who wants to go and watch women's rugby"...and I was like...."you haven't even given it a chance", you know, there's that one guy at my work whose never seen a women's game, and so you probably have the NZ rugby union saying that women's rugby doesn't bring in enough money, well they 
haven't given it a chance to bring in money, like they haven't put it on TV or they don't do enough curtain raisers...they haven't done enough to give it a chance to make it more popular, you know. (Selina)

What is important is that, though these practises involve bodily and physical movements, they are also saying that their physical or biological character should not make them culturally significant in rugby, but simply that they are performing in a similar way to fulfil the core requirements of playing the game. However despite this as rugby players they are still treated as second class citizens.

I myself am expected to be aggressive and hit $200 \%$ with force. Like, I didn't even care if they were big or whatever size. But, I think there is aggressiveness in me... I made my first hit, the girl fell... (Nelly)

We go against society's ideas...if you say that females aren't usually allowed to use their bodies as weapons in rugby...then you could argue that women do use their bodies as weapons of a different nature every Saturday night down Courtenay Place, then we have slipped under the radar in an effort to be seen as equals (Phyllis)

Onlookers outside of rugby circles could be somewhat puzzled because of the inability to understand the meaning behind the women's reasoning to play a masculine sport or to put up with the physicality of the sport. Therefore the physical impact could possibly be understood only by those inside rugby circles or sports in general.

What is important is that, if according to Bourdieu (1978) different social classes can be have a distinct taste structure and lifestyle, then what these women rugby players are asking for is to be located in the same circle as male rugby players and not rated differently. This, I believe is the argument presented by early sports feminists (Birrell and Richter, 1987; Theberge, 1985; Daly, 1978; Millett, 1971; Oakley, 1972) as being disconnected with women in sports, especially women rugby players. These participants want to be seen as rugby players in the sense of the way they choose to use their bodies in the context of rugby. Works by other sport sociologists have shown women engaging in physical activity in general increase perceptions of the self and bodily connectness (Blinde, Taub \& Han, 1993; 
Wedgwood, 2004; Wright \& Dewar, 1997), and generally conclude positive effects which can influence beyond their own context and to an extent provide an empowering experience (Grishaw, 1999; Wedgewood, 2004). A call for more in-depth research is needed into the pleasure of physicality of women rugby players against other women rugby players involved in the sport, and to provide a more solid connection to the value and acceptance of women rugby players putting their bodies on the line for a rugby game. There is a collective experience highlighted by these participants that help us to understand how habituality is located in personal experience of their bodies and how they use it within their own worlds (Wright \& Dewar, 1997). Similar to what (Rouhiainen, 2008) points out that moving bodies is a way "to gain an ever more variegated sense of ourselves and to be capable of manipulating the world and acquiring new skills" (Rouhiainen, 2008, p. 246). Furthermore, these participants call for the value placed on male rugby players and their bodies needs the same value applied to women rugby players.

It's a shame they don't show much of women's rugby on TV even if it was on grassroots television that would be awesome, cos they always screen first 15 school games on there but not women's or even club rugby by women's rugby (Karoline)

\section{The cultural impact}

The majority of these participants experience a sense of identity that they unconsciously inherit from just being in a rugby oriented country like New Zealand. For some, rugby has always been in integral part of their upbringing whether it was home influenced, a sense of community or regional identity.

Rugby is my life, I need to find a life outside of rugby...I don't know who I am if I don't have rugby just because I've been playing for a long time (Ollie)

What is evident in the data is the impact their rugby has in their lives, however what was also worth noting was the different impact it had on the various age groups.

If I could be training all day every day I would be, definitely....but I suppose I did do something else with it, just cause it's not that professional, so yeah I'd be sitting in class... it's just, it's taking over and like now... it's like shit, I don't wanna drink 
anymore, like I'll have a drink and I'll feel so guilty... it's probably at the moment I'd say it's my top priority, above uni even, which is really bad but, It's my passion, I can study at any time of my life I'm not gonna be able to play rugby forever, so you gotta make hay while the sun shines I guess (Jasmine)

Marama summed up the majority of responses from those in their early to late 20s. This age group rugby playing journey was at different stage where rugby played a priority in their lives.

...I don't find that rugby takes up day life but it's the priority and it does tend to dominate things so... and then a Saturday is a big no no, Saturday is rugby, and often rugby team events will take precedence I might on that night, it will be like I'll go to the rugby thing first and fit in whatever else ... (Marama)

Staci shared the majority of the responses from those in their 30s. The majority of this age group highlighted potential moves to other roles with rugby or as Staci indicates, a sport that use to be a priority but does not consume as much as her life as it once did in her early rugby playing experience

Um, rugby used to define me, well it doesn't now, I had 3 years off from it and it was great and cause I had a passion for rugby, I couldn't wait for winters to start and at the end it was good to have a break, but it was...my Saturday was always taken up with rugby and trainings...I've enjoyed it over the years...but it definitely doesn't define me now, like I enjoy playing it...it's a part of who I am and it's a sport that I play but not how I use (Staci)

What should be noted is that while the participants highlighted the important of women's rugby to themselves and their community, they were also able to talk about the lack of its social and cultural significance in New Zealand. This lack of significance extends from the national to the regional rugby unions as well as the lack of profiling of women's rugby. The following participant positions herself as still a everyday rugby player at a grass root level $\mathrm{r}$. 
Holly story and experience is strikingly interesting as her journey of reaching higher levels with her rugby. As she told about her journey, her experiences at higher levels of rugby became more apparent in her story telling. She is not bound by the code of professional rugby players and expresses what Laidlaw (1999) refers to Amateurs having a choice and able to maintain their individuality compared to professional rugby players who lose their independence and operate on a conveyor playing for a corporate enterprise on the basis of a contract that dictates almost every aspect of their lifestyle.

The NZ Rugby museum said it has all the names of all the Blacks Ferns who have ever played rugby for the New Zealand Black Ferns, and here's their name and profile. So I'm looking up my own name, and it's not updated...it's obviously not important for them to update the Black Ferns information every year....also I have massive issues with the New Zealand rugby magazine... when the Black Ferns won, they put this tiny little photo and article in... there are people and shows on TV with rugby centre and try and promote women's rugby as much as they can, but when you think about the hours they spend on men's rugby versus what they give to women's rugby even then it's not significant and its very small...I don't think the higher up people see it as very important, and another reason...there are processes to appointing coaches, management, uniforms etc. and what women are getting. What tier are women at is the question I would like to ask them? ... we have the same coach for 3 years and it's now the third year with the same coach. The men nearly have a new coach every year, they obviously have a more stringent criteria that they have stick too, the gear that we play in, like we are wearing shorts that can't even stay down, they roll up and are like miniskirts because they are so wide and roll up...I don't know, I just think that all these messages for me as a women rugby player show me that people, not so much the public, but the people in charge of our rugby in New Zealand, they don't seem to give it significance in the messages that they send me as a women rugby player (Holly)

What Holly articulates in the above summary is that there is no level playing field for women's rugby and for the actual player themselves. They still experience institutional bias 
and discrimination and low priority in terms of funding and resources. This argument was a reoccurring theme that other participants discussed in their respective groups, with an additional comment on the same question from another person in a different group who was in a different age group

I think the real culture are with those that play it and those that watch it...I think beyond that I don't think there's much significance, like I don't think it matters to those that aren't affected by it, whereas the All Blacks even if they don't watch it...you still feel a part of it, but with women's rugby there's no sort of national support or any significance culturally or recognition (Jasmine)

What is important is the underlying question of why women continue to be consumed by a sport that is not popular and which receives little attention. It is a question where there one possible answer is that society is not ready for change, in particular in an area where sport is seen as the last bastion for men. I claim this because, we already recognise that there is a series of cultural values and meanings around rugby and rugby players - values to do with masculinity. It is through women's active participation in playing rugby that has signalled a change in the type of masculinity ascribed to the sport by men and as a result of women's active involvement they are forging new versions of femininity on their own terms. This is an argument made by Coakley, in which society has failed to capture the changing images of women in sports. It is an argument that the women athletes and their performance in sports are similar to the aspects of physical prowess of training hard, strength and power (Coakley, 1990; Haig-Muir, 2004).

Another possible answer to the question can be drawn from Karl Marx and his analysis of the relations of capitalist production (cited in Foley \& Dumenil, 2008) where consumption is an integral part to production. That is, if the ideal woman rugby player is portrayed as aggressive and competitive then it is assumed that is what women's rugby calls for, and that 
is the only sort of group it will attract and be able to keep engaged. However if the women rugby player is a woman after the game, then what sort of woman is she? There is a misalignment where society cannot make sense of the different accounts and representations of these everyday women rugby players. Their accounts and representations or meanings provide an insight into the contested character and indicate how the women rugby player has accumulated different meanings by different groups such as rugby clubrooms, men rugby players, friends and family, but also amongst from those who participate in its very consumption (Finnegan in Mackay, 1997:67). So when applied to women's rugby, they are consumed by what they produce. In this sense, production and consumption are not completely separate in existence but rather interlink with one another. There is an on-going cycle, where (the women rugby player) make new meanings or different versions of old meanings. For example, reinventing the image of the women rugby player off the field. This as a result leads to various interpretations of meanings or activities (the women rugby player activities on and off the field) and therefore affects how meanings are consumed and produced in some way.

The social impact that women's rugby has placed on them is the continued support and involvement in the social activities within their own teams and clubs. They continue to socialise with others as way to stay connected and build their rugby networks. To these women rugby players it is 'part and parcel 'of rugby and forms a part of their identity of who they are and how they carry themselves outside of rugby.

It's the friendships and the people you meet...that's the life skills you learn from such a simple sport (Sue)

In most cases, participants talked about how their involvement in playing women's rugby has taken them to places outside New Zealand. Some have played in countries also known for 
their rugby culture while continuously working towards to building their rugby networks and increasing the profile of women's rugby through either their own personal involvement as a player, supporter or facilitator. Their involvement to whatever level of the women's game produces significant meaning in the sense it provides a living description of how significant their rugby is to them

I've met so many different people, I've travelled to lots of exciting and wonderful places. I've played on big grounds in front of crowds, I've been on TV and watched my team play with commentators and stats and replays - equal with the boys! I've made lifelong friends and bonded with people I never would have met if it weren't through rugby. I've developed confidence and skills like leadership, organisation, time management and relationship management - rugby has helped shaped my personality and craft a skill set that spills over into my career as well (Phyllis)

What is evident throughout this chapter is what Hall (1997) points out, that we constantly draw on the wider connotations to make sense or to expand of specific meanings. It is my contention that the women rugby player will bring in a new range of meanings to help our understanding of what the everyday women rugby player represents. What can be concluded is that over time there has been a shift in meaning to one that is not driven by masculine standards and one that becomes more widely accepted and understood, rather than meanings that appear removed, remote or isolated to the fringes of the sport of rugby. 


\section{CHAPTER SIX: CONCLUSION}

I set out to examine the lived experiences of the everyday women rugby player at a grass roots level within the Wellington region. From the beginning I was clear that the stories and experiences I collected would inform my observations of different rugby clubs and teams, as well to reconcile my own reasons for getting involved in women's rugby in the first place.

What I found was a whole range of stories and experiences that could be explored in depth under different sociological themes, such as family and agency, structural debates between amateurism versus professionalism of women's rugby, community identity in a rugby context or stratification in a rugby context, themes that fell outside the scope of this research. When I embarked on this research project, interest of this project reached to areas outside of Wellington city. As anticipated the participation request exceeded the original sample number and I had to request further approval to increase my sample size. Increasing the sample size also required me to carefully screen those to include or exclude in the project. I had managed to obtain a range of participants in relation to age, playing experience and ethnicity. Other characteristics of participants, such as sexual orientation or where they had grown up, only became known during the data collection process.

I was researching in a field in which I participate. Therefore that allowed me access to an often protected space where shared frameworks of meanings and understandings evolve. In order to provide an analysis on the lived experiences of the everyday women rugby player I gathered stories and experiences from 12 different participants across a four week period. These participants were arranged in focus groups of no more than five people that featured a mixed range of age groups, playing experience and ethnicity. Holding focus groups with a small number of participants was used so I could get the richest source of data with respect to 
the beliefs, perceptions and expectations of the everyday rugby player. The participants were provided a space where they could express their feelings, opinions and understandings on their own terms. The focus groups were audiotaped and later transcribed. The sessions followed a general guide with a list of questions under headings that were used to explore themes in the course of the focus groups (See Appendix B). My role as the researcher cannot be overlooked. Although I was an insider to the domain of women's rugby and was familiar with the participants, I left it up to the participants to decide what they wanted to disclose. As I was the inquirer of the phenomenon I recognised that the data was selective and based on the themes of the research project. In this area of investigation it was evitable that discussion would be diverted to other topics. In retrospect, these off-the-topic discussions often led to interesting themes that participants felt were important to them to discuss. During the data collection process, it was revealed by the participant's background stories that different regional backgrounds were represented in the groups. For example, each group had at least one participant who identified their early experiences of playing rugby outside of Wellington, in places like the central north or as far south as Invercargill. I found this interesting because the influence of rugby culture carried more weight in certain areas than in others, for example, in areas in the Bay of Plenty, Taranaki and in the South Island where the influence was likely to be stronger. In addition, this provided an opportunity for participants from different parts of the country to gain an understanding of the rugby context in regions other than their own.

In the first chapter, I looked at the images and experiences these women rugby players had growing up. While some revealed iconic rugby legends such as Jonah Lomu, Sean Fitzpatrick or even John Kirwan as the dominant rugby images while growing up, on a personal level the majority came from an all-girl families. In these cases, what the data 
reveals was that for at least half of the participants rugby featured in their household mainly through their father who played rugby as their early memories of rugby, however there was limited or no influence in the home to play or participate in rugby. This was in contrast to the literature (Greendorfer and Yiannatis,1974 \& 1976; Lamb, 1976; McPherson, Guppy and McKay, 1976; McPherson, 1978; Watson, 1975) that indicated that socialisation into sports would come predominantly from family influence and participation. The participants experienced less opposition to playing the sport from their fathers and more opposition from their mothers over their decision to play rugby. Furthermore, since their active participation in the sport and through their playing career, there has been a gradual increase in parental support and more often, the mutual respect and relationship bonding between that would traditionally exist between father and son, was being forged between father and daughter who had either been rugby players themselves or supporters of rugby or sharing a passion of sports in general.

The analysis chapters concentrated on the rituals associated with playing rugby, with sexuality and masculinity as well as the social and cultural impact of women's rugby. The routines or rituals described by these participants were those involved in preparing for a game the next day - abstaining from drinking or late night socialising were the main examples the majority of the participants highlighted. They all shared experiences in the way they physically prepared themselves on the day, however on an individual level, the mental preparation was more varied and personal. What was indicated was either a one hundred percent focus on the task at hand through to not wanting to think about rugby at all until the team warms up. A few participants performed tasks that formed part of their ritual, from always putting strapping tape on the balls of one foot, to only shaving legs on a Thursday night, to always packing and repacking bags the night before the game. The important 
element to remember in trying to understand the experiences of the everyday women rugby players is the acknowledgment that on top of being an invisible athlete in the sport, they experience routines that are their own rather than those dictated by what society expects their routine to be.

As mentioned earlier, the team routines were similar in the majority of the teams where the participants showed little variance in their team ritual in the lead up to the game. One rugby team looked to set team and individual goals, which participants in the same rugby team but in different focus groups expressed disapproval of established team routines as expressed by Phyllis. This was compared to another club that performed number counting as a way to unify the team.

A look into the clubroom environment provided some insight into some clubroom specific activities. It also provided the means to explore how hegemonic masculinity is secured and reproduced in a specifically public social site like the clubrooms. What was already known by these participants was that the clubrooms have traditionally been male zones with no or limited presence of women rugby players. This was a zone where men followed a distinct pattern of drinking consumption, conversation and behaviour that has somewhat eased over time (Campbell, Law \& Honeyfield, 1999). While some data indicated negative experiences from some participants such as Marama, Arataki, Staci, one participant Ollie indicated that with one club in particular, the regular presence of women rugby players and women in general at the clubrooms lifted the spirit of the club again.

The next section looked at sexuality. As mentioned in my analysis, this section was difficult to generate discussion. The short responses and reluctance to engage was something that 
featured in most of the focus groups. The participants were aware of the dominant perception of women who play rugby as masculine, and were adamant that questions of their sexuality and feminity as a collective unit should be made in comparison to other women rugby players and women rugby teams rather than to sports traditionally played by women, a dominant binary that they wished to escape. In this section, I also drew on Saussure's (1974) concept of difference and otherness to illustrate how the invisible symbolic boundary is readjusted to restore status quo in traditionally male dominated sports such as rugby (HaigMuir, 1995; Nelson, 1994). In some instances I had to adjust my questioning to deal with gaps in the discussion, and I switched my strategy to presenting generalised statements that did not call for specific examples, but rather presented an opportunity for the participants to offer an example to support their position when or if probed for clarification by other members of their own group. I also had requests for one-on-one interviews, which revealed a different perspective on sexuality. I was enlightened by a gay person who offered a different perception on the sexuality with what it meant to be a gay women rugby player.

What could be concluded from the data is the recognition by these participants that they already play a sport that is considered masculine (Messner, 1992), where male rugby players are seen as heterosexual and women rugby players seen as a team of lesbians. What is interesting to note is the contesting of these images by these women rugby players and their respective teams, where they adopted an inclusive approach of being gay-friendly rather than homophobic as mentioned by Selina and Arataki (Dunning and Sheard 1979; Pringle and Markula 2005).

The final section looked at how much women's rugby impacted on their lives. What the data showed was a greater impact on younger participants, possibly either because they are just 
breaking into senior club rugby or chasing higher honours on the regional team, compared to those who had been in the game for a very long time. These latter participants placed importance on increasing the profile of women's rugby and looking for structural improvements in the women's game in general. For these participants the sport consumed much of their life and in the majority of cases it was difficult to distance themselves from the sport because they have developed a sense of belonging in a close knit community and appeared to be most comfortable with themselves and their identity

I think its cool hearing other stories because you're such a different background and such a different age and at a different stage of the game but you know, I get real excited when you (Sue) and Jasmine talk about your reasons why you play and what's it's been like for you guys and stuff (Phyllis)

These women rugby players reported the experience of the physical empowerment they achieve by having control of their own bodies and are reproducing the dominant image of the ideal rugby player. These everyday women players push their bodies to maximum physical capacity in spite of pain and injury, not to emulate male players but to be smarter about their bodies by becoming rugby fit. What this means is as Theberg's argues, women playing a highly combative sport come accept the physicality of the sport if they are to be successful in their participation and in the process accept the dominant model (Theberge 1997: 83). When applying Elias's (1986) model of civilising bodies in the context of sports, what the data reveals is that these everyday women rugby players undergo the norms of a rugby player by using their bodies as a weapon as suggested by Ferguson (2004). However it would seem these participants exhibit the self-control and self-restraint within the context of rugby culture. These behaviours such as engaging in rugby conversation or an analysis of the game could possibly be applied to what Gregor Paul calls the almost " patriotic duty to watch a game...the idea is that all New Zealanders will build a good sense of being able to read the 
game"(Paul, 2009: 14). My experience of watching games and having rugby conversations has meant playing down the knowledge by repeating well known phrases "tackle, forward pass, wide..." These participants explained their ability to converse with the public about rugby if they wanted and clearly indicated their knowledge of the game and environment was just as valuable and make no apology for the love of the game

...I'm challenging you and your bullshit stereotype or whatever, and I can have a real good rugby conversation, and like wake up, cause chicks do this...I think in New Zealand, we're really critical of rugby players and what they should've done and everyone is an expert, and everyone thinks they're Graham Henry...but I sort of challenge that a lot because I think, I've played to a higher level than you crusty old man, who sat at home and just watched it on TV...(Phyllis)

\section{Implications for the women rugby player}

The interactions between participants within their own group have either provided another connection to expanding their network or tighten up on already established contacts. These participants opened their stories and experiences up to other women rugby players and to me as a researcher in their field. What that means for me is the challenge to tell of their experiences through a sociological lens.

The implication of this research for the participants has been two fold. One is my observation of the growing interest expressed by these participants of having their experiences told and analysed in a sociological sense. Jasmine pointed out early in chapter four the taken-for-granted experiences that are not reflected upon when she says 'you know stuff that you don't consider cause you just play and don't think about the stuff behind it'.

What is hopefully achieved through this research is that these participants start to take a closer look at their privileged position of being able to play rugby and what it means socially, 
physically and culturally not only to themselves but also to those outside of their rugby circles.

Furthermore, what the research tells me is that these everyday women rugby players do not consider themselves as a separate entity within the sport. They acknowledge the biological and physiological differences between women and men, however this is where it stops. Their participation in the sport moves beyond to simply just playing a sport, it moves into a space where they are rugby. They are rugby on a Monday, Wednesday and Saturday. They use their bodies as weapons in the sport because that is what the sport calls for and is no different to how male rugby players use their bodies on the field (Ferguson, 2004). They participate in social activities on and off the field, because to their knowledge it is 'part and parcel' of rugby. They have presence in the clubrooms because they understand that to increase their profile as rugby players they need to be more visible and accountable for their membership in the traditionally male zone.

If they are trying to catch up to the men, the preference would to be travel a similar path and not be accused of taking short cuts to reach the same level. I conclude that what these participants aspire to is being valued in the same way as male rugby players and having their contribution to the game recognised.

The reasons these women players chose to participate in rugby is varied, for some it appears to be to do something different other than play a 'prissy sport like netball', to some it was a sense of identity or the enjoyment of the social activities off the field, and, as mentioned earlier, a sense of belonging. So it is hoped that for these participants, the research has provided a space to allow them to reflect on their stories and experiences in a group that is 
built on shared meaning and understandings, and is hoped that they continue to share these experiences in forums that they feel comfortable in.

I am by no means the first person to write about women's rugby, but I would say that I am someone who is very close to the people on the ground and who make rugby what it is. The grassroots of women's rugby is invisible in the analysis of women's rugby in general. I take note of the literature on women's rugby, however I do not feel connected enough to the narratives to be able to draw on my own experience nor reflect on my own memories of my rugby journey. I disagree with Messner's (1992) suggestion to selecting elite participants because they might have a greater understanding of their perception on themes relating to masculinity and sexuality in relation to their sport than any other single factor. These everyday women rugby players show awareness of the dominant perception of women rugby players, with the ability to articulate their position on themes relating to the perception of women rugby player femininity, masculinity and sexuality. These participants provided stories and experiences of moments where they challenged the perception of women rugby players as butch and overly masculine off the field. The everyday women rugby player in this research displays dedication and commitment to their sport with some reaching elite levels, however again, I found it was more interesting to hear their early experiences of how they got there.

Part of building relationships and networks meant following up on the matters of interest or issues raised during the research, for example, the women's rugby database and lack of profiling of women's rugby at a local level. I have taken steps to get the ball rolling by initiating dialogue with such institutions. Engaging in reciprocal action set the benchmark that I was, and still am, genuinely interested in their experiences of "the good and the bad and 
the ugly'. These are some of the principles that underpin the Talanoa methodology. Although I do not use the method explicitly, I have captured some of the key features of Talanoa reciprocal principles.

\section{Future research}

As mentioned before, there were themes that deserved in depth analysis that were outside the scope of this research, themes looking at the structural debate between rugby unions and women's rugby, family and agency, structural debates between amateurism versus professionalism, community identity or stratification in a rugby context, where I see an exploration would offer insights and better understandings of women's rugby from the perspective of the women rugby players themselves.

An important structural theme I would like to see explored in relation to women's rugby is Duncan and Brummett's (1993) analysis of the trivialisation of women in sports in the media (Burke, 2002; Ferguson, 2004). As well as further content analysis of announcer discourse to uncover the framework of sport broadcasts, the scripting tactics by sport casters and whether these purposely enhance the salience of story lines to viewers, possibly to seek or generate a large viewership (Wilson, Gutierrez, \& Chao, 2003).

It is hoped from this research that a better understanding of the experiences of these everyday women players will help bring meaning and understanding to the general public, as to why they play the sport and why they still continue to play a sport that dominantly under values them as rugby players. What is clear in their stories and experiences that they have travelled through a life cycle from the early images of rugby. It has hooked them through their early playing experiences and has made them accountable for their team mates on the field, and has 
kept them engaged off the field through camaraderie. It has provided skills of leadership, management, conflict resolution and strategic thinking which these participants have transferred into other aspects of their life as summed up by Sue "it's the friendships and the people you meet, and that's the life skills, like you learn so much from a simple game"

It is also summed up by Phyllis in her final statement when she mentions 'that's the passion, it doesn't decrease over time'. I identified closely with the participants about the nature of the game and the culture that is embedded in rugby. There is something about women's rugby that is intriguing to watch and play. It is hard to walk away from the sport if you're been so involved in the sport for so long, so like others in the research, I too would find it hard to walk away or find something on the same level as rugby., As Staci said when she summarised the general response from the participants: 'it's like the whole package that you want out of life...fighting hard and front on battles...camaraderie... and contributing every bit of yourself'. 


\section{APPENDICES}

A: INFORMATION SHEET \& CONSENT FORM - APPROVED BY ETHICS

B: MASTER QUESTION SHEET 


\section{Appendix A}

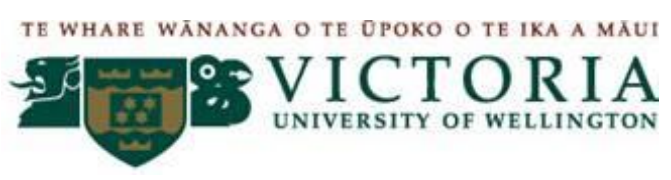

INFORMATION SHEET

\section{Women's rugby: An analysis of the lived experience of women rugby players on and off the field.}

Researcher: Katerina Tovia: School of Social and Cultural studies, Victoria University of Wellington

I am Masters student in the Sociology programme at Victoria University of Wellington. As part of this degree I am undertaking a research project leading to a thesis. The project I am undertaking is a study into the lived experiences of women rugby players on and off the field. The project has ethics approval from the School of Social and Cultural Studies Human Ethics Committee.

I am inviting women rugby players to participate in this study. As a participant you will placed in a group pod of three to four made up with other participants from different club rooms and different ethnic groups.

Each group pod will meet once a week across a four week period to talk through a series of topics. Each session is expected to vary in length between one to two hours. Participants are able to opt for individual interview sessions if they feel more comfortable doing this. With permission all sessions will be audio recorded and transcribed. You are welcome to review the written or recorded data of your group pod to ensure it is accurate at the end of week four.

I will be using field notes to record observations of participants in their team and club room environment as a comparative exercise to identify significant cultural or social experiences that are club unique. These team and club observations will not be audio or video recorded. However they may be included in my field notes.

Participation is voluntary and should you feel the need to withdraw from the project, you may do so without question at any time up until two weeks after the final discussion.

Responses collected will form the basis of my research project and will be put into a written report on a non identifiable basis. It will not be possible for you to be identified personally.

All material collected will be kept confidential and stored securely. No other person besides me and my supervisor, Dr Allison Kirkman, will read the transcripts and listen to tape recordings.

The thesis will be submitted for marking to the School of Social and Cultural Studies and deposited in the University Library. It is intended that one or more articles will be submitted for publication in scholarly journals such as the International Review of the Sociology of Sport and possible citation by other scholarly academics in the field. Transcripts and recordings will be destroyed two years after the end of the project. 
If you would like to take part please check that you meet the inclusion criteria listed below:

Gender: Women

Age range: $18-40$ years old

Experience: Three years or more for any rugby club level or senior college level or administrative or management involvement in women's rugby at a local level.

If you have any questions or would like to receive further information about the project, please contact me at Katerina.Tovia@vuw.ac.nz or my supervisor, Dr Allison Kirkman at the School of Social and Cultural Studies at Victoria University of Wellington, PO Box 600, Wellington, phone (04) 4635676.

\section{Katerina Tovia}

MA Candidate in Sociology

School of Social and Cultural studies

Victoria University of Wellington

Katerina.Tovia@vuw.ac.nz

MY 909 


\title{
Appendix A
}

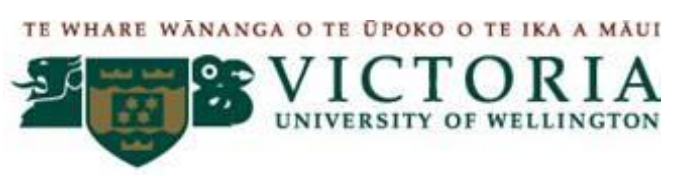

\section{CONSENT FORM}

Women's rugby: An analysis of the lived experience of women rugby players on and off the field.

\author{
Katerina Tovia \\ MA Candidate in Sociology \\ School of Social and Cultural Studies \\ MY909
}

Extension 6179

I confirm that I have read and understand the information sheet for the above study and have had the opportunity to ask questions.

I understand that the study involves a focus group interview that lasts two hours or less, and will be audio recorded and transcribed.

I understand that my participation in this study is entirely voluntary, and that if I wish to withdraw from the study or to leave, I may do so at any time up until two weeks after the final discussion. I do not need to give any reasons or explanations for doing so. If I do withdraw from the study, I understand that this will have no effect on my relationship with the research or any other organisation.

I understand that sensitive subjects may be discussed in the focus group interview, To protect my own and others' privacy, I have been asked not to talk about any of the discussions outside of the group.

I understand that all the information I give will be kept confidential, and that the names of all the people in the study will be kept confidential.

I understand that I may not receive any direct benefit from participating in this study, but that my participation may help others in the future.

I understand that when this research is completed the information obtained will be destroyed two years after the end of the project.

I understand that I can check interview notes belonging to my specific group pod. 
I agree to the interview/focus group consultation being audio recorded.

I agree to the use of non identifiable quotes in publications.

I agree to take part in this research.

Name of Participant

Date

Signature 


\section{Appendix B}

\section{Question Sheet}

\section{Topic 1}

\section{Images and experiences}

- What images and experiences of rugby did you have growing up?

- Can you describe what interested you to playing rugby?

- Can you describe your first experience playing women's rugby?

- Why continue playing the game?

- What were the attitudes of your family/friends/partners watching your play?

\section{Topic 2 \& Topic 3}

\section{The perception \& Sexuality}

- What sort of reactions do you get when you tell people you play women's rugby?

- Are you able to easily have a conversation about rugby to male/female family/friends?

- Are you taken seriously in the conversation?

- Can women rugby players be considered experts in their fields vs. a nonplaying male?

- How much do you think impacts on assumptions made about the sexual identity of women rugby players?

- Have you come across incidents where your sexuality has been questioned?

- Rugby as a Gendered sport?

\section{Topic 4}

\section{The rituals on and off the field}

- Can you describe what rituals and experiences you go through as an individual or a team?

- What do you like about your club room?

- What sorts of activities do you engage in or the club puts on for its members?

- Can you tell me what keeps you engaged to playing rugby? 


\section{Topic 5}

\section{Impact}

- How integrated is rugby with other aspects of your life and work?

- How involved is your family/partner in your rugby experiences?

- How does rugby rate in terms of its cultural/social significance? 


\section{REFERENCES}

Anderson, B. G. (1990). First fieldwork: The misadventures of an anthropologist. Prospect Heights, IL: Waveland Press.

Adelman, M., \& Woods, K. (2006). Identification Without Intervention: Transforming the AntiLGBTQ School Climate. Journal of Poverty, 10, 2, 5-26. doi:10.1300/J134v10n02

Albinson, J.G., \& Andrew, G.M. (Eds.). (1976). The Child in Sport and Physical Activity. Baltimore, University Park Press.

Anderson, K., \& Jack, D.C. (1991) 'Learning to Listen: Interview Techniques and Analysis'. In S. Gluck and D. Patai (Eds.). Women's Words: The Feminist Practice of Oral History. London, Routledge and Kegan Paul.

Anderson, E., \& McGuire, R. (2010). Inclusive masculinity theory and the gendered politics of men's rugby. Journal of Gender Students, 19: 3,249-261. Irvine.

Atkinson, P. (1987). The feminist physique: Physical education and the medicalisation of women's education. In J.A. Mangan \& R.J. Park (Eds.) Fair sex to feminism: Sport and socialisation of women in the industrial and post-industrial eras. London, Frank Cass.

Bain, L. L. (1985). Implicit values in physical education. In A.Yiannakis \& S. Greendofer, (1992), Applied Sociology of Sport (pp. 55-63). Illinois, Human Kinetics Publishers Inc.

Baker, A., \& Boyd, T. (Eds.). (1997). Out of Bounds: Sports, Media and the Politics of Identity. Bloomington, Indiana University Press.

Banks, O. (1981). Faces of Feminism: A study of feminism as a social movement. Oxford, Martin Robertson.

Barrett, M. (1982). Feminism and the definition of cultural politics. In R. Brunt (Ed.), Feminism, culture and politics. London, Lawrence \& Wishart.

Birrell, S. (1988). Discourses on the gender/sport relations from women. In Sport to Gender Relations, Exercise and Sport Science Reviews, 16, 459-502

Birrell, S., \& Cole, C.L. (1994). Women, sport and culture. Champaign, IL: Human Kinetics

Birrell, S., \& Richter, D. (1987). Is a Diamond Forever? Feminist transformations of sport. Women's International Forum, 10, 4

Blinde, E.M., Taub, D.E., \& Han, L. (1993). Sport participation and women's personal empowerment: Experiences of the college athlete. Journal of Sport and Social Issues, 17(1), 47-60.

Blue, A. (1987). Grace under pressure: the emergence of women in sport. London, Sedgwick and Jackson. 
Bobel, C., \& S, Kwan, S. (2011). Challenging the Norms, Breaking the Rules: Embodied Resistance. Nashville, Tennessee, Vanderbilt University Press.

Bourdieu, P. (1978). Sport \& social class, in social class information. In J. Hargreaves, Sporting Females: Critical issues in the history and sociology of women's sports (pp.821). London, Routledge.

Bourdieu, P. (1984). Distinction: A social critique of the judgement of taste. In J. Hargreaves, Sporting Females: Critical issues in the history and sociology of women's sports (pp.173). London, Routledge.

Boutilier, M.A., \& San Giovanni, L. (1983). The sporting woman. Champaign, Illinois: Human Kinetics.

Brown, M.E. (1990). Television and Women's Culture. The Politics of the Popular. London, Sage Publications.

Broverman, I.K., Broverman, D.M., Carlson, F.E., Rosencrantz, P.S., \& Vogel, S.R. (1970). Sex-role stereotypes and clinical judgments of mental health. Journal of Consulting and Clinical Psychology, 34, 1-7.

Burke, M. (2002). Joshing and nudging the big boys: Sports comedy shows on television. In D. Hemphill \& C. Symons (Eds.), Gender, sexualities and sport: A dangerous-mix (pp. 8191). Petersham, New South Wales, Walla Walla Press.

Burkitt, I. (1987). Bodies of Thought. London, Sage Publications.

Cahn, S.K. (1993). From the Muscle Moll to the Butch ballplayer: Mannishness, Lesbianism and homophobia in U.S women's sport. F.S Feminist Sports, 19, 2, 343-368.

Cameron, J., \& Kerr, R. (1999). The issue of gender in sport: 'No bloody room for Sheilas'. In C. Collins (Ed.), Sport in New Zealand Society (pp. 171-181). Palmerston North, New Zealand: Dunmore Press.

Campbell, H.W. R., \& Honeyfield, J. (1999). What it means to be a man: Hegemonic masculinity and the reinvention of beer. In R. Law, H, Campbell, \& J, Dolan (Eds.), Masculinities in Aotearoa/New Zealand (pp. 166-186). Palmerston North, Dunmore Press.

Carl, A., \& Nauright, J. (1999). A man's game? Women playing rugby union in Australia. The University of Queensland, Department of Human Movement.

Chandler, T.J.L., \& Nauright, J. (1996). Introduction: rugby manhood and identity.In J. Nauright (Ed.). Sport, Power and Society in New Zealand: Historical and Contemporary Perspectives (pp.1-12). ASSH Studies in Sports History No. 11.

Charman, P., \& Exelby, K. (2010, August, 14). Sad demise of women's rugby Bay of Plenty Times. 
Chu, M., Leberman, S., Howe, B., \& Bachor, D. (2003). The Black Ferns: The experience of New Zealand's elite women rugby players. Journal of Sport Behaviour, 26, 2, 109-120.

Coakley, J. (1990). Sport in Society $\left(4^{\text {th }}\right.$ Ed). St Louis, Times Mirror.

Collins, M.F. (2008). Social Exclusion from Sport and Leisure. In B. Houlihan, Sport and Society: A student introduction (pp.77-105). London, Sage Publications.

Collins, C., \& Jackson, S.J. (2007). Sport in Aotearoa/New Zealand Society. Albany, Thomson.

Connell, R.W. (2000). The men and the boys. University of California Press, Allen \& Unwin.

Costa, D.M., \& Guthrie, S.R. (Eds.). (1994). Women and Sport: Interdisciplinary Perspectives. Place of publication, Human Kinetics.

Crawley, S.L., Foley, L.J., \& Shehan, C.L. (2008). The Gender Lens: Gendering Bodies. United Kingdom, Rowman \& Littlefield Publishers Inc.

Crosset T.W. (1995). Outsiders in the Clubhouse. The World of Women's Professional Golf. New York, SUNY Press.

Culpan, I., \& Bruce, J. (2007). New Zealand Physical Education and Critical Pedagogy: Refocusing the Curriculum. International Journal of Sport and Health Science, 5, 1-11.

Curtin, J. (2011). More than Male Gazing: Reflections of Women's Engagement with Rugby Union in New Zealand. In R. Hess \& N. Wedgewood (Eds.), Women, football and history. (pp.1-15). Melbourne, Maribyrnong Press.

Currie, J. (2004). Motherhood, stress and the exercise experience: freedom or constraint? Leisure Studies, 23, 225-242.

Daly, M. (1978). Gyn/Ecology: The meta ethics of radical feminism. In J. Hargreaves, Sporting Females: Critical issues in the history and sociology of women's sports (pp.31). London, Routledge.

Deem, R. (1986). All work and no play: the sociology of women and leisure. Milton Keynes, Open University Press.

Dempsey, K. (1991). Married to the game. The incorporation of wives into their husband's leisure. New Zealand Sociology, 6, 2, 88-108.

Denzin, N.K., \& Lincoln, Y. (1994). Introduction: The discipline and practise of qualitative research. In N. Denzin \& Y. Lincoln (Eds.), Handbook of Qualitative Research (2 $\left.{ }^{\text {nd }} \mathrm{ed}\right)$, (pp. 1-29). London, Sage Publications.

Derrida, J. (1981). Positions. In J. Coakley \& E Dunning, Handbook of Sports Studies, (2000). (pp.118-133). Thousand Oaks, Sage Publications. 
Donnelly, P., \& Young, K. (1988). The construction and confirmation of identity in sport subcultures. Sociology of Sport Journal. 5, 223-240.

Drummond, M. (1994). Muscle, men and masculinity. Unpublished paper presented at the Australian Association for Research in Education conference, Newcastle, New South Wales.

Du Gay, P. (Ed.). (1997). Production of culture/cultures of production. London, The Open University, Sage Publications.

Duncan, M.C., \& Brummett, B. (1993). Liberal and Radical Sources of Female Empowerment in Sport Media. Sociology of Sport Journal, 10,1, 57-72.

Duncan, M.C., Messner, M.A. \& Williams, L., (1990). Gender Stereotyping in Televised Sports. Los Angeles, The Amateur Athletic Association of Los Angeles.

Dunning, E., \& Rojek, C. (Eds.). (1992). Sport and Leisure in the Civilising Process. London, Macmillan.

Dunning E., \& Sheard, K. (1979). Barbarians, gentlemen and players: a sociological study of the development of rugby football. Oxford, Martin Robertson.

Dunning, E., \& McGuire, J. (1996). Process-sociological notes on sport, gender relations and violence control. International Review of Sociology of Sport, 31, 3, 295-321.

Durocher, L. (1990). 'Male perception as a social construction. In J. Hearn \& D. Morgan (Eds.), Men, Masculinities and Social Theory. London, Hyman.

Dyer, K. (1982). Catching up the men: Women in sport. London, Junction Books.

Eitzen, D.S. (2009). Sport and Gender in Contemporary Society: An Anthology ( $\left.8^{\text {th }} \mathrm{ed}\right)$, (pp. 313-18). Boulder, CO, Paradigm.

Elias, N., \& Dunning, E. (1986). Quest for excitement: sport and leisure in the civilsing process. Oxford, Basil Blackwell.

Featherstone, M. (1987). The body in consumer culture. Theory, culture and society, 1, 2, 18-33.

Felski, R. (1999). The Invention of Everyday Life. A Journal of culture/theory/politics. 39, 15-31. Cambridge, University Press.

Ferguson, G.W. (2004). You'll be a man if you play Rugby: Sport and the construction of gender. with the Christchurch College of Education and Whitireia Publishing, New Zealand Dunmore Press. 
Finnegan, R. (1997). Storying the self: Personal narratives and identity. In H. Mackay (Ed.), Consumption and everyday life (pp. 66-111). London, The Open University, Sage

Publications.

Foley, D., \& Gérard D. (Eds.). (2008). Marx's analysis of capitalist production. The New Palgrave Dictionary of Economics. ( ${ }^{\text {nd }}$ ed.). Steven N. Durlauf (Ed.), and Lawrence E. Blume (Ed.). Place of publication, Palgrave Macmillan.

Fougere, G. (1989). Sport, Culture and Identity: The case of rugby football. In D. Novitz \& B. Willmott (Eds.), Culture and identity in New Zealand (pp.110-22). Wellington, New Zealand, GP Books.

Game, A. (1991). The Sociological Mirror. In Undoing the social: Towards a Deconstructive sociology (pp. 20-36). Milton Keynes, Open University Press.

Gamman, L., \& Marshment, M. (Eds.). (1988). The Female Gaze: Women as Viewers of Popular Culture. London, The Women's Press.

Gill, D.L. (1986). The psychological dynamics of sport. Champaign, ILL Human Kinetics.

Goffman, E. (1959). The presentation of self in everyday life. New York, Anchor Books.

Goldie, K. (2002). Pectoral Poseurs: Gender and Sexuality in Gladiators. In D. Hemphill, \& C. Symons (Eds.), Gender, Sexuality and Sport: A Dangerous Mix (pp. 69-81). Petersham, New South Wales, Walla Walla Press.

Gove, K. \& Watt, S. (2004). Identity and gender. In L. Woodward (Ed.), Questioning Identity: Gender, Glass, Ethnicity ( $\left.2^{\text {nd }} \mathrm{ed}\right)$. London, The Open University, Routledge.

Griffin, P. (1998). Strong Women, Deep closets. Lesbians and Homophobia in Sport .In D, Hemphill \& C, Symons (pp.53). Gender, Sexuality and Sport: A Dangerous Mix. Petersham, New South Wales, Walla Walla Press.

Grimshaw, J. (1999). Working out with Merleau-Ponty. In J. Arthurs \& J. Grimshaw (Eds.), Women's bodies: Discipline and transgression (pp. 91-116). London: Cassell.

Guba, E.G., \& Lincoln, Y.S. (2000). Paradigmatic controversies, contradictions, and emerging confluences. In N.K Denzin \& Y.S. Lincoln (Eds.), Handbook of Council Research ( $2^{\text {nd }}$ ed), (pp. 163-188). London, Sage Publications.

Haig-Muir, M. (2002). Is That a Woman? Gender and Sexuality in Women's Golf. In D, Hemphill, \& C. Symons (pp. 49-61). Gender, Sexuality and Sport: A Dangerous Mix. Petersham, New South Wales, Walla Walla Press.

Hall, M.A (1984). Feminist prospects for the sociology of sport. Arena Review, 8, 2, 1-9.

Hall, M.A. (1993). Gender and sports in the 1990s: Feminism, sports, culture and politics. Sports Science Review, 2, 1, 48-68. 
Hall, M.A. (1994). Women's sport advocacy organisations: Comparing feminist activism in sports. Journal of comparative physical education and sport, 16, 2, 50-59.

Hall, S. (1997a). 'The spectacle of the Other'. In S, Hall (Ed.), Representation: cultural representation and signifying practices. London, The Open University, Sage Publications.

Hall, S. (Ed.). (1997). Representation: cultural representation and signifying practises. London, The Open University, Sage.

Hargreaves, J.A. (1994). Sporting Females: Critical Issues in the History and Sociology of women's sports. London, Routledge.

Hargreaves, J.A (1985). 'Playing like gentlemen while behaving like ladies: contradictory features of the formative years of women's sport. British Journal of Sports History, 2,1, 4052.

Hargreaves, J.A. (1984). Action replay: Looking at women in sport. In J. Holland (Ed.), Feminist Action. Hounslow, Battle Axe Books.

Hargreaves, J.A. (1982). Sport, Culture and Ideology. London, Routledge \& Kegan Paul.

Hargreaves, J.A. (1986), Where's the virtue? Where's the grace? A discussion of the social production of gender relations in and through sport. Theory, Culture and Society, 3, 1,109123

Harris, D.V. (1981). Femininity and athleticism. Encyclopaedia of Physical Education. G.H. Sage (Ed.), \& L.G, Liischen (Ed.). Champaign, IL, Stipes Publishing Company.

Harrison, L.A., \& Secarea, A.M. (2010). College women's attitudes towards the sexualisation of professional women athletes. Journal of Sport Behaviour, 33, 4, 403-426

Hauge, A. (1973). The influence of the family on female sport participation. In D. Harris (Ed.). DGWS Research Reports: Women in sports. Volume 12.Washington, D.C, AAHPER Publications.

Harvey, J., \& Cantelon, H. (Eds.). (1988). Not Just a Game: Essays in Canadian sports society. Ottawa, University of Ottawa Press.

Haravon Collins, L. (2002). Working out the contradictions: Feminism and aerobics. Journal of Sport and Social Issues, 26(1), 85-109.

Hemphill, D. (2002). Writing Gender and Sexuality in Sport Studies. In D. Hemphill \& C. Symons, Gender, Sexuality and Sport: A Dangerous Mix (pp. 116-122). Petersham, New South Wales, Walla Walla Press.

Hemphill, D., \& Symons, C. (2002). Gender, Sexuality and Sport: A Dangerous Mix. Petersham, New South Wales, Walla Walla Press. 
Hey, V. (1986). Patriarchy and Pub Culture. London, Tavistock Publications Limited.

Holmlund, C. (1997). Visible Difference and Flex Appeal. In A., Baker \& Boyd. T. (Eds.), Out of Bounds: Sports, Media and the Politics of Identity. Bloomington, Indiana University Press.

Houlihan, B. (2008). Sport and Society: A student introduction. London, Sage Publications.

Howe, P.D. (2001). An Ethnography of Pain and Injury in Professional Rugby Union: The Case of Pontypridd RFC. International Review for the Sociology of Sport, 36, 289-303

Howe, P.D. (2003). Kicking stereotypes into touch. An ethnographic account of women's rugby. In A. Bolin \& J. Granskog (Eds.), Athletic Intruders: Ethnographic Research on women, culture, and exercise (pp. 227-246). New York, State University of New York.

Hughes, R., \& Coakley, J. (1991). Positive deviance among athletes: the implications of over conformity to the sport ethic. Sociology of Sport Journal, 8, 307-325

Hughes, G., \& Ferguson, R. (2000). Orderings lives: family, work and welfare. London, The Open University, Sage Publications.

Huw, R. (2006). A Game for Hooligans: The History of Rugby Union. Edinburgh, Mainstream Publishing.

Jackson, S.J., \& McKenzie, A.D. (2000). Violence and Sport in New Zealand. In C.Collins (Ed.). Sport in New Zealand Society (pp. 153-70). Palmerston North, New Zealand, Dunmore Press.

Janes, L. (2002). Understanding gender divisions: feminist perspectives. In P. Braham, \& L, Janes (Eds.). Social differences and divisions (pp101-159). London, The Open University: Blackwell Publishing.

Jarratt, E.H. (1990). Feminist Issues in Sport. Women's Studies International Forum, 13, $5,491-499$

Kay, T., \& Jeanes, R. (2008). Women, Sport and Gender Inequity. In B. Houlihan, Sport and Society: A student introduction (pp. 130-154). London, Sage Publications.

Kenyon, G., \& McPherson, B. (1974). An approach to the study of sport socialisation. International Review of Sport Sociology, 9, 1, 127-138.

Kenyon, G., \& McPherson, B. (1973). Becoming involved in physical activity and sport: A process of socialisation. In G Rarick (Ed.). Physical Activity: Human Growth and Development. New York, Academic Press.

Kidder, L.H. (1981). Research Methods in Social Relations. New York, Holt.

King, G., Keohane, R., Sidney, V. (1994). Designing Social Inquiry: Scientific Inference in Qualitative Research. Princeton, NJ, Princeton University. 
King, T. (1906). The Evils of Cram. In W.J. Baker, The Making of a Working-class Football Culture (pp. 278). (1978). Journal of Social History. Volume no?

Kvale, I. (1996). Interviews: An introduction to qualitative research interviewing. Thousand Oaks, CA, Sage Publications.

Krueger, R.A. (1998). Analyzing \& Reporting Focus Group Results. Thousand Oaks, CA, Sage Publications.

Laidlaw, C. (1999). Sport and national identity: Race relations, business, professionalism. In B. Patterson (Ed.)., Sport, society and culture in New Zealand. Wellington, New Zealand. Stout Research Centre.

Labaree, R.V. (2002). The risk of going observationalist: negotiating the hidden dilemmas of being an insider participant observer. Qualitative Research, 2, 1, 97-122.

Lamb, M. (1976). The Role of the Father in Child Development. In A.Yiannakis \& S, Greendorfer, Applied Sociology of Sport (1992), (pp111-124). Illinois, Human Kinetics Publishers Inc.

Leberman, S.I., \& Palmer, F.R. (2009). Motherhood, sport leadership and domain theory: Experiences from New Zealand. Journal of Sport Management, 23, 3, 303-334.

Lefebvre, H. (1984). Everyday Life in the Modern World. (S. Rabinovitch, Trans). With introduction by P. Wander. London and New York, Continuum.

Lefebvre, H. (1991). The Production of Space. London, Wiley Blackwell.

Lenskyj, H.J. (1995). Sport and the Threat to Gender boundaries. Sporting Tradition, 12,1, 47-60.

Lenskyj, H.J. (1995). Sexuality and femininity in sport contexts: Issues and alternatives. Journal of Sport and Social Issues, 18, 4, 356-376.

Light, R., \& Kirk, D. (2000). High school rugby, the body and the reproduction of hegemonic masculinity. Journal of Sport, Education and Society, 5,2, 163-176.

Liimakka, S. (2011). I am My Body: Objectification, Empowering Embodiment, and Physical Activity in Women's Studies Students'Accounts. Sociology of Sport Journal, 28, 411-460.

Lindley, M. (2002). Taking a joke too far and footballers' shorts. In D. Hemphill, \& C, Symons. Gender, Sexuality and Sport: A Dangerous Mix (pp. 61-68). Petersham, New South Wales, Walla Walla Press.

Lukacs, G. (1971). History and Class Consciousness. In I. Shor. (1987). Critical Teaching and Everyday Life (pp. 56-70). The University of Chicago Press.

Mandell, R. (1984). Sport: A Cultural History. New York, Columbia University Press. 
Mangan, J.A. \& Park, R.J. (Eds.). (1987). Fair Sex to Feminism: sport and socialisation of women in the Industrial and Post-Industrial Eras. London, Frank Cass.

Mansfield, L., and Maguire, J. (1999). Active women, power relations and gendered identities: Embodied experiences or aerobics. In S. Rosenell and J, Seymour (Eds.), Practicing Identities: Power and resistance (pp. 81-106). Basingstoke, Macmillan Press.

Markula, P. (2003). The technologies of the self: Sport, feminism, and Foucault. Sociology of Sport Journal, 20(2), 87-107.

Mauthner, N.S \& Doucet, A. (2003). Reflexive Accounts and Accounts of Reflexivity in Qualitative Data Analysis. Sociology, 37,413-432

Millett, K. (1971). Sexual Politics. London, Sphere.

McDermott, L. (2000). A qualitative assessment of the significance of body perception to women's physical activity experiences:

McGregor, J. (2000). The mass media and sport. In C. Collins (Ed.). Sport in New Zealand Society (pp. 187-200). Palmerston North, Dunmore Press.

McKay, J. (1991). No Pain No Gain? Sport and Australian Culture. Sydney, Australia, Prentice Hall.

McKay, J. (1992). Sport and the Social Construction of Gender. In G, Lupton, P.M. Short, $\&$ R. Whip (Eds.)., Society and Gender. South Melbourne, Macmillan.

McKay, J., Messner, M.A., \& Sabo, D. (Eds.)., (2000). Masculinities, Gender Relations, and Sport. Thousand Oaks, CA, Sage Publications.

McNeill, M. (1988). Active women, media representations, ideology. In J. Harvey \& G. Cantelon (Eds.)., Not just a game (pp. 195-212). Altona, MB, University of Ottawa Press.

McPherson, B., Guppy, L., \& McKay, J. (1976). The social structure of the game and sport milieu. In J.G. Albinson \& G.M. Andrew (Eds.)., The Child in Sport and Physical Activity (pp. 161-200). Baltimore, University Park Press.

McPherson, B. (1978). The child in competitive sport: Influence of the social milieu. In R. Magill, M. Ash, \& F. Smoll. (Eds.)., Children in Sport: A contemporary Anthology. Champaign, III, Human Kinetics Publishers.

McPherson, B., Curtis, J., \& Loy, J. (1989). The social significance of sport: An introduction to the sociology of sport. Champaign IL, Human Kinetics.

Messner, M. (1990). When bodies are weapons: Masculinity and violence in sport. International Review of Sociology of Sport, 25, 3, 203-19. 
Messner, M. (1992). Power at play: sports and the problem of masculinity. Boston, Beacon Press.

Messner, M. (2002). Taking the field: women, men and sports. Minneapolis, MN, University of Minnesota Press.

Messner, M. (1985b). The changing meaning of male identity in the life course of the athlete. Arena Review, 9, 31-60.

Messner, M.A. (1990). Men studying masculinity: Some epistemological issues in sport sociology. Sociology of Sport Journal, 7, 2, 136-153.

Messner, M.A. (1993). Masculinities and athletic careers: bonding and status differences. In A. Minas (Ed.)., Gender Basics: Feminist Perspectives on Women and Men (pp. 137-142). Belmont, CA, Wadsworth Publishing.

Messner, M.A. \& Sabo, D.F.(Eds.).,(1990). Sport, Men and the Gender Order: Critical Feminist Perspectives. Champaign, Human Kinetics.

Muir, K., \& Seitz, T. (2004). Machismo, misogyny, and homophobia in a male athletic subculture: A participant observation study of deviant rituals in collegiate rugby. Deviant Behaviour, 25, 4, 303-327.

Nauright, J., \& Black, D. (1999). New Zealand and International Sport: The Case of All Black-Springbok Rugby, Sanctions and Protest Against Apartheid 1959-1992. In J. Nauright (Ed.)., Sport, Power and Society in New Zealand: Historical and Contemporary Perspectives. ASSH Studies in Sports History No. 11.

Nauright, J. (1990). Myth and reality: Reflections on Rugby and New Zealand Historiography. Sporting Traditions, 6, 2, 219-30.

Nauright, J. (1991). Sport, manhood and empire: British responses to the New Zealand rugby tour of 1905. International Journal of the History of Sport, 8, 2, 239-55.

Nauright, J. (1996). Sustaining masculine hegemony: rugby and the nostalgia of masculinity. In J. Nauright \& T.J Chandler (Eds.). Making Men: rugby and Masculine Identity. London, Frank Cass.

Nelson, M.B. (1991). Are we winning yet? How women are changing sports and sports are changing women. New York, Random House.

Nixon, S. (1997). 'Exhibiting masculinity. In S. Hall (Ed.). Representation: cultural representations and signifying practices. London, The Open University, Sage Publications.

Oakley, A. (1972). Sex, Gender and Society. London, Maurice Temple Smith.

Orbach, S. (1978). Fat Is A Feminist Issue. London, Paddington Press. 
Orlick, T. (1974). Sport participation - a process of sharing behaviour. Human Factors, 5, 558-561.

Oswell, D. (2006). Culture and Society: An Introduction to Cultural Studies. London, Sage Publications.

Otago Witness. Alice's letter to her readers, June 18, 1891, p 37.

Patton, M.Q. (1990). Qualitative evaluation and research methods. Thousand Oaks, CA, Sage Publications

Paul, G. (2009). Black Obsession: The All Blacks' Quest for World Cup Success. Auckland, Exisle Publishing Limited.

Philips, J. (1987). A man's country? The image of the Pakeha Male - A History. Auckland, Penguin Books.

Philips, J. (1996). Our History, Our Selves: The Historians and National Identity. New Zealand Journal of History, 30, 2, 107-123.

Polkinghorne, D. (1995). Reporting Qualitative Research as Practice. In W. Tierney \& Y.S. Lincoln (eds.). Representation and the Text: Reframing the Narrative Voice (pp.3-21). New York, State University of New York Press.

Poynton, B., \& Hartley, J. (1990). Male viewing. In M.E Brown (Ed.)., Television and Women's Culture. The Politics of the Popular. London, Sage Publications.

Pringle, R. (2009). A social history of the articulations between rugby union and masculinities within Aotearoa/New Zealand. New Zealand Sociology, 19, 1, 102-128.

Pringle R., \& Markula, P. (2005). No pain is same for all: a Foucauldian analysis of masculinities and men experiences in rugby. Sociology of Sport Journal, 22, 472-497.

Pronger, B. (1990). The Arena of Masculinity: Sports, homosexuality and the meaning of sex. New York, St Martin's Press.

Rankin, J. (1995). Golf is a woman's game. Chicago,Contemporary Books.

Reinharz, S. (1979). On becoming a social scientist. San Francisco, Jossey-Bass.

Reinharz, S. (1992). Feminist Methods in Social Research. New York, Oxford University Press.

Rich, A. (1979). On Lies, Secrets and Silence. New York, Norton.

Richards, T. (1996). Thou shalt play! What 60 years of controversy over New Zealand's sporting contacts with South Africa tells us about ourselves (pp.25-32). New Zealand Studies: July 1996.

Rouhiainen, L. (2008). Somatic dance as a means of cultivating ethically embodied subjects. 
Research in Dance Education, 9(3), 241-256.

Ruth, S. (1995). Issues in Feminism: An Introduction to Women's Studies. Mountain View, California, Mayfield Publishing Company.

Sabo, D.F. (1986). Pigskin, patriarchy and pain. Changing Men: Issues.Gender, Sex and Politics, 16, 24-5.

Sabo, D.F \& Runfola, R. (1980). Jock: Sports and male identity. Englewood Cliffs. Prentice-Hall.

Salisbury, J., and Jackson, D. (1996). School sport and the making of boys and men. London, Falmer Press.

Saussure, F. (1974). Course in General Linguistics (W.Baskin, Trans). In P. Chilliers \& R. Presier, (2010). Complexity, Difference and Identity (pp. 6-95). London and New York, Springer.

Scraton, S. (1986). Images of Femininity and the Teaching of girls Physical Education. In J Evans (ed.)., Physical Education, Sport and Schooling. Lewes, Falmer Press.

Scraton, S., \& Flintoff, A. (2002). Sports feminism: The contribution of feminist thought to our understanding of gender and sport. In S. Scraton \& A. Flintoff (Eds.)., Gender and Sport: a Reader (pp.30-45). London and New York, Routledge.

Segal, L. (1990). Slow Motion: Changing Masculinities, Changing Men. London, Virago.

Shaw, S., \& Frisby, W. (2006). Can gender equity be more equitable? Promoting an Alternative Frame for Sport Management Research, Education, and Practice. Journal of Sport Management, 20, 4,483-509.

Shaw, S. (2006). Gender suppression in New Zealand regional sports trusts. Women in Management Review, 21,7, 554-566.

Shaw, S., \& Hober, L. (2003). A stronger man is direct and a direct women is a bitch. Gendered discourses and their influence on employment roles in sport organisations. Journal of Sport Management, 17, 347-75.

Simri, U. (1979). Women at the Olympic Games. Wingate Monograph Series no. 7 , Netanya,Wingate Institute for Physical Education and Sport.

Sinclair, K. (1986). A Destiny apart: New Zealand's search for National Identity. Wellington, Allen \& Urwin: Port Nicholson Press.

Silverman, D. (1993). “Beginning Research” Interpreting Qualitative Data. Methods for Analysing Talk, Text and Interaction. Londres, Sage Publications.

Smith, C. (1997). Control of the female body: Physical training at three New Zealand Girls' High Schools 1890s-1920s. Sporting Traditions, 13, 2, 59-71. 
Smith, D. (1979). 'A sociology for women'. In J.A. Sherman \& E.T Beck (Eds.). The prism of sex: Essays in the sociology of knowledge. Madison, University of Wisconsin Press.

Sparkes, A.C. (1989). Culture and ideology in physical education. In T. J Templin \& P.G Schempp (Eds.)., Socialisation into physical education: Learning to teach (pp.: 315-338). Indianapolis, Benchmark Press.

Sport and Recreation New Zealand (2003). Results of the New Zealand sport and physical activity surveys (1997-2001). Wellington, New Zealand: SPARC.

Sport and Recreation New Zealand (2009). Sport and Recreation Profile: Rugby UnionFindings from the 2007-2008 Active NZ Survey. Wellington, New Zealand: SPARC.

Strauss, A.L. \& Corbin, J. (1990). Basics of qualitative research: Grounded theory procedures and techniques. Thousand Oaks, CA, Sage Publications.

Stewart, D.W., Shamdasani, P.N., \& Rook, D.W. (2 ${ }^{\text {nd }}$ ed.). (2007). Focus Groups: Theory and Practice. Applied Social Research Methods Series, Vol 20, Sage Publications.

Sutton-Smith, B., Roberts, J., \& Rosenburg, B. (1964). Sibling association and role involvement. Merrill-Palmer Quarterly, 10, 25-38.

Talbot, M. (1988), Understanding the relationships between women and sport: The contribution of British feminist approaches in leisure and cultural studies. International Review for the Sociology of Sport, 23,1.

Taylor, J. (2011). The intimate insider: negotiating the ethics of friendship when doing insider research. Qualitative Research, 11, 1, 3-22.

Theberge, N. (1981). A critique of critiques: Radical and feminist writings on sport. Social Forces. University of North Carolina Press, 60, 2, 341-353.

Theberge, N. (1985). Toward a Feminist Alternative to Sport as a Male Preserve. Quest No. 37

Theberge, N. (2000). Higher Goals: Women's Ice Hockey and the Politics of Gender. Albany, State University of New York Press.

Thompson, S.M. (1988). Challenging the hegemony: New Zealand women's opposition to rugby and the reproduction of a capitalist patriarchy. International Review for the Sociology of Sport, 23, 3, 205-12.

Thompson, S.M. (1992). Men play football: Women wash dirty socks, Refractory Girl,43, $2-5$

Thompson, S.M. (1995). The Gender Servicing of Children's Tennis. Belconnen, A.C.T: Australian Sports Commission. 
Thompson, S. M. (1999). Mother's Taxi. Sport and Women's Leisure. New York, SUNY.

Turner, B.S. (1984). The Body and Society. Oxford, Basil Blackwell.

Twin, S. (Ed.) (1979). Out of the Bleachers. New York, Feminist Press.

Vaioleti, T.M. (2006). Talanoa Research Methodology: A developing position on Pacific research. Waikato Journal of Education, 12, 21-34.

Clifford, J. (2001). Indigenous Articulations. The Contemporary Pacific, 13, 2, 468-490.

Diaz, V.M., \& Kehaulani, K. (2001). Native Pacific Cultural Studies on the Edge. The Contemporary Pacific, 13, 2, 315-341.

Thaman, K.H. (2003). Decolonising Pacific Studies: Indigenous Perspectives, Knowledge, and Wisdom in Higher Education. The Contemporary Pacific, 15, 1, 1-17.

Wesley-Smith, T. (1995). Rethinking Pacific Islands Studies. Pacific Studies, 18, 2, 115-137.

Watson, G. (1975). Sex role socialisation and the competitive process in little athletics. The Australian Journal of Health, Physical Education and Recreation, 70, 10-21.

Wedgwood, N. (2004). Kicking like a boy: Schoolgirl Australian rules football and bigendered female embodiment. Sociology of Sport Journal, 21(2), 140-162.

Weinberg, R.S., \& Jackson, J. (1979). Competition and extrinsic rewards. Effect on intrinsic motivation and attribution. Research Quarterly, 50, 494-502.

Weinberg, R.S., \& Ragan, J. (1979). Effects of competition, success/failure and sex on intrinsic motivation. Research Quarterly, 50, 503-510.

Williams, R. (1961). The Long Revolution. In J. Storey (2010), Culture and Power in Cultural Studies: The Politics of Signification. Edinburgh, University Press Limited.

Wilson, C.C,II, Gutierrez, F., \& Chao, L. (2003). Racism, Sexism, and the Media: The Rise of Class Communication in Multicultural America. Thousand Oaks, CA, Sage Publications.

Wilton, T. (Ed.). (1995). Immortal, Invisible, Lesbians and the Moving Image. London, and New York, Routledge.

Wright, J., \& Dewar, A. (1997). On pleasure and pain: Women speak out about physical activity. In G. Clarke \& B. Humberstone (Eds.), Researching women and sport (pp. 80-95). London: Macmillan Press.

Woodward, K. (1997). Questioning Identity: gender, class, ethnicity. London, The Open University, Sage Publications. 
Yiannakis, A., \& Greendorfer, S. (1992). Applied Sociology of Sport. Illinois, Human Kinetics Publishers Inc.

Zavos, S. (1979). After the Final Whistle. Wellington, New Zealand, Fourth Estate Books Limited.

\section{Newspaper}

Charman, P. \& Exelby, K. (2010). Sad demise of women's rugby in the Bay of Plenty Times retrieved from http://www.nzherald.co.nz/bay-of-plenty$\underline{\text { times/sport/news/article.cfm?c_id=1503345\&objectid=11000271 }}$

\section{Websites}

Oriental-Rongotai Rugby Football Club. Retrieved from http://www.ories.co.nz

Poneke Rugby Football Club. Retrieved from http://www.poneke.co.nz

Marist St Pats Rugby Football Club. Retrieved from http://www.msprugby.co.nz

Old Boys University Rugby Football Club. Retrieved from_http:// www.obu.co.nz 